Florida International University FIU Digital Commons

\title{
Integration of Colombian refugees in Costa Rica : an ethnographic approach to the refugees' legal, economic, and social experiences
}

Angela P. Bonilla

Florida International University

DOI: $10.25148 /$ etd.FI14051191

Follow this and additional works at: https://digitalcommons.fiu.edu/etd

Part of the Latin American Studies Commons

\section{Recommended Citation}

Bonilla, Angela P., "Integration of Colombian refugees in Costa Rica : an ethnographic approach to the refugees' legal, economic, and social experiences" (2006). FIU Electronic Theses and Dissertations. 1728.

https://digitalcommons.fiu.edu/etd/1728 
FLORIDA INTERNATIONAL UNIVERSITY

Miami, Florida

INTEGRATION OF COLOMBIAN REFUGEES IN COSTA RICA: AN

ETHNOGRAPHIC APPROACH TO THE REFUGEES`LEG $A$ L, ECONOMIC, AND

SOCIAL EXPERIENCES

A thesis submitted in partial fulfillment of the

requirements for the degree of

MASTER OF ARTS

in

LATIN AMERICAN AND CARIBBEAN STUDIES

by

Angela P. Bonilla 
To: Interim Dean Mark Szuchman

College of Arts and Sciences

This thesis, written by Angela P. Bonilla, and entitled Integration of Colombian Refugees in Costa Rica: An Ethnographic Approach to the Refugees' Legal. Iiconomic, and Social Experiences. having been approved in respect to style and intellectual content, is referred to you for judgment.

We have read this thesis and recommend that it be approved.

Eduardo Gamarra

Michael W. Collier

Victor Uribe, Major Professor

Date of Defense: March 30. 2006

The thesis of Angela P. Bonilla is approved.

Interim Dean Mark Szuchman

College of Arts and Sciences

Interim Dean Stephan L. Mintz

University Graduate School

Florida International University, 2006 
(C) Copyright 2006 by Angela P. Bonilla

All rights reserved. 


\section{DEDICATION}

I want to dedicate this thesis to my parents, my sister, my brother and to my partner Ricardo. Your trust and unconditional support gave me always the strength to finish this work and to graduate. Thanks! 


\section{ACKNOWLEDGMENTS}

I would like to thank my committee for their patience and their confidence in my capacity to finish this thesis despite my commitment to work. Dr. Uribe you open my eyes to many social realities since my first undergraduate class with you. Thanks for changing my life. I was honored to have you as my Major Professor and hope to continue being your student. Dr. Gamarra thanks so much for having such confidence in me since I was an undergraduate student. I will strive to uphold such confidence and continue close to LACC. Dr. Collier it has been a pleasure working with you and thanks so much for helping me improve my research skills and saving me in the most obscure moments of this thesis' writing.

Also, although not secondly, I would like to thank all my colleagues and Directors at the International Rescue Committee, whose confidence and guidance were the sparks for this journey. Kay, Leslye and Nicola, although time has placed us all in different paths I would always remember your courage in this challenging career of helping refugees. Your professionalism was always inspiring and your confidence in my work what filled me with enthusiasm and strength to keep doing this research. To Ceci, Ana, Carolina, Lauren, Oasis, John, Elena, Mariam, Claudia, and all IRC Miami staff, I will always remember the way you give your heart to all those in despair who need caring and support. I will keep such loving lesson in me.

I would also like to thank very especially my thesis-writing partner and good friend Meme. I know... we made it! Thanks so much my friend. My special gratitude also goes to Ricardo, whose support and patience especially in this last part of my thesis 
made my graduation possible. My good friends Virna and Natalia, you also never let me down.

Last, but not least. I would like to express my sincere gratitude to all the refugee families that opened their homes and hearts to me in Costa Rica. I wish these findings could in some way bring some light to your process of rebuilding a life in this country. Without your sincere cooperation I would have not been able to finish this work. 
ABSTRACT OF THE THESIS

\section{INTEGRATION OF COLOMBIAN REFUGEES IN COSTA RICA: AN \\ ETHNOGRAPHIC APPROACH TO THE REFUGEES`LEGAL, ECONOMIC, AND \\ SOCIAL EXPERIENCES}

by

Angela P. Bonilla

Florida International University, 2006

Miami, Florida

Professor Victor Uribe, Major Professor

This qualitative study, based on interviews to 17 refugee families, attempts to identify the reasons behind the lack of integration of Colombian refugees in Costa Rica. The model of Immigrant Modes of Incorporation and the studies of Alejandro Portes and Julia Sensenbrenner about the sources of social capital on migrant communities provided the theoretical framework used to identify the roots of the integration challenges. The findings suggest that Costa Rican policies towards the reception and integration of Colombian refugees are exclusionary. The host labor market is marked by sentiments of xenophobia towards the sample population while reported cases of persecution in the country also inhibit this population's economic integration. The lack of social capital sources contributes to inhibit this community's development, despite their participation in informal networks. There were signs of collective action. Yet, the refugee community fails to come together, while it also seems alienated from the community of Colombian entrepreneurs in Costa Rica. 


\section{TABLE OF CONTENTS}

CHAPTER

I. HOW WAS THIS WORK ENVISIONED?

Introduction

Basic Definitions

Literature Review

Theoretical Framework

Social Capital

Causal Model

Research Design

Design, Implementation and Data Analysis

II. LEGAL INTEGRATION

History of Refugee Legal Processing in Costa Rica 43

Definition of Legal Integration

Legal Process of Refugee Status Recognition to Colombian Refugees in Costa Rica 49

Rights Granted to Colombian Refugees in Costa Rica

Conclusions

III. ECONOMIC INTEGRATION 75

Overview of the Labor Market in Costa Rica 76

Employment Conditions of Colombian Refugees__ 80

Barriers Faced by Colombian Refugees to Find Employment __ 91

Conclusions

IV. SOCIAL INTEGRATION $\quad 110$

Receiving Colombian Community__ 111

Social Capital in Colombia 115

Social Capital Among Colombians in Costa Rica $\quad 119$

Conclusions 148

V. RECOMMENDATIONS 154

REFERENCES 158 
Table 1. Refugee`s Urban/Rural Background ......................................................... 81

Table 2. Occupation of Colombian Refugees in Costa Rica and Colombia ................... 82

Table 3. Barriers to Find Employment Identified by Colombian Refugee Head of Family on UNHCR - UCR Diagnosis About the Degree of Local Integration of the Colombia Population in Costa Rica 2003.

Table 4. Barriers to Finding Employment Identified by Colombian Refugees During IRC Assessment Trip

Table 5. Barriers to Finding Employment Identified by Colombian Refugees During Field Trip on February 2005

Table 6. Costa Rican Population Rates Colombians With Whom They Have Had Contact

Table 7. Number of Social Interactions in Networks of Colombian Refugees and Networks Usefulness

Table 8. Solidarity Among Colombians in Costa Rica.

Table 9. Trust Levels Among Colombian Refugee Families 138 
"I rather die from a gunshot in Colombia than starve to death while loosing my dignity in Costa Rica"

Statement from Colombian Refugee in Costa Rica

\section{HOW WAS THIS WORK ENVISIONED?}

\section{Introduction}

Since the late $90^{\circ} \mathrm{s}$ Colombia has experienced an exodus of its citizens due in large part to the country`s intensifying internal conflict. Raging for over half a century. by the year 2003 the devastating conflict placed Colombia as the nation with the second largest number of Internally Displaced People (IDP) in the world, with figures ranging from one million to over 3 million IDPs. The humanitarian crisis brought about by the conflict also turned Colombia into a refugee-generating country. By early 2001 the United Nations Iligh Commissioner for Refugees (UNHCR) had recognized that due to the growing violence and numerous human rights violations taking place all across the country, many Colombians who escaped abroad were becoming refugees in need of international protection and therefore programs to help them needed to be developed.

Costa Rica is one of the countries offering refuge to uprooted Colombians. Along with UNIICR, in the year 2000 responding to the massive influx of Colombians requesting refuge that year the Costa Rican government reactivated the process to handle the reception and determination of refugee status. Once approved, refugees have three options for durable solutions: integration into the host country: resettlement to a third country; or, return to Colombia. The UNHCR in Costa Rica has decided that local integration is the most viable durable solution for Colombian refugees in this country. 
Costa Rica is one of the few countries receiving Colombian refugees that has been able to achieve a system for refugee processing free of backlogs. Costa Rican officials estimate a Colombian population of up to 50,000 residing in the country, from which over 8.000 had been approved as refugees by the start of the year 2004 ("Un total de," 2004) and approximately 12.891 had applied for refugee status between 2000 and 2004 ("Ecuador," 2005). Yet, despite the efforts of the Costa Rican government and the UNHCR in providing timely responses to requests and assistance to approved Colombian refugees, a large percentage of these refugees are currently experiencing strong hurdles in their integration process. A mission undertaken by the International Rescue Committee (IRC) in October of 2003, of which I was a member, found that some of these hurdles include difficulties to find employment or a stable income-generating activity; signs of increasing discriminatory sentiments among the Costa Ricans toward Colombian refugees: lack of awareness in the Costa Rican community about refugee needs and rights: and, the apparent lack of trust, solidarity and network formations within the Colombian refugee community.

In comparison with the situation of Colombian refugees in countries such as Ecuador, Venezuela. Canada or the United States, the case of Colombian refugees in Costa Rica is of special interest as cultural, linguistic and, especially, legal conditions seem to be in place for a smooth integration. The processing of a refugee status is, for instance, done in only one month in Costa Rica. This allows refugees to have fast access to a wide spectrum of rights and services in this country. Yet, refugees seem to be facing a rather difficult integration process and many look for possibilities to continue their journey into yet a third country. 
In face of these hurdles the question: "Why are Colombian refigees not readily. adapting afier migrating to Costa Rica?" becomes the pivotal point for this study. Due to the challenges faced by Colombian refugees in Costa Rica and the lack of other durable solutions available for them, it is important to identify the problems that are inhibiting their successful integration and discuss possible reasons for the existence of these problems. The failure of the integration process can have detrimental consequences not only for the refugees themselves but also for Costa Rican society, as refugees could become a burden to its social and economic systems instead of a contribution to the country's development. Additionally, this study responds to the need of understanding the nature of the movement of Colombians across borders in recent years, and identifying some factors generally required for the cohesive integration of Colombians abroad. Finally, this case study will also contribute to evaluating some standing academic theories on the world and experiences of migrants. Following, I will provide some definitions required for a better understanding of the thesis and evaluate some of the most relevant academic literature in the field, including some cases studies on integration of other refugee populations. Then. I will look at the theoretical framework that will support the development of this thesis to finally propose on a causal model. some of the major variables this study relies on, and formulate the hypothesis.

\section{Basic Definitions}

In this section I will present some basic definitions of terms that will be used throughout this thesis in order to provide a stronger foundation to draw the variables that will be used later on. First of all, this thesis deals with "refugees," a particular category of 
migrants in need of a precise definition and differentiation from other closely related categories, in particular "economic migrants." Thus, definitions to understand clearly who is considered a refugee will be explored in this section. Economic migrants are people who decide to leave their country of nationality voluntarily in search of a better life. A refugee, on the other hand. is forced to flee the country of nationality due to political, religious, social (particularly racial) or nationality-related persecution causing a fear for his or her life. With the 1951 Convention relating to the Status of Refugees, the definition of a refugee was made internationally binding within the framework of developments in humanitarian international law after the Second World War (WWII). This definition was limited only to people who had fled due to WWII, as it took into consideration individuals suffering from events before 1 January 1951. Later, with the 1967 Protocol of the 1951 Convention and in consideration of other refugee situations. the definition developed in the 1951 Convention was extended to any person meeting the initial definition's criteria. The current definition of a refugee, therefore, would read as follows:

A refugee is a person who owing to well-founded fear of being persecuted for reasons of race, religion, nationality, membership of a particular social group or political opinion, is outside the country of his nationality and is unable or, owing to such fear, is unwilling to avail himself of the protection of that country: or who. not having a nationality and being outside the country of his former habitual residence as a result of such events, is unable or, owing to such fear, is unwilling to return to it' (UNHCR, 1996).

Refugees flee in search of safe heaven. They usually flee to states where they look for protection through a process of asylum or by obtaining refugee status, if these options

\footnotetext{
'Definition adapted from article 1 of the Convention Relating to the Status of Refugees, Adopted on 28 July 1951 by the United Nations Conference of Plenipotentiaries on the Status of Refugees and Statcless lersons. Words "As a result of events occurring before 1 January 1951 and..." and the words... "a result of such events". in article I A (2) omitted by 1967 protocol.
} 
are available in the country of reception. Once these victims of violent conflict receive legal protection in a second country, they arguably start a process of integration into these countries" communities. To have a clear understanding of the process of integration that is core to this thesis it is also necessary to introduce the reader to discussions about refugees processes of integration and the main differences with assimilation and adaptation processes, which are two other closely related concepts found in immigration literature. Even though the very definition of these notions would require us to enter into some academic debates about what precisely would be the best indicators to measure them, it is important to provide from the outset a preliminary and tentative definition of the same in order to orient the reader.

Assimilation is a term that has long been used in immigration literature and it implies "the disappearance of differences between refugees and their hosts as well as permanence within the host society" (Harrell-Bond, 2000). Members of the Chicago School of Sociology, who among other themes concentrated in immigration and its consequences when immigration theory started to develop in the United States, pioneered the term assimilation since the 1920s and 1930s, and it remained until the 1960s as the dominant sociological paradigm in immigration literature. One of its principal proponents was Robert E. Park (1928), who claimed assimilation was the eventual outcome of "all the incidental collision, conflict, and fusions of people and culture resulting from migration" (Park, 1928). Today the term is still used by some authors to explain instances when refugees resettle successfully in the country offering protection. Yet, as ethnic and racial conflict persists in diverse cultures such as the US and ethnicity issues take more importance in the sociological arena, the assimilation perspective is no longer 
seen by most refugee scholars as describing accurately the successful resettlement of refugees in host communities.

In the late 1970s and early 1980s the notion of assimilation started to be challenged and terms such as adaptation or incorporation where first used when referring to the modes by which immigrants integrate and are accepted into mainstream America, a region that because of constant immigration has become the subject of various studies of this phenomenon. Scholars challenging the notion of assimilation opted to use the new terms after recognizing that in a process of integration. immigrants confront different situations and hence they do not necessarily need to change their cultural values to find economic success in America or elsewhere. Different models of adaptation or incorporation have been formulated, therefore, based on cases where immigrants find economic success while usually upholding their ethnic and cultural values (Schmitter Heisler, 2000).

Despite the other terms used by several immigration scholars to denote the immigrants' process of making a life in the country of reception, with the United States of America being a case for which studies abound. this thesis will refer to the term integration. This is the best concept to refer to processes specific to refugees. International Voluntary Organizations and international bodies for refugee protection, such as the UNHCR. use the term integration when referring to a refugee's rights and ability to become a successful member in host communities. The UN 1951 Refugee Convention. however, lacks a definition of the term integration. The absence of a formal definition in international law thus leaves it open to academic interpretation and debate. Some such debates are about when should a refugee be considered successfully 
integrated. Others are about the best indicators to deem that integration has occurred.

Thus, as Dryden-Peterson and Hovil (2003) have argued,

While the impact of refugees on host populations has been explored at a theoretical level, there has been little academic research on the costs and benefits of refugee presence to host populations in a country's specific context. In addition, methods to quantify levels of integration among refugees and host communities are lacking in the literature. Indeed, disagreement over the mere definition of the word "integration" makes analysis of this topic difficult and has prevented adequate research. (pp. 3).

The mention of assimilation instead of integration in the 1951 UN Refugee Convention has generated confusion, as it could be assumed from it that refugees are expected to "assimilate" -adopting culture and traditions of host societies-, rather than to "integrate" into host communities. Overcoming this confusion Dryden-Peterson and Hovil (2003) explain that local integration was actually envisioned as a durable solution since the establishment of the 1951 UN Refugee Convention, for "throughout its articles it suggests that restoring refugees to dignity and ensuring the provision of human rights includes an approach that would lead to their integration into the host society" (pp. 3). These authors recognize that the Convention centered this process of integration particularly on the responsibility of host states to facilitate the assimilation and naturalization of refugees. Thus, they go on to explain, "recent thinking, however, emphasizes both the importance of maintaining individual identity and the possibility of promoting self-reliance" (pp. 3).

Jeff Crisp (2004) also makes a distinction between assimilation and integration of refugees. Crisp explains that

The concept of local integration does not imply the assimilation of refugees in the society where they have found asylum. While the concept of assimilation is to be found in the 1951 UN Refugee Convention, the international community has always rejected the notion that refugees should be required or expected to 
abandon their own culture, as to become indistinguishable from members of the host community. As one scholar (T. Kuhlman) has pointed out. integration is a more useful term than assimilation suggesting as it does that refugees "maintain their own identity, yet become part of the host society to the extent that host population and refugees can live together in an acceptable way. (pp. 2).

Despite these debates and the difficulties in being precise about the boundaries between a refugee"s successful integration or lack thereof, this thesis attempts to explore how successfully integrated Colombian refugees truly are in Costa Rica. Therefore, it is necessary to look at different academic interpretations of integration as well as other academic research focusing generally on immigrants instead of just refugces. for such immigration research is relevant to this study. To study a refugee's integration process the first step would be to search for academic works addressing different dimensions of the issue. Some authors seem concerned with the costs and benefits of refugees and their integration: others pay more attention to indicators appropriate to measure integration: and yet others concentrate mainly on strategies to accomplish integration. Out of these diverse perspectives, one could draw some useful conclusions as to the best variables to study the issue, though I will actually save the discussion of the variables until reviewing some available case studies.

Barbara Harrell-Bond (1986) defines local integration as a situation in which host and refugee communities are able to co-exist, sharing the same resources - both economic and social - with no greater mutual conflict than that which exists within the host community. Other theoretical attempts to define local integration include the work of Tom Kuhlman (1991). who has developed a framework and outlined the indices that can be used to measure refugees integration to a host community. Kuhlman has identified different characteristics of successful integration such as the refugces capacity to 
maintain an identity of their own and to adjust psychologically during the socio-cultural change they face. Another characteristic identified by Kuhlman is a level of friction between the refugees and the host populations that should not be worse than the frictions within the host population. Finally, he explains that for a successful integration the levels of discrimination faced by refugees cannot be higher than discrimination levels between groups previously settled in the host community.

In an effort to find methods to effectively address refugee situations where voluntary repatriation is not a viable alternative for refugees, Jeff Crisp (2004) explains that local integration should be addressed more carefully as an alternative and strategies should be designed to make this alternative viable for refugees. Crisp finds in this process of local integration three interrelated dimensions, a legal, an economic, and a social dimension.

In the legal dimension Crisp (2004) offers that refugees should be granted a wide range of rights. These include the right to seek employment, to engage in income generating activities, to own and dispose of property, to enjoy freedom of movement, and to have access to public services such as education. In this process of obtaining rights he explains that in order to becoming fully integrated refugees ultimately should be granted the right to the acquisition of citizenship.

Concerning the economic dimension, Crisp (2004) explains that after being granted these rights refugees would improve their potential to establish sustainable livelihoods and therefore become less reliant on state or humanitarian aid. In this respect, Crisp explains that refugees prevented or deterred from participating in the local 
economy, and whose standard of living is consistently lower than that of the poorest members of the host community, cannot be considered to be locally integrated.

Finally, as for the social dimension. Crisp (2004) explains that refugees should be able to live amongst the host population without fear of systematic discrimination. intimidation, or exploitation by the authorities or people of the country granting them asylum.

From the conditions, dimensions, and characteristics explained above, and despite the fact that a definition has not been formally adopted for local integration, it is possible to draw common variables that would be useful for this research. From this discussion we can see. for instance, that the process of local integration can be regarded as an economic, social, and legal process in which refugees are not expected to assimilate into host communities but to acquire a range of rights that would make them able to co-exist and share resources with the host population to develop a sustainable livelihood mainaining their own identity. In this view, refugees should be able to live without fear of systematic discrimination. intimidation, or exploitation by the athorities or people of the asylum country and their standard of living should not be consistenty lower than that of the poorest members of the host community:

From this summary definition of integration it becomes apparent that social and economic strategies are closely connected. Some case studies highlighting the relationships between these two dimensions will provide more insight into what should be considered a successful integration process for refugees. The examples chosen are from the mainstream of refugee cases. Most studied cases are of refugees arriving to the United States of America and therefore to a country that is economically much stronger 
than the sending country; that usually speaks a different language: and that in most cases has a different culture from the culture of sending states. Despite the difference between the host community of these various cases and the host community of the Colombian refugees being studied here, the cases selected are still useful as the integration models that will later be explored have been developed based on integration processes in America.

\section{Literature Review}

In the first section of the literature review I will go over previous findings about Colombian refugees in Costa Rica and findings about the integration and assimilation of Colombian communities in other countries, specifically in South Florida. Then. I will look at other communities of refugees integrating in the United States to search for elements in their integration processes that may be particular to their refugee condition and therefore may be absent in the studies of Colombian migrants to South Florida.

The "Diagnóstico sobre el grado de Integración local de la Población Refugiada Colombiana en Costa Rica, $2003^{{ }^{2}}$ provides a general profile of the population and a snapshot of their living conditions in the host community. As a project completed mostly by students of the University of Costa Rica and sponsored by the UNHCR. the 2003 Diagnosis may be considered a report of the work performed by the Asociccion C'onsultores y Asesores Internacionales (ACAI) as service providers of the UNHCR. These findings are useful, however, especially to understand some of the legal issues

\footnotetext{
2 Further references of "Diagnóstico sobre el grado de integración local de la Población Refugiada Colombiana en Costa Rica, 2003, which translates to "The UNHCR/UC'R Diagnosis About the Integration Decree of the colombian Refugee Population in costa Rica, 2003" will be addressed as "The 2003 Diagnosis".
} 
related with the process of refugee determination for Colombians and some of the current legal challenges due to the undergoing immigration law reform. The 2003 Diagnosis is also useful to understand demographic information of the refugee population since it includes the results of interviews to a sample of 320 refugee families. Thus, from these interviews is possible to get a glance of the refugee's access to social services such as health and education, their housing conditions, and their occupations. Finally, in the social area the 2003 Diagnosis also contributed with a survey of the Costa Rican population to identify the perceptions the host community may have of the Colombian refugee population.

Yet, these findings provide more statistical data, as a census would, in the areas of social and economic integration instead of looking in detail at the integration challenges in these areas and the reasons behind these challenges. For example in the area of economic integration almost 20 percent of the refugee population interviewed was found without occupation. Yet, the 2003 Diagnosis does not provide an explanation of the causes behind such condition in the cases interviewed. Also the 2003 Diagnosis is not clear in differentiating between occupations in the commerce sector, as formal employment and the informal sector, even though 34 percent of the population interviewed is found to be in the commerce sector. Thus, although the 2003 Diagnosis is useful to understand the overall living environment of Colombian refugees in Costa Rica and can also be helpful as a source of quantitative data regarding this population, it fails to address with neutrality some of the reasons that may be causing the lack of integration of this population and to provide qualitative data from the refugees experiences. 
Moreover, it is precisely due to the lack of explanations to the challenges faced by refugees in their integration process that this thesis work was envisioned.

Another area that needs to be explored is the findings about integration of Colombians in other communities, especially in South Florida. Colombians studied in this community are not all necessarily refugees. Yet, since South Florida is also home for a large percentage of Colombian asylees, then it would be useful to look at their levels of integration there and at some special characteristics they may have due to their ethnic condition and social nature. In a research summary report Michael W. Collier (2004) offers an indication of the lack of integration of some Colombians living in South Florida, evidenced from the return of many Colombians to their country of origin. Collier attributed these returns in part to "their inability to reestablish a stable environment. combined with a loss of social class" (pp. 14). The author also explains that the reasons the pilot research subjects identified for the difficulty to find employment were the lack of permanent or work visa and the lack of English language skills. It is interesting to note these findings, as even before exploring with detail the economic and employment conditions of the Colombian refugees in Costa Rica, the barriers identified in Collier's work would not apply to refugees in this country as the native language is also Spanish and refugees today receive a refugee ID that is supposed to serve as a work permit as well.

Collier's findings are based in part on the findings of Nathalia Franco (2002) and Cristyn Casey (2002), who were part of the pilot research team of the Latin American and Caribbean Center at FIU established to study the Colombian Diaspora to South Florida. In an effort to understand the reasoning behind the migration of Colombians to South 
Florida. Franco analyzes how Colombians gather information before migrating. the type of expectations that they create based on the information gathered, and how these expectations affect their integration in South Florida. Overall Franco suggests that Colombians experience disillusion after migrating to South Florida due to high expectations created by false information gathered before migrating. Among these findings, however, it is important to highlight the ones related to the Colombians who claimed to have fled to South Florida due to persecution. First she suggests that Colombians who were victims of persecution face also difficulties and uncertainty since their process of asylum approval is usually long and in most cases the social security card takes longer than it should, making it hard for asylum seekers to work and make a living in the United States. Moreover. her findings, although based only on qualitative data from one interview, suggest that Colombians once granted asylum continue to experience difficulties to find employment due to "lack of language skills, networks, and knowledge of US employment practices (resumes, interviews and the like) to succed in the professional job market" (pp. 89). With the lack of language not being a barrier for refugees in Costa Rica, it is important to keep in mind the lack of networks and information about professional job attainment as possible factors contributing to the lack of integration of Colombian refugees in Costa Rica.

Another study that may also be relevant is the thesis work of Crystin Casey (2002) regarding the effect of social capital on the formation of a Colombian community in South Florida. Casey found the presence of social capital among this community but in very incipient forms; she found evidence of community mobilization, especially in local and Colombian political processes, but also found a negative context of reception 
that has affected the levels of trust and solidarity among Colombians. Moreover, Casey found evidence of social and geographic fragmentation among the previous waves of Colombian migrants and the latest wave of migrants, which corresponds with the migration of refugees to Costa Rica. This community fragmentation, which Casey found to be based in part on a negative stereotyping among Colombians, also hinders the development of social capital in this community while also limiting the possibilities for the formation of a Colombian enclave.

In regard to formal networks Casey (2002) also found that the "third wave" of Colombians perceive a lack of solidarity among the community while Colombian Associations ' leaders believe Colombians in general do not trust these Associations. It is important to note however the evidence Casey found of upper class Colombians developing ties with Cubans and therefore of having the potential to develop bridging capital. Also while support and cooperation is not perceived in the formal networks. Casey found Colombians seem to rely more on informal networks formed by family, friends and close associates. This highlights the tendency Colombians have on developing social capital of the bonding type instead of social capital of the bridging type, which explains in part the weakness in this community"s social capital development as an instrument to strengthening the community.

The findings regarding the formation of the Colombian community in South Florida provide a good foundation to the understanding of some behaviors of Colombians in Costa Rica, as these studies were done to a group of Colombians who migrated during the same timeframe Colombian refugees fled to Costa Rica. Yet, not all Colombians in these studies can be characterized as refugees, as South Florida also received a great 
number of economic migrants as also evidenced from these studies. Thus, it is still important to take a look at case studies of other refugee groups, even of different origin and racial backgrounds, as it is important to identify which variables are significant in the integration of refugee populations. Since most case studies of Central American refugees focus in their processes of repatriation instead of integration, it is useful to look at other refugee groups.

In case studies of refugee integration processes mainly in the U.S. many variables such as the right to citizenship; trust an solidarity: networks: ethnic enclaves; or ethnic entrepreneurship, are highlighted as foundations of successful integration processes (Iloltzman 2000. Ong 2003, Welaratna 1993, Portes and Stepick 1993). The following selection of case studies highlights the social and ethnic dynamics of the refugees integration process. Later, I will address the economic dimension and find that social, ethnicity, and economic aspects are in any case closely linked. In both instances, we will be dealing, though. with refugee groups and recipient countries rather different from the ones of our interest. Nevertheless, the significance of the following discussion is that it does provide us some comparative elements making the case of Colombians in Costa Rica easier to understand by contrast. Unlike Cambodians, Laotians or Sudanese in the United States, Colombian refugees have great similarities with Costa Ricans as far as ethnicity, language, culture, and religion. However, in an effort to find the reasons behind the challenges in the integration process of all refugees and the refugee"s feelings of exclusion, it is important to take into account diverse refugees" integration processes. This allows us to learn ways in which not only ethnicity but also factors such as 
economic dependency, kinship, regionalism, membership into associations, education and job experience and skills, among others, play a role in the integration of refugees.

Within the dimension of social and legal integration Aihwa Ong (2003) explores the process of integration of Cambodian refugees in the U.S, concentrating in the relationship of integration and the refugees process of citizenship. He explains that the citizenship process is more than the possession of legal rights. He defines the process of citizenship more as a process of belonging, which is defined in part by unofficial social meanings and criteria that ultimately affect the ways in which refugees are integrated into host communities. In the case of Cambodian refugees the author argues that the cultural differences of these refugees make them more vulnerable to assimilating into the American society instead of following a process of integration. Thus, in the process of legal integration and citizenship building, special characteristics in the Cambodian refugee population have placed them in a minority and disadvantaged category where they have received pressure to assimilate into the community instead of integrating economically while upholding their cultural differences ( $p$. xiv prologue).

Ong (2003) distinguishes two waves of Cambodian refugees: the first being an upper class better educated, that integrated more easily into American mainstream. The second wave of Cambodian and Laotian were peasants that entered the U.S. as refugees and were later "located ideologically at the underclass end of the continuum, a position close to the black pole of the ethno-racial scheme" (pp. 86). He found in a report completed by the Office of Refugee Resettlement (ORR) a description of Cambodian refugees as more individualistic and more prone to place feelings and emotions above obligations while also having Americans as role models. By being subject to this 
ideological "blackening", the author argues that refugees from Cambodia and Laos came to be perceived as having more in common with other poor newcomers among whom they were found in low-wage jobs or largely as welfare recipients. Within this assistancerecipient structure, this group of refugees found a support network in the social workers and other professionals providing them assistance. These professionals were mostly first. second or third generation ethnic Americans feeling compelled to assist the huddled masses, more with the intention of making them simulate the American system to become self-sufficient citizens than self-sufficient members of an ethnic group they identified with comfortably. By categorizing Cambodian refugees as disadvantaged minorities and assistance recipients. most of these refugees where subject to racial differentiations that. within the American welfare system, made them prone to remain in this system of dependency instead of becoming self-sufficient.

The process of citizenship explained in this case depicts the ways in which cultural distinctions are translated into detrimental racial differentiations that can inhibit the successful economic integration process of refugees. The minority stereotyping within the legal process of citizenship seen in the case of Cambodian refugees might teach us something about the case of Colombians in Costa Rica. Even though Colombian refugees in Costa Rica generally do not have ample ethnic differences with the host community, becoming a minority due to their immigrant profile alone can be a fact increasing the levels of discrimination experienced by these refugees. As in the case of Cambodian refugees, what made them become marginal was not necessarily these refugees" different ethnicity, since refugees from other Asian countries have easily achieved economic self-sufficiency. Instead, the fact that they became a minority 
associated with the poorest welfare-recipient Afro American communities was the critical factor. From the author's perspective this association, other cultural conditions of Cambodian refugees, and the welfare system itself, formed a structure that inhibited the ability of refugees to become self-sufficient and thereiore successfully integrated.

With a contrasting view Usha Welaratna (1993) provides a case study with an example of how Cambodian refugees feel successfully integrated as they are able to live up to their cultural and ethnic values instead of merely concentrating on economic selfsufficiency. She explains that the U.S. Refugee Act of 1980 is a policy by which a process of Americanization, which can be assumed as assimilation, is enforced in refugee populations through "the achievement of self-sufficiency as quickly as possible". Welaratna does not specify how this policy specifically enforces a process of Americanization. Ilowever, through the narrative of nine Cambodian refugees integrating into U.S. mainstream, the author concludes that by selecting to adopt only certain American values and activities that are compatible with their own ways of life. Cambodians can achieve economic self-sufficiency while maintaining successful and fulfilling lives (p.p. 275). In this case study, it is compared how the American way of looking at successful integration is founded on the achievement of economic selfsufficiency without which refugees should not be considered successfully integrated. However, the author explores the values of Cambodian refugees to find that they consider themselves to be successfully integrated regardless of their economic success. For them. happiness for having a close family; community and family cooperation: good conduct: respect for their culture; and the merit of doing a good deed, among other values derived from their Theravada Buddhist culture, are fulfilling values allowing them to feel well 
integrated. Thus, in this case, even though some authors have described Cambodian refugees as individualistic. Welaratna argues instead that it is their feeling of family and community responsibility which makes them supportive of each other and leads them to achieve an overall feeling of well being.

For a host community, however, the fact that refugees will not become a burden on the social welfare is primordial for the development of policies and institutions facilitating the integration of refugees. Thus, to develop strategies to help them overcome their dependency on welfare or humanitarian aid and become self-sufficient. yet without enforcing pressure on them to change their cultural values, it is important for states to make efforts to understand the values and cultures of refugees in a process of integration. Both cases of Cambodian refugee integration are examples useful to understand the contrasting views on what should be considered successful integration. From the case studies it can be inferred that feelings of integration are closely related to both a refugee's ability to achieve economic independence as well as his/her capacity to feel part of a community respecting cultural values and ethnicity. The examples also suggest that in addition to defining "successful integration" from an academic point of view. it is important to consider too how the refugee community itself defines it.

A group of refugees in the U.S. that are highly dependent on welfare and are constantly among the poorest sectors of the society are the Sudanese refugees. Jon D. Holtzman (2000) developed a study of Nuer Sudanese refugees in Minnesota. He finds that despite efforts, these refugees face problems to find and hold employment due to reasons such as language barriers and lack of education, job experience, and job skills. Nuer refugees have tried to understand and accommodate to ways of life in the U.S. Yet. 
their rural background and therefore vast differences in the lifestyles and values of Minnesota and Sudan makes it even harder for them to integrate economically. The integration of this group of refugees varies significantly from the integration of Colombian refugees since Colombians do not differ so radically from host community residents. However, it is important to bring up the approach to network formation seen in this case of Sudanese refugees' integration to further explore the relationship between ethnic associations and economic independence in a refugee integration process.

Socially, the community of Nuer refugees in Sudan is based on kinship relationships. Once in America, however, these links are generally lost and refugees are mostly on their own, ties in the family nucleus becoming primordial. Not used to act independently, Holtzman (2000) finds that, due to language, culture and shared experiences, these refugees are driven to form a community. Even though they express a desire of moving away from seeing themselves identified by the community they were a part of in Sudan, the author finds that these regional and kin differentiations remain pivotal in their process of community formation among the Sudanese in Minnesota. Ethnic mutual assistance associations have been formed to support the integration of these refugees. These attempts have been useless however, as a race for power within and the lack of leadership have led some of these organizations to be terminated. American Churches, on the other hand, have proven to be successful in bringing Nuer together. These congregations provide support in the early stages of the resettlement process and even economic incentives for their participation in their particular congregations. Yet, the author does not define the Nuer's participation in these networks as a way by which this group of refugees would have access to economic mobilization. 
From the cases seen above, it is worth noting how ethnic values might affect positively or negatively the process of refugee integration. In the first study of Cambodian refugees, ethnic and cultural characteristics placed refugees in a minority group where they found greater hardships to become economically independent. In the second case of Cambodian refugees, it was seen how despite sustained economic hardships these refugees found in their ethnicity and cultural values enough reason to feel successfully integrated in the host community. From the case of Sudanese refugees, it is possible to see how ethnicity can become a mechanism to unite refugees and how even though the creation of networks is not closely related to economic mobility in this case, it is linked to a feeling of well being in refugees.

The challenges Cambodian and Sudanese groups have in their integration processes due to their distinct cultural and ethnic values are not the rule for refugee integrations in America. A case such as the integration of Cuban refugees has become material for the creation of models of adaptation, as this case has specific characteristics placing it among the successful contemporary cases of integration. In the following section the theoretical framework will be provided with models developed mostly from the Cubans experience. In this section the "formulas for success" presented by different authors will be explained and these theories will then provide the variables needed to support the development of this thesis work. As it could be expected, these formulas are based mostly on economic achievement although it is important to note too that in most cases this achievement is derived from processes of integration based on special ethnic characteristics. 
Moving away from cases where the relationship between economic and ethnic characteristics has been loosely explored, in this section we will see examples where actual adaptation models have been formulated for different groups of immigrants and refugees settling in the United States. These models address interchangeably cconomic. legal, and social or ethnic issues, although the main area of concentration in adaptation models has been the economic. As we continue to understand the complex nature of integration processes, ultimately a set of variables will be drawn.

As in some instances the cases used for the design of these models include refugees, the theoretical body on the economic adaptation of migrants in general provides a foundation for the study of refugee integration processes. Additionally, despite the fact that these models address in general the economic adaptation of immigrants arriving in America, some variables relating to legal, ethnic and social issues seen in these models are also found in the narratives of refugees" integration explored previously. Therefore, these models can be used as a foundation to understand the integration of Colombian refugees even though they are resettling into a different country.

As explained previously, the assimilation approach failed to explain the resurgence of ethnicity and the persistence of racial inequality and conflict among immigrant populations. Some of the models of immigrant incorporation challenging the assimilation approach include the "middleman minority model" (Bonacich 1973, Bonacich and Modell 1980), the "entrepreneur/ethnic economy model" (Light 1972. 1979), and the "ethnic enclave economy" (Portes and Bach 1985, Portes and Rumbaut 1990). By looking at immigrants' enterprise, the authors developing these models look at 
how some immigrant groups have been able to retain employment and advance the social and economic ladder not merely because of skills brought from home countries but due to their solidarity to organize and their capacity to develop ethnic networks. Among these theories it is common as well to argue that as they are exposed to racism. discrimination and alienation, immigrants are usually motivated to restore back to their ethnicity.

Through the middleman minority model authors explain how as a result of their exclusion from American mainstream employment, immigrant groups such as the Chinese, the Japanese, and the Jews have become small-traders and merchants (Bonacich 1973, Bonacich and Modell 1980). Bonacich, for instance. linked the success of middleman minorities to their social solidarity. Yet, in later studies the authors found that the solidarity characteristic of the first generation eroded in the second one.

The ethnic entrepreneur model initially introduced by Ivan Light (1979) explains that when facing an integration process into a new community some immigrant groups have a reactive solidarity. This characteristic makes them take advantage of resources within their ethnic community. Some resources mentioned include social networks, and the availability of underemployed or disadvantaged co-ethnic workers. The author also explains that groups developing entrepreneurial skills respond to a distinct cultural endowment of certain nationalities that leads them to seek avenues for profitable enterprise while others remain content with wage employment.

Alejandro Portes is one of the authors responding critically to culturalist explanations for the development of entrepreneurial skills among some immigrant groups. He argues that such approaches lack sufficient ground as they are formulated after a group has achieved a notable level of business success but fail in identifying 
which groups could acquire such skills. Moreover. Portes and Rumbaut (1996) argue that these approaches fail to explain how groups with similar cultural backgrounds, such as the Chinese Buddhist and the Buddhist Cambodian, have such different economic outcomes in their integration processes (pp. 75).

Along with other authors, by the end of the 1980s Portes and his colleagues and students developed the ethnic enclave economy model. The main characteristics in this model are a spatial concentration of the immigrant group. sectoral specialization. and two labor markets within the group: the primary one with good jobs, decent wages, and secure employment: and, the secondary one with unskilled jobs, poor wages, and insecure employment. Based on the segmented market theory, which explains how low-skilled workers are mainly found in dead-end low-paying jobs. Portes model explains that immigrants on the secondary labor market have better chances of moving to the primary one as they overcome language barriers and usually have more training opportunities within the enclave. Additionally, businesses developed within an enclave usually start by serving their ethnic community and later expand to the larger community (Portes and Bach 1985; Portes and Stepick 1993; Portes and Rumbaut 1996; Portes and Rumbaut $2001)$.

Portes and Rumbaut (1990) advanced the ethnic enclave model incorporating the variables identified in other models. This model of immigrant modes of incorporation includes a social and legal framework of analysis, which affects immigrants" integration. in addition to the initial economic and entrepreneurial framework. The model explains that the integration process depends on the contexts of reception defined by (1) the policies of the receiving government. (2) the conditions of the host labor market. and (3) 
the characteristics of their own ethnic communities. Since this is the model that better incorporates the social, economic, and legal aspects already found to be important for the integration of refugees, the variables of this model will be used for the construction of the causal model in this thesis.

The policies of the receiving country are grouped into three categories: exclusion. passive acceptance, or active encouragement. Exclusion forces immigrants into an underground existence. Passive acceptance means the governments grant access to immigrants but do not make any effort to facilitate or impede the process of migration. Thus, as explained by Portes and Rumbaut (2001), "this neutral stance places newcomers under the protection of the law but does not grant them any special concessions to compensate for their unfamiliarity with their new environment" (pp. 47). The third set of policies, active encouragement, occurs when governments take active steps to motivate the migration of a particular group of migrants or to facilitate their resettlement. The authors explain that in the case of U.S., for example, this set of policies has been applied to different refugee flows that have fled communist regimes. Moreover, in different migration flows studied, the authors have assigned this set of policies to refugee groups while the other two sets of policies have been assigned to groups that have migrated under other conditions. The U.S. establishes the nationalities and numbers of refugees it is willing to receive each year through a Presidential Determination. Refugees are processed overseas and before coming to the U.S. they are granted the refugee status and are ready for resettlement to the U.S. Thus, in the case of the U.S, the encouraging set of policics under which many refugees fall, are a result of the "Determination" passed by the government. 
The conditions of labor markets are the second set of characteristics taken into consideration in this model. The common features included in a set of labor market characteristics include, among others, the receiving government's stage of the business cycle, the demands for a specific kind of labor, and regional wage differentials. Yet, Portes and Rumbaut (1990) explain that these characteristics are not as relevant as sociological aspects of the labor markets such as the manner in which particular immigrant groups are typified. In this context, the authors explain how groups that are believed to be workers of a particular sector, such as agrarian labor, would most likely have employment mainly in this field. Moreover, positive attitudes toward hiring a particular ethnic group are not common and when they occur are the result of having employers of the same nationality, such as occurs in "enclave economies" like "Chinatown" or "Little Ilavana". Another important aspect of the labor market explained by the authors are the resources or ability that immigrants have to escape stereotyping or neutralize discrimination by, for instance, disguising their nationality or moving to another region.

The last set of characteristics identified in the immigrant modes of incorporation model is the ethnic community of the immigrant group. Two possibilities can exist. One is that there is not a community at all when the wave of immigrants arrives, in which case the immigrants" integration will depend more on the host labor market. In this case. the ideal situation is when employers do not discriminate against immigrants for their education, resources, or the efforts of voluntary agencies resettling refugees. If one of these conditions were present it would indeed be a decisive factor for their integration. 
The second possibility is when immigrants arrive to a place where a community formed by co-nationals already exists. In such case, the authors explain that the process of socioeconomic attainment is entirely network driven. which means that networks would provide information about outside employment, jobs inside the community, and sources of credit and support for entrepreneurial ventures. The authors also explain that these communities could be either formed primarily by manual workers or contain a significant professional or business element. When immigrants arrive to working-class communities there is usually pressure from earlier ethnic arrivals towards conformity. as these earlier arrivals expect newcomers to follow the same path they did. Arriving to a community of members holding higher status occupations is different, as the support to newcomers is not dependent of their working-class lifestyle and because these types of communities are usually sources of both low tier employment and employment with avenues for managerial or supervisory mobility.

From combining the three main contexts of reception identified in the model of immigrant modes of incorporation, the authors provide twelve alternative contexts of incorporation ${ }^{3}$ :

\begin{tabular}{|l|l|l|l|l|}
\hline 1. U.S. Corermment Policy: & II. Labor Market Reception: & $\begin{array}{l}\text { III. Ethnic Community: } \\
\text { None }\end{array}$ & $\begin{array}{l}\text { Working } \\
\text { Class }\end{array}$ & $\begin{array}{l}\text { lintreprencurial } \\
\text { Profesciomals }\end{array}$ \\
\hline Passice Acceptance & Neutral or Positive & 1 & 2 & 3 \\
\hline & Discriminatory & 4 & 5 & 6 \\
\hline Active Support & Neutral or Positive & 7 & 8 & 9 \\
\hline & Discriminatory & 10 & 11 & 12 \\
\hline
\end{tabular}

\footnotetext{
"Table has been adjusted from original table on Portes and Rumbatut 1990: 89.
} 
Finally, one of the most important factors when looking at how some immigrants "make it" in America, Portes and Rumbaut (1990) argue, has to do with the human capital. the motivation, and the resources migrants bring with them. Professionals, on one hand, might have a tough time in the beginning due to language barriers and lack of jobseeking experience, yet over time they have a high chance of obtaining better-paid jobs. Immigrants with previous entrepreneurial experience, on the other hand, would most likely take the road of self-employment, although also after they overcome some barriers through time. For refugee groups, however, the authors make a distinction. They explain that for refugees time does not necessarily transforms into better income. as is the case of regular migrants. They attribute this to the fact that many refugees come from a declining socioeconomic background. Thus, in most cases the fate of lower income refugees depends on the kind of community built by co-national higher-income refugees who usually are the first wave that migrates. The authors explain that this fact brings attention to their main argument: "Individuals with similar background skills may be channeled toward very different positions in the stratification system, depending on the type of community and labor market in which they become incorporated" (pp. 83). This approach, indeed, moves away from the integration explanations based solely on ethnicity, as seen in some of the refugee cases reviewed previously, and offers a more complete and structural method of analysis. Thus, since the model of immigrant modes of incorporation, which include the policies of the receiving government. the conditions of the host labor market, and the characteristics of the migrant's ethnic community, has been the only one including legal and social in addition to economic factors, then it will be the main theoretical foundation for this thesis work. 
Social capital is an additional variable that has not been looked at it in depth yet. as it is not commonly used by social scientists studying immigration but by sociologists trying to identify how communities, immigrant or not, organize to succeed. Despite not being used by social scientists for the study of immigrant communities, some variables such as trust and solidarity, the formation of networks, and ethnic support, which are part of the social capital development. have been important in the cases of refugees and migrant's integrations seen previously. Social capital has been used more often now to determine some communities and countries' potential for development. ${ }^{+}$The unit of analysis of immigrant studies is usually the individual, not the community. This is why some in academia do not find social capital to be a variable of great significance in the study of immigrant groups. Yet, as surveys to identify social capital are usually designed and delivered on an individual basis, this thesis will try to capture the presence, nature and degree of social capital found in the individuals identified for interviews. Moreover, as will be explained in following sections, the nature of social capital is also captured through the solidarity and trust levels identified within a particular community. As seen in the above literature. solidarity has been a variable commonly identified in processes of successful integration of immigrants or refugees. Thus, the attempt to look closely at solidarity and indeed at social capital is fundamental for a comprehensive understanding of the integration process of Colombian refugees in Costa Rica.

\footnotetext{
tParticular efforts hare been advanced by the World Bank in studies of development of some countries.
} 
Robert Putnam (2003) has been one of the main authors in the study of social capital. He summarizes this concept by explaining, "as used by social scientists, social capital refers to the social networks, norms of reciprocity, mutual assistance. and trustworthiness. The central insight in this approach is that social networks have real value both for people in those networks as well as for bystanders" (pp. 2). The author specifies, however, that just as social capital can be useful to advance a community, it could also be a malign source of power as in the case of, say, the Ku Klux Klan or organized crime. Thus, the intangible social structures developed by social capital can have positive effects in one community, negative in others, as well as negative in all.

Putnam explains that there are two types of social capital, the bridging and the bonding social capital. The bonding social capital is the type where networks are created by kin or by people who are linked by crucial similarities, such as ethnicity, and is more inward looking. The bridging social capital is the hardest to create, as it is conformed by networks of different types of people who are more outward looking. The author explains how for the formation of a healthy community it is important to have more of the bridging type, especially for a diverse community. However, one could ask for immigrant communities with similar ethnicities, is bridging social capital the most recommended type? As seen in the literature explained above, ethnicity is usually a source of different resources useful for integration processes. Thus, it is legitimate to wonder, as this thesis will, whether or not bonding social capital is more effective in the formation of immigrant communities.

To study the effects of social capital in immigrant populations Alejandro Portes and Julia Sensenbrenner (1993) developed a set of hypothesis-like statements in which they 
summarize how structures of social capital affect economic action in immigrant groups. To develop these statements or propositions the authors tirst identify the sources of social capital. Then, based on immigration research, they study how each of the sources found affect positively or negatively immigration. From a definition of social capital developed by James Coleman", the authors redefine social capital "as those expectations for action within a collectivity that affect the economic goals and goal-seeking behavior of its members, even if these expectations are not oriented toward the economic sphere" (pp. 1323).

For the purposes of this study, even though some authors find two more sources ("value introjection" and "reciprocity exchanges"), "bounded solidarity" and "enforceable trust" will be the two sources of social capital taken into consideration. First. bounded solidarity is defined as a reactive situational sentiment that arises from a sense of belonging to a particular group. This sentiment depends more on a collective moral than on its enforceability. Thus, it is common to see this sentiment arising from situations in which a group faces common adversity, although Portes and Sensenbrenner (1993) specify that such groups need to have as well "the ability to activate a cultural repertoire, brought from the home country, which allows them to construct an autonomous portrayal of their situation that goes beyond a mere adversarial reaction“" (pp. 1329).

Enforceable trust as a source of social capital is based on the internal sanctioning capacity of the community itself. In this case, members of a group behave according to

\footnotetext{
"Coleman defines social capital as a variety of entities with two characteristics in common: They all consist of some aspects of social structures, and they facilitate actions within that structure" (coleman 1988: \$98. found in Portes and Sensenbrenner 1993:1321 - 1322).
} 
expectations out of fear of punishment or in anticipation of rewards. Areas of such

punishment or reward usually include financial networks or business networks in enclaves.

Since one of their objectives is to show the positive and negative effects of social capital, the following concluding argument and table shall give a clear idea of their model:

The reactive mechanism giving rise to bounded solidarity in response to outward discrimination is the same as outlined earlier (based on phenotypical and cultural differences). The crucial difference lies in the extent of discrimination and its duration. Protracted periods of oppression, especially in a no-exit situation. undermine the cultural and linguistic resources available to a group for constructing an alternative definition of the situation. A situation of permanent subordination also deprives a collectivity of the resources necessary to reward or punish its members independently, so that its enforcement capacity is entirely dependent on outside discrimination that forces its members to band together. The downward leveling pressures reviewed here are a reaction of the partial breakdown of this last source of sanctioning capacity, as fissures in the barriers confronting the group allow some of its members - "wannabes" or "turnovers" to escape its hold (Portes and Sensenbrenner, 2003, 1344).

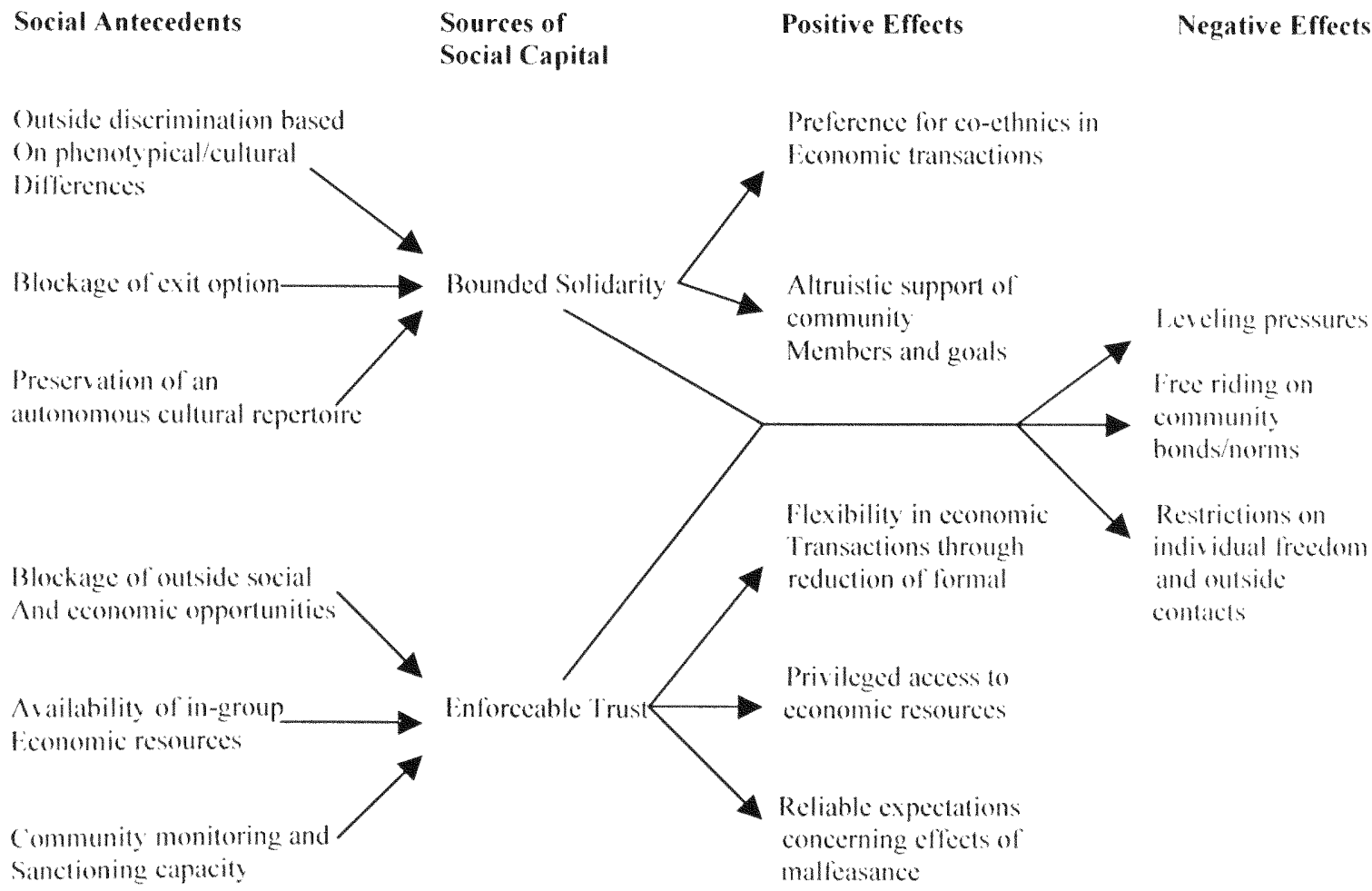


From this overview of the literature on refugees' integration processes and different theories of immigrants' adaptation, understanding the integration process of refugees specifically might seem a complicated task. Therefore, the following chapters must be structured based on a clear set of variables aimed at finding the explanations for the lack of integration of Colombian refugees in Costa Rica.

First since integration is the main variable of this study, it will be the dependent variable. The independent variables will be organized into three separate groups, based mainly in the model of immigrant modes of incorporation as explained in the theoretical framework and on the integration definition gathered from different authors in the first section of this chapter. which regards integration as a legal, social an economic process. The three sets of variables will be, therefore, the government context of reception explained in a legal framework of study, the conditions of the host labor market explained in an economic framework, and the nature of the ethnic community explained in a social framework of study. The social capital formation variable will be included in the social framework of study since through the exploration of social capital. manifested through bounded solidarity and enforceable trust, it will be possible to have a more accurate idea of the community`s capacity for development. Additionally, some specific factors of these three sets of variables were also seen in the literature review and will be included in the explanations of each set of variables. 
After identifying the presence of the variables explained above, this thesis will bring them together to analyze their interactions and therefore explore how these variables might affect the integration of Colombian refugees in Costa Rica. The analysis of these interactions wiil allow us to answer this thesis's main question: Why are C'olombian refugees not readily integrating after migrating to Costa Rica? Conclusions and possible areas of recommendations will be also provided in the final section of each chapter.

Responding to the question stated above the following hypothesis will be tested throughout this research:

\section{Hypothesis 1:}

"There is a "passive acceptance" of the receiving government towards Colombian refugees that inhibit their legal integration".

\section{Hypothesis 2:}

"The negative conditions of the labor market in Costa Rica inhibit the economic integration of the Colombian refugees".

\section{Hypothesis 3:}

"Due to the negative conditions of the host labor market, the lack of bounded solidarity and enforceable trust within the Colombian community, and the lack of potential formation of social capital among Colombian refugees, the success of their integration process is inhibited".

This study will assess the experiences of Colombian refugees in Costa Rica as well as the positive and negative aspects of the receiving society to find the determinants 
to the refugees" levels of integration and possible explanations for their challenges. This is an exploratory research, mostly qualitative, and based on interviews to refugees as method of research.

Testing Hypothesis 1: The Legal Integration of Colombian Refugees in Costa Rica. The first set of variables that will be studied will be the legal aspects related to the reception and integration of Colombian refugees in Costa Rica to identify if these policies can be regarded as passively or actively encouraging or as inhibiting the refugees' integration. To start this chapter it will be important to look at the history of Costa Rican policies toward refugees and the overall legal context at the time Colombian refugees started to arrive. This analysis will provide a foundation for the understanding of the main variable tested in this chapter. Then, variables such as the refugee's possibility to obtain citizenship and the rights granted to them through their legalization process, which should be equal to the host community rights, will be taken into consideration, as identified in the integration definition. In this section the rights of refugees will be analyzed from the perspective of how the law grants these rights and the state's capacity to respond to the massive arrival of Colombian refugees. Then, the granting of rights will be assessed from the refugees' perspective, through interview questions aimed at identifying if they feel they access to these rights. Additionally, this chapter will look at the strategies, policies, and laws the government may have developed or failed to develop to procure the integration of Colombian refugees.

Testing Hypothesis 2: The Economic Integration in Costa Rica. This section will concentrate on the type of labor market in Costa Rica, more from the micro-social perspective than the macroeconomic perspective. It will start providing an overview of 
the labor market in Costa Rica, focusing on factors that may inhibit the economic integration of refugees rather than on an overall summary of the economy of the country. Also to have a clear understanding of the economic conditions of refugees, the chapter will assess the types of employments of the refugee population interviewed and compare these findings with the findings of the 2003 Diagnosis about the Integration of Colombian Refugees in Costa Rica, as they also provide statistical data on this area. The definition of integration explains refugees should live in a community with absence of discrimination and fear, as foundation for their sustainability. Moreover. Portes and Rumbaut explain that the labor market is dependent mainly on the way immigrant groups are typified. rather than on the labor and economic opportunities the community may present. Thus, this chapter will also identify the stereotypes developed by the host community about Colombians, if there is evidence of discrimination towards Colombian refugees in Costa Rica, and the fears Colombian refugees might have towards discrimination, possible exploitation, or intimidation by members of the host community. This section will also look at possible barriers to employment such as the lack of education, job experience in the host community, or low job skills among the Colombian refugee population. Since the above literature review also showed the limitations Colombians have to find employment in the U.S., even after overcoming the lack of working papers, it will also be useful to identify if Colombian refugees in Costa Rica, as some Colombians in South Florida, face barriers to find employment due to lack of networks within their new communities and due to lack of information about the labor market. Finally, this section will also look at the spatial concentration of Colombian refugees in Costa Rica. It will also inquire if there is sectoral employment specialization. 
Both spatial concentration and employment specialization are variables of great importance to identify whether or not this community has the potential of becoming an enclave.

Testing Hypothesis 3: The Social Integration of Colombian Refugees in Costa Rica. Since Portes and Rumbaut's main argument is that migrants with similar characteristics brought from home may have very different integration experiences, then this section will not place particular attention to the human capital and resources brought from home by refugees. Rather, the focus will be on the community of Colombians in Costa Rica, particularly the spaces where refugees interact with other Colombians that do not have refugee status, and the potential formation of social capital in this community. After identifying these main variables. I will look closely at the type of Colombian community in Costa Rica, focusing on existing networks, the nature of the community, and the absence or presence of a Colombian entrepreneurial class in Costa Rica supporting the refugee population. From the overview of other refugee communities in the literature review it was possible to understand the importance that ethnicity plays in the integration of refugees. Negative stereotyping can cause the segregation of a community while ethnic bonding can develop feelings of social cohesion and strengthen indeed the process of integration. For the understanding of Colombian refugees" integration it will be important therefore to identify if ethnicity plays an important role in the formation of their community or if on the contrary their Colombian origin generates mistrust and fragmentation. After understanding the nature of the Colombian community this chapter will look at the sources of social capital for Colombian refugees in Costa Rica. Based on the studies by Portes and Sensenbrenner, the goal will be to identify 
bounded solidarity in the form of reactive situations to common adversities, and to identify enforceable trust from the presence of a sanctioning capacity within the Colombian community. Following the research emphasis of Portes and Rumbaut on the social dimension, a section of the thesis will, first of all. focus on the variables concerning social capital in Colombia to identify general cultural characteristics brought from home. Also the above literature review on Colombians in South Florida evidenced their limitations for the formation of social capital based on community fragmentation, lack of trust and solidarity among formal networks, and their tendency to rely more on informal networks. Thus, it is necessary to identify if Colombians in Costa Rica follow the same pattern and therefore also face challenges for the creation of social capital and therefore for the development of cohesiveness within their community.

\section{Design, Implementation and Data Analysis}

In order to identify the level of integration of Colombian refugees, I developed a questionnaire with the variables identified in the literature review and the theoretical framework. The variables mentioned in the legal, economic, and social sections above will first help identify if refugees are integrated and then they will help identify the possible reasons for their lack of integration, if any. This questionnaire was administered to 17 cases, individuals or families. In depth interviews ranging from 2 to 5 hours were also conducted as they responded to the questionnaire. After gathering data from these interviews, the results were organized in an excel spreadsheet divided in the legal, economic, and social sections. Then, through a pattern matching approach a comparative analysis of the variables was conducted to find patterns of similarities and differences. 
Since this is an exploratory research, it would have an ethnographic and descriptive nature and the results would not be representative of the whole sample refugee population in Costa Rica but could highlight trends that can be later tested with a broader quantitative research.

The process of selecting the families for the interview was based on reaching the families in a space where they could feel comfortable and not pressured to answer in ways different to their experiences. During the assessment trip completed with the International Rescue Committee I was able to interview over 26 families at the ACAI offices. Yet, from this experience I was able to determine that refugee families did not feel comfortable responding to the survey at this office. Some of them would wait for me outside the office until the end of the day to tell me their experiences with detail. Others would lower their voice while responding to some of the questions, especially to those regarding their employment conditions. A couple of cases actually cried when responding to the survey without actually giving me explanations for their frustration. It was not necessarily the fact that they did not trust ACAI officials, as most of these cases had a positive experience with the ACAI. It was rather an overall discomfort of opening up to a stranger at an official site and the fear of becoming more vulnerable in case they said something wrong during the interview. These reactions prompted me to stay away from interviewing families at the ACAI offices during my field trip research and rather to meet families by referral from other refugee families. Thus, through a connection to a refugee family in Costa Rica that works at an Internet service site frequented by other Colombian refugees, it was possible to reach and schedule meetings with all the refugee families interviewed during the fieldwork for this thesis. From the 17 refugee individuals or 
families interviewed 9 met with me at their homes and the remaining 8 met with me at restaurants or coffee places where they felt comfortable responding to the questionnaire.

Some of the biases posed by reaching the families in this matter come from the fact that the contact at the Internet service site was a refugee case in the process of resettlement. Since another refugee who had actually been resettled to the United States before referred me to her, and since I had previously completed an assessment in Costa Rica with an international organization helping refugees, then these refugees perceived me as someone that could help them in their process of resettlement. The situation of anguish and desperation experienced by some of the refugee families interviewed became a negative factor in the perception they had towards outsiders like me, as they assumed that if someone was at least interested in listening to them, then that person could become a helping hand. This could have affected the reliability of the study since some of the most desperate cases could have exaggerated their stories to raise more awareness towards their particular situations. Thus, to avoid the development of these false expectations and the weakness of the interviews, I explained to all families interviewed, even before they met with me, that the purpose of the questionnaire was an academic study and that my presence in Costa Rica was not related at all with a mission to help them, advocate for them, or represent them with any international non-governmental organization. After listening to this explanation and understanding I was not going to help them in any way, the cases in the process of resettlement thank me in any case for being there and listening to their stories. Most of these cases actually talked to me for the longest periods of time and during my stay in Costa Rica looked for me several times at the Internet site to give more information that could help support the thesis work. 


\section{LEGAL INTEGRATION}

In order to assess the legal process of integration and understand how it affects the overall integration of refugees, this chapter will divide the study of legal variables in two. First. it will look at the "policies of the receiving government," a central element within What the model of immigrant modes of incorporation proposed by Portes and Rumbaut (1990) terms "the context of reception". The analysis will consider whether the policies of the receiving government are exclusionist, passive, or encouraging towards the refugee community being integrated. Then, the Chapter will take a look at the definition of legal integration to understand how it is conventionally understood and assessed. This exploration is relevant since the basic definition of legal integration relates to the perception refugees have of the rights being granted to them by the host society. By assessing how the Costa Rican Government has developed the policies that affect Colombian refugees and then exploring how refugees perceive the rights they have been granted, including the right to obtain permanent residency or citizenship, this chapter will conclude with an assessment of positive or negative effects of the legal aspects surrounding the Colombian refugees ${ }^{*}$ integration process.

To start, it is important to understand the history of Costa Rica's overall policies towards refugee reception. Then, we will look specifically at the legal framework within which Colombian refugees were initially processed in Costa Rica to assess the character of the policies developed for this wave of refugees. However, we will not look merely at the formal legal context but address the actual reality, particularly the institutional capacity to implement some of the law's provisions concerning the treatment of refugees. 
In addition to the local legal framework and institutional capacity, we will also refer to some of the policies implemented within Costa Rica by the United Nations, for they are also a key component of the context of reception. Finally, taken into consideration the definition of legal integration and based on the results of the study on Colombian refugees completed by UNHCR and UCR in 2003, we will explore which rights have been granted to Colombian refugees and how the refugee community perceives these rights.

\section{History of Refugee Legal Processing in Costa Rica}

Costa Rica has been a receptor of refugees, asylees, and economic migrants for several decades. Its political stability, the country's promotion and protection of human rights, and the positive economic environment, has made Costa Rica and important pulling force of Central and South American migration flows. Yet, although the Costa Rican government has made efforts on providing refuge and developing a legal framework for the processing of refugees, this has been a slow process and the rights of refugees have not always been protected through the Costa Rican law.

Through Law 6079 of August 29.1977 Costa Rica ratified the 1951 UN Refugee Convention and its 1967 Protocol (UNHCR - UCR, 2003). This meant that Costa Rica agreed to provide protection to refugees and to develop and implement the structures necessary for this end. In 1978 refugees became a prominent part of the Costa Rican life for the first time with the arrival of Nicaraguans fleeing the war in their country. This refugee movement did not impact the legal migration system in Costa Rica too much as these refugees returned to their country in 1979 when the Sandinistas won the revolution 
in Nicaragua. It was only until the Salvadoran refugees started to arrive in significant numbers in the early 1980 s that the country began developing policies governing refugee affairs. First in 1980 the UNHCR took the task of receiving applications for refugee status. Then by May of 1982, a government commission known as CONAPARE (Comision Nacional para los Refugiados), was formed to expedite the six thousand applications of refugee status pending. With increasing numbers of Nicaraguan refugees arriving to Costa Rica", only until 1983 the Decree 14845-G created the Refugee Office of the General Migration and Foreign Direction (DGME), a division of the Police and Governance Ministry? ${ }^{7}$ It was then until August of 1986 that the current Ley General de Migracion y Extranjeria was issued and until 1989 that the regulations for the Law were developed. Through Article 7 of this Law, the DGME was designated as the responsible entity for determining the refugee status, resolving about the refugee solicitations, and providing the necessary documentation to refugees according to the Costa Rican law and the international conventions (UNHCR - UCR, 2003). The DGME's Department of Migration for Refugees (DMR) became the governmental institution responsible for processing the solicitations for refugee status in Costa Rica. This Department was not, however, responsible for providing protection or any other service to refugees.

An important component of the context of reception has been the active involvement of the United Nations and international NGOs in the handling of refugee claims within Costa Rica. UN`s involvement can be considered an intervening legal

\footnotetext{
"Nicaraguan refugees started to llee again to Costa Rica in 1982, 1043 Nicaraguan refugees registered this year and then 5.731 refugees registered in 1983.

7 The Decree 14845-G was replaced by Decree 32195-6 on November 22, 2004. The new decree extablishes the statistical information that needs to be submitted to the UNHCR in relation to the refugee status approwals. The new decree also regulates the procedures to grant the refugee slatus in Costa Rica.
} 
variable, for among other things they were meant to facilitate the implementation of the country's refugee's legislation. In 1980 the UNHCR made an agreement with the Episcopal Church to assist all refugees. Then UN sponsored assistance programs were passes to the Red Cross in 1982. In 1983 the Costa Rican government wished to have the control of assistance programs and the Instituto Mixto the Ayuda Sociul was created. In 1985 the programs were transferred back to the Asociacion Centro-Integral Atencion a Refigiados and then from 1989 to 1993, when most programs of assistance for refugees were terminated, the International Rescue Committee managed the assistance programs. With the rise in numbers of Colombians requesting refuge in Costa Rica. by the year 2000 the UNHCR designated the Agencia de Consultores y Asesores Internacionales (ACAI) as the organization in charge of implementing UNHCR's assistance programs. specifically developed to serve the refugee population in this country. Today the CAI is responsible for providing services basically in four areas: legal, social. micro enterprise. and psychological. Specific services in these areas include legal counseling, case management, screening and management of cases for resettlement, vocational courses. and assistance to individuals applying for the refugee status and to approved refugees ${ }^{\wedge}$.

Bridget Hayden (2003) in a study of Salvadorian refugees in Costa Rica argues that the constant changes and instability in the regulations and administration of refugee programs reflected a constant attempt to respond to the changing social, economic, and

\footnotetext{
* The criteria for assistance is defined based on four basic principles: 1. Assistance is a sers ice, not a right: 2. Assistance should be fair, accessible, and limited: 3. Sell-help is the best help: t. The relugec should participate in the search of solutions. Additionally the CAI, hased on UNHCR directions, dercloped the following criteria to provide assistance: 1. Individuals applying for the refugee status and approned refuges are eligible for assistance after a sociocconomic study of the case has been performed: 2 . The amount of financial assistance will be based using as a base the minimum salary of local population: 3 . The time of assistance will be limited, most often will no be provided for a time longer than three months. and will be assigned based on the number of lamily members.
} 
political conditions of the country while also gave indications of how conlusing it was for the Costa Rican government to deal with such large numbers of refugees. Moreover, the author argues "the Costa Rican government created the category of refugee as a bureaucratic necessity because the country needed international assistance to deal with the unexpected and unprecedented numbers of Central American refugees who arrived in the $1980 \mathrm{~s}^{\mathrm{m}}$. The author moves on to explain that the way to obtain assistance was through the United Nations and international NGOs, which required for the Costa Rican government to use the legal categories these entities recognized. The Costa Rican government created its own legal definitions of asylum and refugee. Yet, these legal definitions ultimately affected the way Costa Ricans perceived refugee settlements in their country.

Before the 1980s Costa Rica gave asylum to professionals, authors, and scholars; an elite group of people who had fled mainly due to political persecution caused by Latin American dictatorships. Asylum was granted by the president's office and this condition was granted to those with political reason for taking refuge. In 1986 Costa Rica changed its legal code to include the categories of refugee and asylee in a single system of classification. Refugees were defined as people who have any other reason to fear for their lives in their home country, which in the context of Central America in the 1980s meant the victims of war ${ }^{10}$. During the 1980 s Salvadorans and Nicaraguans were granted refugee status, rather than asylee status. Hayden argues there was a clear bias in the use of these terms; asylees had always been relatively elite while refugees were common

\footnotetext{
"Most Salvadorans arrived hetween 1980 and 1982; these were also the worst years of the economic crisis in (osta Rica. In 1982 inflation was between 90 and 100 percent in the country (Hay den. 2003).

Through the 1984 Cartagena Convention many Latin American countries ratified a new definition for refuges to include those who flee from generalized violence.
} 
people. most relatively poor, and many in need of some form of assistance because they arrived with nothing and because they were not permitted to work legally in the early years of their time in Costa Rica.

The Costa Rican distinction is a result of the prior existence of the mainly elite category of "asilo" in Latin America, but it also reflects, and was made more meaningful by, the contrast between a few elite and professional asylees and the masses of Salvadoran and Nicaraguan refugees who came to exemplify the category "refugiado" for Costa Ricans... Consequently the word took on connotations within the national context of the time - a context of economic and political crisis throughout the region that seemed to threaten the most fundamental aspects of Costa Rican experience. "Refugiado" came to mean. for the most Cost Ricans, the stereotypes they had about the Central Americans who were the majority of refugiados. The Costa Rican government encouraged the consequent prejudice against refugees by subtly using the refugee policy to deflect criticism against the state for worsening social conditions toward an outside cause. (pp. $28)$.

In addition to the basis for discrimination caused in part by the legal characterization of refugees, the Costa Rican law has been restraining refugees' access to housing and social programs. Article 2 from Law Number 5662 of Asignaciones Familiares December 23, 1974 and Article 42 from Law Number 7052 of Sistema Financiero Nacional para la Vivienda November 6, 1986, limit the access to the National Fund for Housing (FONAVI) and the Fund for Social Development and Family Assignations by specifying such funds should be given only to Costa Rican families. These restrictions violate Articles 19,33,50,51 and 65 of the Political Constitution of the Republic of Costa Rica and articles 13 and 21 from the 1951 Refugee Convention. A legal action to change these articles was introduced in 1997 , but no changes have been made to the law so far. Actually, on February 26, 1999, the Constitutional Court voted against the unconstitutionality of Article 2, arguing that excluding foreigners as beneficiaries was not limiting their right but instead guaranteeing the State's capacity to protect its citizens by securing the use of some economic resources to the benelit of a 
certain sector of the population (Defensoria de los Habitantes, 2003)". Moreover, the Constitutional Court ruled in favor of Article 2 arguing this benefit should be kept only to nationals since there are not enough resources to meet the needs of poor Costa Ricans. Based on Article 2, the Article 4 of the FODESAF law establishes that $20 \%$ of the funds for the pension program will be taken from the Fund for Social Development and Family Assignations, which must be available only to Costa Rican citizens. Thus, as the Costa Rican Ombussman reports, since the Regimen No Contributivo de la Caja Costaricense de Seguro Social receives resources from other funds in addition to the Funds for Social Development and Family Assignations, then there is no legal ground for excluding foreigners to receive pension benefits from this Regimen No Contributwo. The Ombussman presented a resource to have the Court ruling reconsidered. In 2003 the Ombussman received an answer restating the position to keep the pensions program only to Costa Rican citizens and to date refugees are excluded from this pension program.

The history of the legal conditions surrounding the integration of Central American refugees in Costa Rica during the 1980s was characterized by the inconsistency in the structuring of the legal framework for the integration of refugees, the slow implementation of needed law, the prejudices created against the category of refugee as a consequence of the legal denominations adopted by the government, and the urgency of different Costa Rican governments to remain as a sanctuary for refugees regardless of their pressing economic needs. Costa Rican migration officials sometimes harassed Salvadoran refugees as they used to go to the refugees homes to verify refugees were not working before 1984, year in which the law was changed to allow refugees to work as

\footnotetext{
"Additional references to the reports of the Defensoria de los Habitantes will be addressed as the "(osta Rican Ombussman" or "Ombussman".
} 
wage-laborers. Even after the change of law, it was only until 1985 that the mechanism

for issuing a work permit to refugees was instituted and in practice, even the legal work was difficult to attain for refugees (Basok, 1993). Moreover, based on reports made by UNHCR, 95 percent of the work permits requests made by refugees were denied by the Labor Ministry (UNHCR -UCR, 2003). Despite of changes in the legal framework to provide protection for refugees during the 1990s and still current legal battles that will be studied later in this chapter, the history of legal integration of refugees provides a foundation for difficulties and continued dilemmas in the current process of integration of Colombian refugees.

\section{Definition of Legal Integration}

The legal integration of refugees can be defined as the process by which refugees receive from the host state a progressive recognition of rights equivalent to those of host nationals or equivalent to the most favorable conditions to foreign nationals in the host state. This process should be geared to the acquisition of permanent residency or in some cases citizenship in the host state. The process is also defined in the context of the refugees' duties and responsibilities to the host state. The success of the legal integration process is reflected in the materialization of diverse social, economic, cultural, and civic rights recognized to refugees (UNHCR - UCR, 2003).

\section{Legal Process of Refugee Status Recognition to Colombian Refugees in Costa Rica}

To decide if the policies of the Costa Rican government towards Colombian refugees are exclusionist. passive, or encouraging it is necessary to look at the way the 
Costa Rican government has handled the legal processing of Colombian refugees as well as the measures it has taken to address issues such as citizenship and other rights refugees are entitled to receive.

The legal environment for the refugees' integration has evolved from the instable developments in the 1980s, times in which it would be fair to affirm that the policies of the Costa Rican government were not exclusionist, since the government was trying to handle the refugee influx. Yet, the policies were not encouraging either as rights such as the right to work, to no discrimination, to housing and social programs, or to permanent residency, were not accessible by refugees due to legal restrictions in the Costa Rican law. Although some laws have changed in recent years to better integrate the recent movement of refugees in Costa Rica, it is necessary to assess if these changes suffice for an appropriate integration of Colombian refugees in this country and to decide if the government has neutral or encouraging policies.

Since the creation of the DMR and throughout the 1980s and 1990s, the Costa Rican government started to build the capacity to handle the influx of refugees primarily arriving from other Central American countries. Yet, by the year 2000 these refugees had either returned voluntarily to their original country, had been resettled, or had integrated in Costa Rica. Therefore. by this time the DMR's capacity had been drastically reduced while other NGOS that had been working with refugees switched operations and focused on serving other needs in the Costa Rican community. Colombian refugees started to come precisely at this inauspicious time.

As explained previously, Costa Rican law established that the solicitations of refugee status are to be processed in one month after all the documents have been 
presented to the DMR. In 1999 the DMR received 88 solicitations for refugee status from Colombians and by the year 2000 that figure had jumped dramatically to a total of 1.451 solicitations. The processing of these solicitations did not respond to the 30 day timeframe designated by Costa Rican law and by January 2001 a total of 1.338 solicitations were still pending. With a very low average of 46 refugee resolutions by month from an average of 442 solicitations, the UNHCR signed an agreement called the Refugee Status Determination (RSD) project with the DMR. The objective of the agreement was to reinforce the DMR's processing capacity and speed up the procedures to determine the refugee status of applicants.

Through the provisions of personnel and technology the refugee resolutions increased to a monthly average of 514 by the end of 2001 . However, due to the long backlog of unresolved cases, by the end of this year there were still 2566 cases pending for resolution, most of which involved Colombian petitioners. Despite achievements, the RSD project had to be suspended by the end of 2001 and forging new alliances with the civil society in Costa Rica became a priority. Indeed, a new alternative to continue addressing the handling of cases was developed and the project between UNHCR and the University of Costa Rica (UCR) was created.

The project "Fortalecimiento de la Protección de los Refugiados y Migrantes Vulnerables en Costa Rica" developed by UNHCR and the UCR was developed as a community project of the University (TCU) Law School to strengthen the protection and assistance to refugees in Costa Rica. The project was based on incorporating students from different schools of the University in different functions of the legal processing and assistance functions to refugees. 
The students" main responsibilities include the collaboration with the DMR as assistants to refugee eligibility officials. Their functions as assistants include creating resolution propositions for the determination of an applicant's condition of refugec. creating ordinary resources of appeal, exit permits, re-entries to Costa Rica, resolutions about family reunification. migratory certifications, reorganizing the files, and interviewing refugee applicants. Another main function of TCU students has been collaborating with the $\mathrm{ACAI}$ in various aspects including legal, social, psychological. and micro enterprise assistance. In the legal area TCU students have been providing legal counseling about immigration, civil. family, housing, and employment issues, and they also have been helping refugee status applicants to organize the papers and documents necessary to present to the DMR office. Also in the ACAI office TCU students provide social assistance by assessing the refugee's socioeconomic situation to determine the economic assistance as well as by helping them with issues related to housing, family reunification and psychological support.

A third area of TCU students' support includes the elaboration of the "Diagnostico sobre el grado de integracion de la poblacion refugiada en el pais". This document, as well as following surveys of both the refugee and the local populations. has been developed with the objective of making an introductory study of the refugee's levels of integration. The results of the study are aimed at educating government and nongovernmental organizations about integration process and allow for the development and implementation of appropriate policies ${ }^{12} . \Lambda$ final area of TCU students support include

\footnotetext{
12 An example of how this study has been efficient includes the results related to the levels of employ ment of the refugee population. The results showed a very high percentage of unemployment among refugecs.
} 
the elaboration of a database and the analysis of the resolutions from the Constitutional Chamber in matters related to refugees and migrants.

The students participation was decisive in helping the DMR reduce the backlog that had been accumulating for almost two years. From 2089 cases that were still pending in January 2002, only 20 cases were still pending by August 2002 and by the end of this year the backlog had been eliminated. To date TCU students continue to participate in different activities related to the integration of Colombian refugees including, among others, the processing of the refugee status with DMR. the screening of cases for resettlement, and studies of the labor market in Costa Rica to strengthen employment for refugees.

Although this student participation has been very effective to speed up the process of status approval and to alleviate the burden of the agencies helping refugees, some of the activities students perform are still arguable, as these activities require personnel with more experience. At the DMR, students were in charged of the cases interviews and of recommending if a case should receive or not the refugee status. At the $\triangle \mathrm{CAI}$. students are in charged of interviewing the cases applying for resettlement and also recommending if the case should be referred to the ACNUR. The Director of the DMR. responded in an interview conducted by the IRC commission where I participated, that DMR officers supervise the students and revise the recommendations, changing them if needed. Management of the ACAI office also responded their students were supervised by officers of the organizations. Yet, from some interviews with refugees in Costa Rica, a sense of discomfort was expressed in regard to their recommendations for status recognition or referral to resettlement. 
Many of the families interviewed had gone through the process of resettlement and were waiting for an answer regarding their referral. The families who made the complaints expressed they thought their cases could have been delayed since the person who interviewed them seemed young and inexperienced. The interviewer is supposed to make an initial assessment trying to identify if the case has a well-grounded fear of a continued persecution in Costa Rica. This interview serves as a first screener of the cases to later refer only the cases that seemed likely to be persecuted to the UNIICR. ACAI personnel expressed on February 2005 that a larger number of cases were requesting resettlement. It is likely that ACAI personnel are not necessarily checking all recommendations made by students due to the great amount of resettlement cases. This will in part explain why some refugees have to write directly to UNHCR or go directly to their offices, even if this process is not encouraged by UNIICR. out of the necessity of being heard by professionals and later enter the process of resettlement.

As seen above the Costa Rican government with the help of UNHCR and the UCR, has been strengthening its response capacity to handle the influx of Colombian refugees. even if that process meant delegating important responsibilities to students at the risk of not providing the fairest treatment to refugees. As refugees continued to arrive in large numbers, the government, responding to economic pressures and fears in the community of job displacement, started to adopt a more restrictive position towards allowing refugees to enter the country by establishing a visa requirement. Then. as Colombians with visa continued arriving to Costa Rica and continued receiving refugee status, although in less numbers, the Costa Rican government started a law project aimed at restraining the refugees ${ }^{\star}$ access to permanent residency. 
To understand why the Costa Rican government has been adopting restraining policies, it is important to take a look again at the history of refugee migrations to Costa Rican. Since the 1980s with the influx of Central American refugees, Costa Rican media has been affecting ticos ${ }^{\circ}$ perception of refugees by causing alarm and creating a sense of loosing control over levels of unemployment in the country. Reports in La Republica on July 1982 with headlines such as "A thousand Salvadorans enter per month" (IJayden, 2003). fueled fears in the community of how thousands arrived to the country in need of assistance and willing to take any type of work. A decade later, since Colombian refugees started to arrive in larger numbers after the year 2000, main national newspapers such as Nacion also published articles with alarming headlines including "Costa Rica takes the third place in the continent in migration". This article starts by reporting, "Costa Rican authorities recognize their preoccupation due to the high migratory burden the country takes, where $10 \%$ of its population are foreigners. Costa Rica, being a small country, is the principal receptor of migrants in Latin America" ("Costa Rica ocupa", 2004). It then moves on to explain Colombians are the second largest foreign population after Nicaraguans and recognizes that the establishment of a visa requirement for Colombians issued by the government has been a successful measure to diminish the amount of requests for a legal migration status ${ }^{13}$.

When Colombians started to arrive to Costa Rica in the thousands and the media started to report the Colombian exodus, Colombians were first seen as a harmless migration movement due to their middle to high-class prolile and the investment

\footnotetext{
1.3 Translation from anticle on La Nacion dated June 10.2004.
} 
expectations in Costa Rica. In 2001 Costa Rica's main newspaper La Nacion reported the

Colombian exodus as follows:

Who are they? The profile of these immigrants is different from the Central Americans that Costa Rica has received up to know, based on the data of the National Council of Migration. Eduardo Vilchez. Migration Director, defines them as affluent and auto-sufficient people. He says this is a positive migration. able to being assimilated by the country, based on its dimensions today. In an interview given to La Nacion a few days before passing away, the Costa Rican Ambassador in Colombia explained that the majority of people llecing to Costa Rica were people with a small capital between $\$ 25.000$ and $\$ 50.000$ (colones) who are trying to escape violence... Chancellor Roberto Rojas explains that although it is not discarded that people linked to crime may arrive, this risk is minimum... Chancellor Rojas said that the government would not establish a visa system. They are the type of people we are looking to attract, they already have education, they bring an income, and they are not a burden to the social services of the country ("Exodo colombiano", 2001)."

Yet, these positive and harmless descriptions as well as the public opinion towards the Colombian migration changed rather fast, resulting indeed in the first change in policy that affected the migration of Colombian refugees to Costa Rica. By September 2001 newspaper articles with headlines like "refuge solicitations increased in a 6.910 percent" ("Alud de Colombianos, 2001) $)^{15}$. started to announce the possibility of issuing a visa requirement for Colombians in an attempt to stop refugee arrivals and alleviate the completely crowded Migration Offices that were trying to help these cases. Shortly after, by March 2002, the government was announcing the visa requirement to Colombia. While during the first public announcement the Costa Rican government did not offer an official explanation for the new policy and said that they were going to facilitate the system so Colombians could get multiple entry and tourist visas, two weeks later the Costa Rican Vice President announced in Bogota that the visa system was going to be

\footnotetext{
H. Translated from article in I a Nacion dated Sunday March 25, 2001.

15 Translation from article in 1 a Nacion dated Sunday September 16, 2001.
} 
temporary. The Vice President explained the system was going to be in place just while the security agreements between the Costa Rican government and the Colombian government were ready to learn information about the individuals who were trying to enter Costa Rica. Other official declarations included Costa Rica's government concerns over the increase of the numbers of victims from the Colombian conflict as a result of the peace process rupture, which could worsen the violence in Colombia and create a new migratory flow.

To date the visa requirement has not changed for Colombians and refugees continue to be approved after the visa was established for Colombians. Yet, it is important to note that the number of Colombians arriving to Costa Rica changed dramatically after the visa requirement was established. The numbers of refugce status requests reached a peak of 1073 solicitations on April 2002, as Colombians seemingly rushed to enter Costa Rica before the deadline of the visa requirement was due and then the number of solicitations came down to a continued level of 250 solicitations after May 2002.

After this first government measure to control the arrivals of Colombian refugees was introduced, the government continued the development of policies that would make the legal integration of Colombian refugees more difficult. To understand how this legal change affected refugees, first it is important to explain initial regulations established by the Law.

The Article 36 of Law number 7033, which is the General Law of Migration, established that temporary residents are all foreigners who, without the intent of staying permanently in the country, enter the country under the category of asylees and refugees. 
among other categories ${ }^{16}$. In relation to the change of status from temporary to permanent resident. the Article 58 of the decree number 19010-G, which is the decree that makes the Regulation of the General Law of Migration, establishes which documents are necessary for the application of status change. The Law establishes that the applicant should present the application at the General Consulate in the country of origin and to have all necessary documentation certified there. Since this was not possible by refugees, who could not return to their countries of origin, it was permitted that refugees presented a sworn declaration to the DMR in Costa Rica. Yet, on August 2002 the government established a series of restrictions and since then sworn declarations were no longer accepted as a mechanism to replace the certified documentation needed for the change of status.

On February 2003 the government established an additional detrimental restriction regarding this change of status. The Article 79 of the decree number 19010-G. established that a temporary resident can apply for permanent residency after a) presenting an application authenticated with a lawyer and b) had lived continually in the country for two consecutive years after having received the temporary resident document. Refugees were affected negatively when the Executive Decree Number 31186 of February 52003 eliminated the article 79 and therefore eliminated the option for refugees of applying for permanent residency after two years of being temporary residents. The arguments for the change in this decree included, among others, that the General Law of

\footnotetext{
If Other categories of foreigners receiving the temporary resident status include, professional scientists. lechnicians or specialized personnel who are hired by companies or established institutions that derelop activities in the country; entreprencurs, businessmen, and directors of national or forcign companies: students: religious people who perform activities that are part of their cult or teachings: the spouse and minors of the individuals in these categories: those authorized by the General Direction of Migration: and the owners and crew of tourist and recreation ships. The Article 35 of this I aw establishes that imestors and retires are entilled to receive the permanent visa status.
} 
Migration does not establish that temporary residents can change their status just as a result of time, and that the Law's Regulation should include the norms to determine requirements and procedures to allow the application of the Law, without establishing things that are not contemplated by this Law. The arguments for the change in this decree also bring up the Article 67 of the Law, which establishes that the foreigners accepted in the country as temporary residents or no residents can stay within the country for the lapse of time authorized and should leave the country once this time comes to an end. The reasoning used in the decree Number 31186 does not mention, however, that the Article 67 also establishes that the Law's Regulation is the one to determine the terms of stay, based on the categories of arrival and permanence, as well as the extensions. Thus, although the Law clearly establishes the right refugees have to obtain permanent residency, the Executive decree is deliberately, and still arguably, negatively affecting the integration of Colombian refugees.

As it will be explained in the chapter exploring the economic integration, refugees face great challenges to obtain and secure employment due to the type of document they get. Permanent residents and citizens receive a cedula, which is a resident ID, whereas refugees holding the temporary resident status receive a refugee $1 D$. which is often not recognized by employers as an authentic document certifying legal work authorization. To date the only viable way for refugees to obtain the cedula is by waiting five years after their refugee status approval date to apply for citizenship.

Another important governmental measurement that will affect the legal integration of Colombian refugees is the project to change the Migration Law. In response to the changes in the migration environment in recent years, the Costa Rican 
government drafted a new Migration Law that was approved on October 27, 2005 (La Nacion, October 28 2005). This Law is specifically looking at encouraging organized international migrations as an important development mechanism while simultaneously discouraging and strongly sanctioning any mechanism that may allow or support irregular or unorganized migration flows. To implement these changes the Law project is aiming to establish the Superior Migration Council formed by the Ministries of Presidency, Public Security, Cult and Foreign Relations, Government and Police, Labor and Social Security, and Justice. The Council will advise the executive on any matter related to migration and will revise any international treaty of migration nature. The law project will also establish the judicial structure for the creation of a Migration Police to control and guard people entering and leaving the country as well as the stay of foreigners in the country. UNIICR officials in Costa Rica have been providing recommendations regarding the need to implement definitions in the law that would protect the refugee"s rights.

The law proposed does not include any definition regarding what means refuge. as it is established in the 1951 Convention of which Costa Rica is signatory, and it does not make reference to the fundamental principle of no return even though this principle is included in the Costa Rican constitution. Additionally the proposed law includes additional motives to cancel the refugee condition opposing the 1951 Convention; for example, any sanction that may lead to the cancellation of an individual's refugee condition would be applied automatically to the individual's family members without considerations of their individual needs for protection.

Finally, the law proposed does not guarantee to the refugees their right to work. Even though Costa Rican authorities respect this right in practice, this right must be part of any new law in a way that refugees may achieve self-sufficiency in the local society without this being a burden to the government" ("Costa Rica: ACNUR', 2005).

\footnotetext{
Tev Translated by Angela Bonilla from I a Nacion. August 12. 2005.
} 
The Costa Rican Ombussman, as secretary of the Forum in charged of drafting the Migration Law project in 2000, recommended that such project should change its national security approach to adopt a human rights approach. The Ombussman also sees with concern that the different migrant categories are not being defined in the Law project but instead in the regulation that will be drafted after the project is approved. Since the Law project has a restrictive character, the Ombussman sees the importance of defining with clarity categories such as the temporary residents, permanent residents, and refugees. It specifically sees with concern that the new project places refugees in a special category that cannot be understood as a permanent nor temporary resident category, which as well as to the other categories not properly defined, causes confusion in relation to the refugee's change of status and does not recognize the explicit rights refugees are entitled to receive.

As evidenced from interviews to refugee families and individuals, the issue of permanent residency or citizenship does not seem to be of great concern for refugees now. From the 17 families responding to questions regarding their expectations to become citizens, only four cases responded they were looking forward to becoming permanent residents or citizens, two cases actually with hopes of improving their conditions after receiving the residency. From the remaining families three either did not know about the legal limitation or did not care about it while the other ten cases did not want to become residents or citizens as they were already very disappointed with their lives in Costa Rica and were more interested in leaving the country if possible. Thus, for many the battle is already lost. Not becoming permanent residents or citizens means refugees need to remain within a legal category that isolates them from the mainstream 
Costa Rican society. Remaining as refugees, instead of allowing them to access a status equal to regular residents of the country, ultimately affects their access to some rights the 1951 Refugee Convention and even the Costa Rican Constitution wish to uphold for all refugees. It is not surprising indeed that many refugees express feelings of despair and have great difficulties integrating in Costa Rica.

\section{Rights Granted to Colombian Refugees in Costa Rica}

In order to continue understanding how the law and other related government policies affect the integration process, it is necessary to assess the process of granting rights to Colombian refugees in Costa Rica. The rights granted to refugees in Costa Rica are based on fundamental rights established by the 1951 UN Refugee Convention and the Universal Declaration of Iluman Rights. They include, among others, the right to no discrimination for any reason (race, religion, or country of origin), which was established in article 3 of the Convention. Similarly, the right to no return. which is the principal right granting protection to refugees, also found in the Convention. Additionally the right to family reunification found in the Declaration of Human Rights.

Currently the right to no return for individuals applying for the refugee status is granted while the person is in the resolution process, which is today back to the one month timeframe. If a person is denied the refugee status, the individual is still able to use different legal resources to appeal the decision. First, the individual can present an ordinary resource responding to the decision of the DMR Director. Simultancously, the person can present an appeal resource to the Ministry of Government and Police, responding to the decision of the ordinary resource. Both resources are presented at the 
same time since they have to be introduced within the first five days after the resolution of refugee status is given to the individual. If new documents supporting the protection claim of the individual appear, the law allows for the introduction of an extraordinary resource of revision. While these resources are processed, the individual is granted protection in Costa Rica. Once all the resources are processed and the resolution continues to be a negation of the refugee status, then the Costa Rican authorities mandate the individual to obtain legal status through other means or to leave the country by his/her own means. If a person with an expired process of refugee status determination is found. he/she can be deported to the country of origin. To date there are very few deportation cases of Colombian nationals from Costa Rica. Yet, the UNHCR - UCR report in 2003 found that between July 2001 and August 2002 forty one percent of the cases that had been negated presented the ordinary resource, which indicates that a very high percentage of individuals applying for refugee status are active in the usage of resources that allows them to exercise their right to no return.

After the refugee status is granted to an individual, the protection and therefore right to no return is effective through the expedition of legal identity documentation and work authorizations. The refugee ID card is issued to refugees for a one-year term once the refugee status is approved, and is renewable for equal periods of time year after year. Similarly, travel documentation is issued to refugees upon request of travel authorization.

The refugee ID is the document that identifies refugees as temporary residents and has a stamp authorizing refugees to work in Costa Rica. The second diagnosis about the degree of the refugee's local integration in Costa Rica, completed by the UNHICR and the TCR in 2003, found that there were several limitations in the documentation given to 
refugees, especially in regard to its quality and accountability. These limitations, the document explains, results from the lack of uniformity, consistency, and presentation of the documentation given to foreigners, migrants, individuals in the process of refugee status application, and approved refugees. UNHCR's and TCR's second diagnosis also found that the informal presentation of the refugee ID has a direct impact in the refugee's access to housing, employment, health. and education. Employers and public officials usually recognize the resident ID or cedula, which is consistent in its color and format. and are usually not familiar with the refugee ID.

From the 43 interviews and many more conversations I conducted with refugees in Costa Rica, over half of the cases expressed the refugee ID did not serve as a work authorization document. Actually, even ironically one case responded she works as a housemaid without providing work authorization proof because when she has shown the refugee ID she has not been able to get employment, even in the same line of work. Two recently approved cases also explained that on top of the inefficiency of the refugee ID. they also had problems at the time of receiving the ID because the machine to produce it at the DMR was broken. Another case that had been approved for over two years also mentioned this problem when he went to get his refugee ID renewed. This case mentioned an official explained to him that he could not tell when the machine was going to be fixed because they did not have money to fix it. "Now I actually feel like an illegal" this case expressed, and adds, "anyway is not like if I had used it to lind work since I work in the streets". Since the machine was not working refugees received a piece of paper without a picture that even less people recognized as legitimate documentation and 
even worst. continued contributing to the general public confusion about the legitimacy of this document.

Many cases interviewed expressed the refugee ID worked as a document for identification but had a limited use as a document to obtain employment. Two cases that did not complain about the inefficiency of the refugee ID as a work authorization document were cases working independently. One case was a cosmetician and the other one was a contractor. These cases get their clients mostly through referrals and expressed the document has identified them to conduct their activities. Two other cases that also mentioned the refugee ID was useful expressed they never got a job after presenting the ID. Yet, that the ID had served as a document to prove their status and their legality in the country when they secured employment after being referred by friends. One case also mentioned his employer recognized the refugee ID. Yet, that this had alienated him from coworkers and that he had suffered discrimination with this ID.

The lack of access to permanent residency and indeed to having the cedula instead of the refugee ID has not only limited the refugee's right and access to employment but also the access to many other rights refugees should be entitled to receive if treated as the 1951 Convention says. From interviews to refugee lamilies, 11 families, from the 17 families responding to questions about access to credit and the Costa Rican financial system, responded they do not have aceess to credit due to the lack of a resident ID or cedula. Additionally, six families expressed they did not even had the opportunity of opening a bank account without the resident ID. One refugee, who had actually worked in a financial firm, even said she knew from her work that it was almost impossible for Colombians to obtain credit since most applicants were refugees and such 
status did not guarantee that the individual was going to stay in the country to meet his or her financial obligations. She said as well however, that there was not an impediment for refugees to open a bank account with a refugee ID and $\$ 10.000$ colones.

The fact that many refugees have had barriers to open a bank account results from the fact that until 2003 banks were not recognizing the refugee ID and the government was not enforcing the acceptance of this ID as proof of identity. A Colombian refugee presented a resource of unconstitutionality that was later won and contributed towards having main banks accept the refugee ID as proof of identity. After 2003 main banks in Costa Rica were notified and instructed about the legality of the refugee ID. Yet, some of the refugee families expressing they had were not able to open a bank account arrived recently, which shows some branches are still not well trained about the legality of this document. Actually, one refugee case who was able to open the bank account even expressed he actually paid $\$ 15,000$ colones to a bank official in order to being able to open his bank account. Thus, even with a legal resource now instructing institutions to respect the refugee right to have access to the financial system, the lack of education and information about the refugee rights among different institutions makes it very hard for refugees to access a right that the State is helping them to access. On this respect. an official from the Costa Rica University working in the students project about the integrations of refugees, responded in an interview that their group was working in an outreach effort to educate the Costa Ricans about refugees and that one of the sectors that was harder to access for presentations was precisely the banking sector. This not only shows the difficulties refugee advocates have to face in their day to day jobs, but also 
shows the overall negative community attitude towards refugee issues, which will be explored in more detail in a later chapter.

In regard to the refugees" access to credit the situation is even more complicated and limited. As explained before in words of a refugee, access to credit for refugees is "almost impossible". It is not only the fact that refugees have barriers due to the lack of cosigners, which is a condition even requested by the UNHCR for its micro enterprise program. The main problems refugees face for their access to credit is the fact that they do not have a permanent residency. A refugee who found the negation to credit by the Banco Popular y De Desarrollo Comunal a discriminatory action also took this situation to the Court. After introducing a protective resource in 2003 claiming the bank should have not denied him a credit for having a temporary residency, the Court found this had been indeed a discriminatory action. The bank argued they could not extend a credit to someone who, in legal terms, was not expected to live permanently in the country. The Court, based on Articles 7,13 and 18 of the 1951 Refugee Convention ratified by Costa Rica, and based on Article 19 of the Costa Rican constitution found that having a temporary residency was not a legal ground for the bank to deny credit to refugees and that the bank should look at other mechanisms to guarantee the repayment of any financial obligation assumed by refugees. The Court ruled in favor of the refugee and set a precedent to avoid discrimination to refugees and the violation of their rights. Yet. as the refugee who worked in the financial institution responded, banks are not informed about this ruling and continue denying credit to refugees. Actually, from the 17 families interviewed in regard to access to credit, only one case had received credit alter presenting a letter from his employer certifying her was paying taxes. The remaining 16 
families expressed they had heard refugees were not entitled to receive credit because they were not residents.

Other important areas where refugees should be granted equal access to rights as Costa Rican citizens are education and health. In regard to health the Costa Rican law, based on the 1951 Geneva Convention, protects specially children and pregnant women through Law Number 5395. Law Number 7739. Articles 21 and 50 of the Costa Rican Constitution. and Decree 28118-S. Through these laws children and pregnant women should receive health benefits with no restriction. The UNHCR-UCR 2003 Diagnosis reported the claims of some refugee pregnant women who had not been helped. The Diagnosis also reported ACAI officials explained one of the reasons for these claims is the confusion in the health centers and hospitals referral system, not the lack of proper identity.

Refugee adults also have access to health services through the Caja ('ostarricense' del Seguro Social (CCSS). The UNHCR established and agreement with the CCSS in 1990, providing refugees access to the contributive regime of the social security. Refugees have access to health benefits when their employer contributes to the CCSS and refugees make monthly payments of $\$ 5,600$ colones. Yet, since only a small percentage of refugees in Costa Rica are formally employed, most refugees do not have access to regular health benefits through the CCSS. In order to fill this gap in the refugee's aceess to health benefits, the ACAI provides a three-month medical insurance to refugees who are in need of such service. From the 17 families responding questions about access to these health services only four refugees confirmed they were receiving regular health coverage through the CCSS, and seven families confirmed they had received the 
insurance form ACAI. One of the refugees interviewed was even schedule to surgery and expressed that knowing everything was going to be covered gave him great comfort. The remaining six families did not have any type of health coverage although some feel confident in case of an emergency they will be helped in any medical facility with their refugee status.

Refugees access to education is actually not as fair as the access to health. The Geneva Convention mandates signatory countries to give equal access to refuges in elementary education and to give the most favorable treatment. and never less favorable. to foreigners in general. The Costa Rican constitution through Article number 78 makes the provision of elementary education and basic education in general mandatory for everyone, including refugees. The last two years of secondary education are not mandated, however, and the acceptance and provision of these services depend on the schools.

Despite the law providing for schools to accept refugees in elementary education. refugees face mostly economic challenges that limit their access to education. both at the elementary and higher education levels. From the seven families with children in Costa Rica of school or College age who responded to questions regarding their access to education, only three families responded they were able to pay for the enrollment and monthly fees of their children's education. Actually, the problem with the access to education is mainly economic. Families living under very precarious economic conditions cannot afford their children`s school and there is not financial aid available to them. Even three single mothers interviewed confessed they had to send their children back to Colombia, to stay with relatives in a main city and away from the place were they 
suffered the persecution, as they were not able to pay for education and after some time the family got more desperate seeing their children getting depressed from doing nothing at home. One of these cases was able to reunite with her daughters when she obtained the resettlement to the United States. The other two cases have not been able to reunite with their siblings and have only been able to see them when family members bring them back to Costa Rica for vacation. Another single mother, who has a son that used to go to a university in Colombia before fleeing the persecution, also expressed her concern, as she did not see any possibility for her son to study in Costa Rica. The situation for college students is even more worrisome as higher education refugee students are not charged resident fees to enter colleges or universities but instead international students fees. This refugee expressed in the interview her son had been looking for a job for some time and that she wished he could leave the country since she did not see any future for him in Costa Rica.

The ACAI does not offer financial assistance to pay for school but they offer courses in some technical areas like computers. Some refugees take advantage of these courses waiting to have more access to employment after completing the courses. However, the main limitation refugees without children see in regard to their education is that many refugees have actually professional or technical degrees and they are not able to validate their titles in Costa Rica. The regulations of professional Colleges and the L.oy del Consejo Nacional de Rectores (CONARE), actually apply the highest fees to temporary residents for the processing of their titles. From the 17 families responding to questions regarding their access to education, 11 responded they have not bee able to get their professional tittles validated. Three of these families actually said they were even 
willing to pay the fee of $\$ 99,000$ colones to validate their titles but expressed frustration due to the complex process to get these validations approved. For example il a family used to leave outside Bogota, where the Costa Rican government has its Lmbassy, then they need to arrange for a relative to travel to Bogota to take originals of the titles to be certified by the Consular officers. Another refugee interviewed even expressed, "I think one of the main reasons I have not had success finding employment is that I have not been able to validate my title. I think the government makes these restrictions purposely to block the refugees" success".

\section{Conclusions}

The lack of access to a permanent residency in Costa Rica has limited refugec's access to a treatment equal to that of the receiving country's residents, as the 1951 Geneva Convention mandates, and therefore has limited the refugees access to some fundamental rights such as access to some financial services, to employment, to social funds, and to education. This is a deliberate legal restriction, as not having access to the permanent residency is the result of an Executive decree, which restrains refugees to do so. Additionally, other legal measures have been developed to limit the refugees' entry to the country and to inhibit their access to certain social services, creating indeed an overall feeling of discomfort and alienation in the refugees that is hard for many of them to overcome.

It is also important to highlight that after the visa requirement was imposed, many Colombian refugees have been arriving to Costa Rica through the Panama border, as they are not able to get their Visas in Colombia and therefore only see the option of crossing 
the border undocumented. Once they are in Costa Rica they can receive refugee status just as if they had entered the country with a Visa. Yet, as reported by two cases interviewed. refugees are put in jail and threatened with deportation while legal representatives start their process of refuge application with the DMR. Thus, right after fleeing persecution, some refugees find a prison in Costa Rica for the first days after their arrival, instead of shelter and refuge.

It is fair to recognize the advances the Costa Rican government conducted throughout the 1980 `s and 1990 s to create a legal framework suitable for the integration of refugees. It is also important to recognize the efficient response of the UNICR and the University of Costa Rica to help the government when Colombian refugees started to flow massively into the country in 2000 . Yet, granting the refugee status is not enough. Refugees should be able to have access to the same rights Costa Ricans have, and with the latest limitations in the legal framework of integration for Colombian refugees in Costa Rica, their access to many rights has been inhibited. Taking into consideration the latest developments in the legal system in Costa Rica and also the way Colombian refugees perceive their access to different rights, it is therefore necessary to conclude that Costa Rican policies towards the integration of Colombian refugees are exclusionist. Since the hypothesis 1 of this thesis work says "There is a "passive acceptance" of the receiving government towards Colombian refugees that inhibit their legal integration" and the findings suggest the current legal system is excluding Colombian refugees instead of passively accepting them, then the hypothesis 1 of this thesis is not supported. By concluding that the Costa Rican policies are exclusionist, the overall environment for the 
successful integration of refugees is therefore harmed and more complex than originally estimated.

The office of the UNHCR in Costa Rica and the ACAI office have legal departments with lawyers fighting for refugees' rights and representing them in some cases related with claims of discrimination or violations of their rights. These legal departments also help refugees to have access to rights such as resettlement and family reunification by helping them process their cases. With almost nine thousand approved Colombian refugees in Costa Rica this legal representation gets easily overwhelmed. specially as from seeing in this chapter the Costa Rican law itself does not always protect refugee's rights. Yet, at least these offices exist to help refugees in their claims and also to fight back governmental initiatives aimed at developing more policies that could continue harming the integration of refugees in Costa Rica. Also the Costa Rican Ombussman has received some claims from refugees regarding violations of their rights. Yet, many families interviewed did not know about the existence of the Ombussman as an entity that could represent them and other families expressed the Ombussman had referred them back to the UNHCR.

In addition to having access to legal representation, it is important to note that despite the limitations refugees have to access some rights, such as the right to work, the right to a work authorization document, and the right to education. there are other rights that are more easily accessible by refugees thanks to laws created during the 1980 s and $1990 \mathrm{~s}$ and the permanence of the UNHCR office in Costa Rica. These rights include the right to no return, the right to documentation. the right to freedom of movement. the right to family reunification, the right to ACAI's assistance, and the right to housing. The fact 
that refugees have access to these rights, however, does not make up for the extremely detrimental consequences some government initiatives have caused in the integration of refugees in Costa Rica. Thus, the exclusionist character of the Costa Rican government policies remains as the appropriate way to describe this context of reception. 


\section{ECONOMIC INTEGRATION}

One of the most important aspects in the process of integration is the capacity refugees may have to become economically independent and able to sustain their houscholds. From interviews to Colombian refugee families in Costa Rica it became evident that economic achievement and stability is one of the areas most valued by them. Refugee's economic independence depends on different variables and although the economic environment in Costa Rica will be considered into this analysis, it is more important to look at the labor market from a micro-social rather than a macroeconomic perspective. Economic integration models such as the model of immigrant modes of incorporation discussed in the first chapter, which provides a structural way of looking at the possibilities of economic integration for a refugee community, concludes that it is necessary to pay attention to sociological factors affecting the access to the labor market. Thus, analyzing the labor market from a micro-social perspective means we will be looking at how the Colombian refugees are typified by the host society and at how the stereotypes developed by the host society may affect the refugee's capacity to access the labor market. Then, we also need to assess the barriers refugees usually lind to access employment by looking at the areas identified by Portes and Rumbaut (1990) and at the areas identified by the refugees themselves. Finally, we will need to find if there is a spatial concentration of Colombian refugees in Costa Rica and if there is a sectoral employment specialization to assess the potential of the refugee community to form an enclave economy in Costa Rica. 
The data provided by the Nation Report from 1990n to 2003 indicates that Costa Rica had an unemployment rate of 6.7 percent by 2003 . From the 1.640 .387 Costa Ricans occupied in 2003 the five areas of occupation with the highest numbers of employment were commerce with 322,392 people occupied; agriculture with 239.811 people occupied: the manufacturing industry with 230.058 people occupied: construction with 109,616 people occupied, and the real estate and entrepreneurial activities with 101,234 people occupied. In regard to the labor market changes during the late $80 \mathrm{~s}$ and $90 \mathrm{~s}$ in Costa Rica it is worth highlighting that the size of the agriculture sector decreased from 34.6 percent in 1984 to 19.5 percent in 2002 while the sizes of the financial and the commerce sector increased during this period from 2.9 percent to 6.2 percent and from 9.5 percent to 13.9 percent of the labor market respectively (Global Policy Network. $2004)$

The Nation Report from 1990 to 2003 informed that 1990 s was not a lost decade for Costa Rica. However, with a weak start due to the debt crisis recovery in the 1980s, the development of the country was not sufficient for the challenges it has to face now. Since 1990 the population has grown in Costa Rica in over one million people, which represents an average population growth rate of $2.5 \%$ throughout the decade, as by the year 2003 the total population was 4.169 .730 and the population in 1990 was 3.050 .556 . (Proyecto Estado de la Nación, 2003) ${ }^{18}$. Even though Costa Rica's population growth rate is lower than the growth rate in neighboring Central American countries like Nicaragua, the population growth rate is considered dramatic by Costa Ricans due to the small size

\footnotetext{
Is Additional references to the "Proyecto Estado de la Nacion. 2003" will be addresses ad the Nation Report.
} 
of their country. In addition to the increase of the Costa Rican population, the 2000 Census actually showed a more complex situation related with the "demographic bonus". Costa Rica has enjoyed a "demographic bonus" for some decades now, meaning there has been a decrease in the dependency rates. The dependency rate is given by the proportion of people below the age of 15 and above 65 with respect to the number of people considered productive between the ages of 15 and 65 . The current rate has decreased from 70 in 1984 to 55 today and is expected to be of 44 dependants for every 100 people in productive age for the year 2018 .

The development of any country can depend greatly on how good the demographic bonus is used. Due to the current low fecundity rate, the young generation in Costa Rica is the last generation that will have a relatively low dependency in the future. Ilowever, this may become a problem or an advantage depending on how the education and the labor market evolve for this generation. If the young generation receives strong education and is able to access quality employment to increase the country"s productivity, then they may represent a boost in the development of Costa Rica for the next three or four decades. Yet, if this generation does not become more productive, then they will become dependent of the next generation, which will be smaller to sustain them and therefore could dramatically affect the already vulnerable pension and social system.

Today the challenge to set the foundation for a future boost is great, as the country has not taken advantage of the demographic bonus and a population that could be more productive now is wasting its potential. Today the majority of the working age population is those who joined the labor force a decade ago. This is problematic since during the 
1980s the secondary education coverage declined considerably in Costa Rica and therefore the people in age to work today are not able to produce at their full potential". Additionally, even though the education coverage has increased in recent years, this improvement has not been enough for the increased amount of children in ages between

\section{3 and 17 years old.}

Since the education and training years have already passed for the majority of the population in age to work, then the government needs to concentrate in offering higher quality jobs to them rather than on providing more education opportunities. Yet, since the early 1990 s the labor force rate has been increasing at a faster pace than the employment generation rate, which in some years has actually declined. Dynamic sectors such as tourism and the new export agriculture have not made up for the loss of employment opportunities in the traditional agricultural sector. Thus, Costa Rica actually reached its peak of unemployment of 6.7 percent in 2003 while the lack of use of the labor force increased by 5 percent in the last decade as well.

The need to make the young generation a more productive one pushes the Costa Rican government to take special measures today, in view of the need to avoid a future burden to the state. Current levels of savings and investment. both private and public. need to increase. Also, the government needs to promote the rapid expansion of quality employment opportunities, in part also to revert the growth of the informal sector ${ }^{2 n}$, while also guaranteeing the provision of secondary education to all who need it. Improving the

\footnotetext{
"The Nation Report explains that there are not exact measurements of the produclivity in Costa Rica due to a lack of reliable data. Yet hased on preliminary findings the report suggests the productivity of costa Rican workers only increased 1.4 percent from $198+$ to 2000.

21 The creation of employments in the informal sector in 2003 was of 6 pereent while in the same year the creation of employ ments in the formal sector was of 5.3 pereent. This trend tends 10 affect the living quality of (osta Ricans due to the incomes vulnerability and the lack of aceess to social security provisions.
} 
quality of employment is also a great challenge as during the last decade the informal sector generated more new employments than the formal sector while an important part of the formal labor force continued to experience problems with the quality of their employments. As a result the salary gap increased between the haves and the have not with the Gini coefficient reaching 0.4 in 1999 and increasing since this year. while the developments in the human index were seen only for the richest groups of the population. A higher Gini coefficient is evidence of a wider economic gap among a country"s population. By 2003 the Costa Rican Gini coefficient was 4.3.

With these challenges the pressures to improve the conditions in the labor market to set the foundation for future economic development increase considerable for the government. This scenario may also create higher expectations for Costa Ricans wanting to see more policies to protect their labor market and diminish the competition for quality employments in a professional field with already limited opportunities. It is actually argued that Costa Rica has been strongly averaging one of the highest GDP growth rates in Latin America, of 4.3 percent between 1994 and 2003. Yet, since this growth has been mostly based on foreign investment. the foreign payments have also increased while the growth rate of the gross per capita income only increased 2 percent between 1992 and 2003.

The labor market environment is therefore not without challenges. Although poverty levels in Costa Rica have been declining since 2000, the weak labor market has mostly affected the poorest sectors in the country as evidenced by the unemployment rate among the poor, which increased from 8.3 percent in 1994 to 16.7 percent in 2003 . In response to the labor market vulnerability the Costa Rican government started a national 
program to strengthen it in 2003. It is still early to make an assessment of how this national program has changed the quality of employments generated or the unemployment rate, which remained at an average 6.7 percent in 2004 . Yet, as seen in the previous chapter, some of the measurements taken by the Labor Ministry in this National Program were also directed at integrating the refugee population to the labor market in Costa Rica. Although it may also be early to assess the success of the Labor Ministry program with the refugee population, it will be possible to draw some preliminary conclusions from the interviews to refugee families that will be seen in this chapter.

\section{Employment Conditions of Colombian Refugees}

Before going into detail about the presence or absence of discrimination towards Colombian refugees in Costa Rica and the refugees" employment conditions in their new country of residence, it will be useful to take a look at the breakdown for the refugees" regions and cities of origin provided in the 2003 Diagnosis. It will be important to have a look at this information to understand the percentages that have a rural background versus the percentages of refugees that have an urban background. To understand the refugee"s employment conditions and their regions of origin the 2003 Diagnosis, prepared by the UCR and the UNHCR, provides the results of surveys conducted with 320 Colombian refugee families. These results allowed the UCR students participating in this project to present a snapshot of the economic, social, and legal conditions of the Colombian refugees in Costa Rica. Yet, since 60 percent of these interviews were conducted in the offices of the ACAI and the DMR offices, then families interviewed could have been frightened to answer the surveys and indeed their answers could have 
been biased ${ }^{21}$. Moreover, the surveys that were given to refugees in their homes were given to refugee families selected by ACAI officials. Since the ACAI office is directly funded by UNIICR, which is involved in the preparation of this Diagnosis. then it is necessary to compare the results of the Diagnosis with the perspectives refugees provided in the interviews conducted for this thesis work. The following table summarizes the findings on regions of origin in Colombia. It is important to highlight, however, that the rural and urban percentages found on the interviews conducted during the IRC assessment trip and the fieldwork differ significantly from the results found in the 2003 Diagnosis. From the 43 cases interviewed during both trips 65 percent of the cases are of urban origin while 35 percent of the cases are of rural origin.

Table 1. Refugee's Urban/Rural Background

\begin{tabular}{|l|l|l|}
\hline Origin & Number of families & Percentage \\
\hline Urban & 262 & $83 \%$ \\
\hline Rural & 44 & $14 \%$ \\
\hline $\begin{array}{l}\text { Background cannot be } \\
\text { established from data } \\
\text { on 2003 Diagnosis }\end{array}$ & 11 & $3 \%$ \\
\hline Total & 317 & $100 \%$ \\
\hline
\end{tabular}

Source: Summary from box 1.12 Colombian Refugee Population Place where they lived before coming to Costa Rica, by sex of head of family. UNHCR - UCR Diagnosis About the Degree of Local Integration of the Colombian Refugee Population in Costa Rica. 2003.

From the 302 families that responded the survey regarding their occupation in Costa Rica for the UNHCR - UCR Diagnosis, 246 heads of family had an occupation by the time of the interview and 56 or an 18.54 percent did not have an occupation. Also from these 246 heads of family with an occupation 37.92 percent were working independently while 61.67 percent were wage earners and only 1 head of family was an

${ }^{21}$ Reference to interviews at the ACA oflice was provided in the final section of chapter 1 in this thesis. 
employer. It is important to note here as well that from the 246 heads of family with an occupation, 25 percent of them only work part time or by hours. The Diagnosis also provides a breakdown of the occupation type and a comparison between their occupations in Costa Rica and in Colombia before fleeing. The following table summarizes these findings.

Table 2. Occupation of Colombian Refugees in Costa Rica and Colombia

\begin{tabular}{|l|l|l|}
\hline Occupation & Colombia & Costa Rica \\
\hline Not occupied & $8.04 \%$ & $18.54 \%$ \\
\hline Commerce & $29.26 \%$ & $29.14 \%$ \\
\hline Administrative & $14.15 \%$ & $10.26 \%$ \\
\hline Manufacturing & $9.32 \%$ & $9.60 \%$ \\
\hline Transportation & $4.82 \%$ & $7.28 \%$ \\
\hline Services & $4.5 \%$ & $6.62 \%$ \\
\hline Professional & $12.86 \%$ & $5.63 \%$ \\
\hline Construction & $6.75 \%$ & $5.30 \%$ \\
\hline Other & $2.89 \%$ & $3.64 \%$ \\
\hline Agriculture & $3.22 \%$ & $2.65 \%$ \\
\hline Mechanic & $1.29 \%$ & $.99 \%$ \\
\hline Medicine & $1.61 \%$ & $.33 \%$ \\
\hline Cattle sector & $1.29 \%$ & $\mathrm{n} / \mathrm{a}$ \\
\hline Total & 311 & 302 \\
\hline
\end{tabular}

Source: Box 12. Colombian refugee population. Type of occupation in Colombia and in Costa Rica, by genre of head of family. UNHCR - UCR Diagnosis About the Degree of Local Integration of the Colombian Refugee Population in Costa Rica, 2003.

In regard to occupations besides the difference between the cases that were working in Colombia and are not working in Costa Rica, which shows that approximately 10 percent of the heads of family that were able to secure employment in Colombia have not been able to secure it in Costa Rica, overall the refugee's working fields in both countries remain similar. The results also show that the quality of employment tends to decline as the employment in the professional and administrative fields felt for over 3 percent. Yet, this is not as alarming as it is to consider that almost 30 percent of the 
refugees interviewed claim to be in the commerce sector and for this population this is mostly informal activities in the streets, by hours, and usually with incomes that do not even reach the minimum wage in Costa Rica.

Actually when looking at the Diagnosis" snapshot of the Colombian refugees" poverty levels, it is easier to get a more accurate idea of the vulnerable economic situation of this population. To understand the parameters first it is important to know the Costa Rican standards. The minimum wage in Costa Rica in 2005 has been approximately $\$ 90,000$ colones. The average monthly income for a Costa Rican household was $\$ 261.532$ in 2003 while the average monthly income for Costa Ricans in the public sector was $\$ 242.000$ colones, in the private sector $\$ 135,000$ colones, and in the commerce sector $\$ 143.025$ colones in the same year. (Proyecto Estado de la Nacion, 2004). The Diagnosis showed that 46 percent of the families interviewed had no income or an income below the minimum wage of $\$ 90,000$ colones. Additionally, 27 percent of the sample had an income between $\$ 91,000$ and $\$ 120,000$ colones, which is still an income far below the national average level in Costa Rica, where the poverty line is set at $\$ 120,000$. Moreover, only 21 percent of the refugees interviewed had an income above poverty levels and just 5 percent of the refugees interviewed had a monthly income above $\$ 201,000$ colones and therefore were considered well accommodated. Therefore, these figures indicate that 73 percent of the refugee sample had incomes below the poverty line and 95 percent had incomes below the national average household incomes. Moreover. the Diagnosis takes a look at the socioeconomic index of the refugee sample by assessing if. based on the possessions in their homes and including basic services. they are able to meet their basic necessities. These findings reveal that 78 percent of the families 
interviewed live in a low economic level and therefore do not meet their basic necessities while 18 percent of the sample population live in a medium level and only 4 pereent of the sample population live in a high economic level.

To better understand the economic situation of the Colombian refugee population and what it means to live in Costa Rica with incomes below poverty levels. it is important to understand what refugees do, where they work, and what do they have to do to make a living. Especially since so many refugees were categorized in the commerce sector, it is important to see what mostly means to be in this sector. Since the UNHCR-UCR Diagnosis section of economic integration was based on a short survey ${ }^{22}$. the researchers did not go into detail about the quality of the refugees`employments or occupations. The research format for this thesis work was more open and in many instances the interviews with the refugee families took over five hours. This gave me the opportunity of exploring and learning about their occupations to find out information beyond the economic potential they had to meet their basic needs.

To give a general picture from the 17 families interviewed during the ficld work on February 2005 and the 26 families interviewed during the IRC assessment trip to Costa Rica on 2003, 37 percent of the families interviewed were unemployed living out of savings or transfers from Colombia by the time of the interviews. Some of these families had been recently granted the refugee status, so they were also receiving the financial assistance from ACAI. Yet, most of the unemployed families had been living in Costa Rica for longer periods of time and therefore it was not likely that they received

\footnotetext{
22 The surtey about the economic integration to the heads of family was only 11 questions and then the same $1 /$ questions to the head of family"s partner if this person was Colombian.
} 
financial assistance from ACAI unless they were in a resettlement process or faced critical conditions related to a continued fear of persecution ${ }^{23}$.

A couple of the unemployed cases had arrived during the last four months before the time of the interview. These cases, like Eduardo and Doris, usually lived the first months out of the savings they brought from Colombia and from the sales of personal items, as in most cases it takes them between four to six months to find their first occupations. By the time of the interview Eduardo and Doris had not received financial assistance from ACAI, which is not offered to all cases, is usually given to the ones that request it and prove to be in need ${ }^{24}$.

But most cases unemployed by the time of the interview had been in Costa Rica for longer periods of time. These cases usually have had unstable occupations in the past. Ramon, a refugee who had been in the country for three years by the time of the interview, is an example. He said he has never been able to find a stable job and that he has done all sort of activities to pay for his rent. At the San Pedro mall he was hired temporarily to replace a sales person on vacation, but by the second week his employer stopped paying him and at the end owed Ramon $\$ 24,000$ colones. Among other temporary jobs he also worked as a dishwasher, as a car washer, and even sometimes went at 3:00 AM to the drivers license office to sell position in the waiting lines before the office opened. He also sold purses and crafts in the street that a Colombian friend

\footnotetext{
23. Not all families in a reseltement process actually received ACAl linancial assistance. Many lamilies were actually in the process of resellement and only two of them, which where single mothers with children, were the recipients of financial assistance while their resellement cases where approsed and they were able to travel to a new host country.

- 1 ) uring the interviews several cases actually expressed the financial assistance was never offered to them during their lirst months after approval. Some even claim it was the person in the fromt desk of the ACAl oflices, who lold them they should request the assistance as it was their right to receive it.
} 
gave him in consignation. He even wanted to start a micro business with this activity but he never got eredit at the ACAI oflice due to lack of a credit history. Then the person lending him the merchandise went back to Colombia and it was time for him to look for another activity.

Most of the cases interviewed who were unemployed and had been in Costa Rica for longer periods of time, presented this type of unstable labor background. Then, in addition to the 37 percent unemployed cases, 19 cases (44 percent of the families interviewed) were in the informal sector and not surprisingly, also mostly with unstable occupations. As in Ramon`s case these occupations ranged from illegal sales in the street of borrowed merchandise, handerafts, or homemade foods, to door-to-door sales, domestic services, or independent car wash, among others.

Most of the income levels of the families working in the informal sector are not only unstable, but also usually not sufficient to allow them to pay for expenses related to their basic needs. Ramon actually said it was depressing to remember he has found himself many times sleeping in the "plaza", which may not be an isolated circumstance as the incomes of 17 out of the 19 families in these activities range between $\$ 30,000$ and $\$ 90,000$ colones and the lowest rent for a room paid by a refugee from the interviews is actually $\$ 25,000$. Besides the ACAI office these cases do not have a social base of support in case of not having income to pay for rent or food, as the nature of their occupations does not allow them to be part of the Caja Costarricense del Seguro Social (CCSS). Moreover, in addition to saying the income from sales in the informal sector was not sufficient to pay for living expenses, at least two of the cases interviewed said they had to sell personal items such as cologne or a gold ring to complete the rent. Thus. 
in reality some of these cases actually make up for their living receiving money from Colombia or from relatives living in other countries, while many that have the responsibility of sending money to their families live with the pressure of knowing they are not providing for their loved ones.

The case of Adrian is one of the most striking cases as far as how far can a refugee go to overcome his desperate situation. He went through Panama without a visa to enter Costa Rica in 2003, as he fled in a rush after being cornered by both the guerrillas and the paramilitaries in the oriental plains of Colombia. After his arrival he faced discrimination in finding employment, as he claims employers would not accept him with a refugee ID. The only occupation he found was selling in the streets the calling cards that a Colombian friend gave him, even though it is illegal to sell in the streets of San Jose without a permit. Adrian claims he received a threat while working in the street by one of the persons who used to persecute him in Colombia, "he told me that if I thought I was going to be hiding all my life I was wrong" (Interview with Adrian, February 2005). With fear from this threat and since he could not provide for his wife and daughter displaced in Bogotá, Adrian started to look for ways of moving on to a country where he could obtain enough income to live and send back to Colombia. With a brother in the U.S., Adrian purchased a false visa to cross the border with Nicaragua shortly after he received the threat. But his journey to the U.S. came to a halt when he was intercepted at the border by Nicaraguan authorities and taken to jail in a bordering Costa Rican town. He spent a month in jail and was then released with the legal representation of an assigned Costa Rican lawyer, who he said, "was very good to me". He moved back to San Jose after this experience and started to work in the streets again. 
although this time making his own handcrafts as he said this activity at least allowed him to make 10 to 15 thousand colones more per month.

In the two years that passed after his journey attempt Adrian has not been able to find a job that would allow him to make a good living. Potential employers have been rejecting his applications when his criminal background is checked. He now feels very depressed and frustrated as he cannot go back to Colombia. he cannot leave Costa Rica. and he cannot work in anything good either. Ile has not stopped thinking about possibilities to leave Costa Rica and even tried resettlement but was never called back. By the time of the interview he recognized the threat he received was probably a bad joke of the person he recognized, as he never received another threat or intimidation. even as Adrian continued working in the streets and therefore was easy to found. But recognizing he did not have an imminent threat has not helped him much. Ile has really good relationships and knows a lot of people, both from Colombia and Costa Rica, as he seems charismatic and a good person to talk to. But even knowing people in the street and being a likable person has not helped him get a good employment. As he recognized he had a talent for handcrafts he even tried to legalize his business by putting a commercial boot in the street. But the disappointment came again. The officials in the municipality told him refugees were not allowed to get a boot in the street, that he needed to be a resident. Also that he needed a checking and savings account to have a boot, which he never even tried to open since he has heard that banks sometimes do not open accounts to refugees.

While most of the refugees in the informal sector were earning below $\$ 90,000$ colones, one case actually said he was doing better with his income but still was looking for options to leave Costa Rica, which means he was not quite integrated either. This 
case said he was making up to $\$ 500,000$ colones as an independent contractor. actually working with a firm of engineers that is apparently getting a lot of construction businesses in Costa Rica and owned by Colombian investors. Cesar came with construction experience from Colombia and in the beginning when looking for a job in this licld nobody hired him, as he was not familiar with the construction terminology in Costa Rica. He got a job in a financing firm and then through referrals of Colombian friends he started working lirst in construction hired by other contractors and then as an independent contractor. But despite his employment success, Cesar had to apply for resettlement when guerrilleros that used to persecute him in Colombia found him. looked for him at his previous home in San Jose, and then even tried to kidnap him on December 2004. He said he could not stop working as he has two daughters and a wife in Colombia waiting for his transfers every month. Yet, his fear grows stronger every day as he thinks the guerrillero he sent to jail for the killing of his father will not stop until he gets revenge.

Unlike the atypical case of the construction contractor, the employment and living conditions of the earlier cases discussed, the ones involving Adrian and Ramon, are more or less similar to all the other cases unemployed or working in the informal sector, which accounts for 81 percent of the families I interviewed during both the IRC assessment trip and the fieldwork trip in February 2005. There is one variation from this pattern in cases like that of Cesar, who had actually found a successful occupation but had become unemployed or are in the resettlement process due to fears of persecution. I will look closer at these cases later on in the chapter, in the section assessing what are the 
employment barriers refugees find. In the meantime it is important to also look at the remaining 19 percent of the sample I interviewed.

The cases that by the time of the interview were occupied in areas different than the informal sector were more stable but not all necessarily living better off. From the 43 cases interviewed 6 cases had formal jobs, 3 in services, 1 in manufacturing. 1 in administration, and 1 in construction. The other 2 cases had a formal employment, 1 in services and the other one in a professional sales position, while also both having independent income generating activities. Both of these cases had incomes for over $\$ 150.000$ colones ( $\$ 300$ US) while the incomes of the 6 cases formally employed ranged between $\$ 90,000$ ( $\$ 180$ US) and $\$ 160,000$ colones ( $\$ 320$ US), with one case working in a professional service field also with an income over $\$ 450,000$ colones $(\$ 900)$. From these 8 cases only 2 felt comfortable, secure and hopeful in Costa Rica: Wilson and his wile who are working in their professional field and make approximately $\$ 450,000$ colones for their household. The other case is Francisco, who works in a company owned by Colombians in a sales position making $\$ 250,000$ ( $\$ 500$ US) and also has an independent business driving a cab at night and making an additional $\$ 150,000$ colones ( $\$ 300$ US).

The overview of these cases' employment situations show that the economic situation for refugees is, in most of the cases, quite more dramatic than what can be concluded from seeing a relatively high percentage of refugees without an occupation or with an occupation that places them in the 3 or 4 lowest decils of the 10 economic decils or economic levels in Costa Rica. But the situation for Colombian refugees does not seem overall much different than the situation for previous waves of refugees. $\Lambda$ s explained by Hayden (2003) in her book Salvadorans in Costa Rica. researches of this 
population during the 1980 s found that approximately one-fifth worked in agriculture. one-tenth as professionals, a third in industry and artisanry, and 40 percent in services. The balance of occupations this author provided can be summarized as follows:

They often worked in the informal sector during the years when they could not work legally, and some remained in that sector in the 1990s. In Costa Rica many men worked in construction at some point and many worked as shoemakers. The latter occupation was attractive because they could work at home with less danger that they would get caught working illegally. An important source of employment for women was domestic work. Some men and women also sold things. especially clothing, door-to-door, and some managed to find a professional employment. (xvi Introduction)

Thus, by comparing both populations it is possible to see that the occupations are similar. From the group of refugees working formally there were some Colombian refugees working in construction and domestic work as the Salvadoran refugees. Also a high percentage of these refugee populations worked in the informal sector selling in the street and many also as artisans. Additionally, very few cases were able to find a professional occupation. But Colombian refugees have a distinctive characteristic. As opposed to Salvadoran refugees, Colombian refugees have a legal status to work: they do not have to be hiding from authorities. In the following section I will be looking at the barriers to employment found by the 2003 Diagnosis and at the barriers described by the refugees themselves. This section will then shed more light on the problems many Colombian refugees face to successfully integrate economically in Costa Rica and the reasons for facing these barriers despite having the legal right to work.

Barriers Faced by Colombian Refugees to Find Employment

The 2003 Diagnosis included in the survey given to the refugee families included a question to identify the reasons by which refugees were not readily integrating into the 
Costa Rican labor force. From the 320 families interviewed only 145 families answered the questions regarding these barriers, 77 out of the 80 cases unemployed and 68 out of the 148 cases that had a formal salary employment by the time of the interview. The results are summarized in the following table.

Table 3. Barriers to Find Employment Identified by Colombian Refugee Head of Family on UNHCR - UCR Diagnosis About the Degree of Local Integration of the Colombia Population in Costa Rica 2003

\begin{tabular}{|l|l|l|l|}
\hline $\begin{array}{l}\text { Reasons for Unemployment or Problems } \\
\text { to Find Employment }\end{array}$ & $\begin{array}{l}\text { Answers } \\
\text { Unemployed } \\
\text { Cases }\end{array}$ & $\begin{array}{l}\text { Answers } \\
\text { Employed } \\
\text { Cases }\end{array}$ & Percentage \\
\hline There is no employment - No Vacancies & 24 & 22 & $32 \%$ \\
\hline $\begin{array}{l}\text { Delay with working papers - problems with } \\
\text { working papers }\end{array}$ & 16 & 22 & $26 \%$ \\
\hline Discrimination for being Colombian & 14 & 4 & $12.5 \%$ \\
\hline Incapacity due to pregnancy or sickness & 8 & 9 & $12 \%$ \\
\hline $\begin{array}{l}\text { Difficulty to revalidate professional title - } \\
\text { does not have a title }\end{array}$ & 2 & 6 & $6 \%$ \\
\hline Age & 4 & 0 & $3 \%$ \\
\hline Takes care of children & 3 & 0 & $2 \%$ \\
\hline $\begin{array}{l}\text { Lack of experience - employer requests } \\
\text { experience }\end{array}$ & 1 & 2 & $2 \%$ \\
\hline Lack of acquaintances & 0 & 3 & $2 \%$ \\
\hline Works for hire & 2 & 0 & $1 \%$ \\
\hline Wants to work independent & 2 & 0 & $1 \%$ \\
\hline Because has been fired & 1 & 0 & $.5 \%$ \\
\hline Total & $\mathbf{7 7}$ & $\mathbf{6 8}$ & $\mathbf{1 0 0 \%}$ \\
\hline
\end{tabular}

Source: Box 16 and Box 17 from the Diagnosis About the Degree of Local Integration of the Colombian Refugee Population in Costa Rica, 2003.

From the results of the Diagnosis it is important to highlight that while the responses from the unemployed and employed population were roughly similar, a greater number of the employed cases said they had problems before finding employment with the working papers while fewer cases of the unemployed group said they had problems due to delays with the papers. The slight difference of thinking in both groups is important to note, as this is also one of the main reasons mentioned by the groups 1 
interviewed. Also as for the reason regarding discrimination for being Colombian it is worth noting the majority of cases who mentioned it are the unemployed cases. This is also relevant to note as from seen in the cases explained above and in other I will move on to describe next, it seems that those who are able to integrate feel more at ease living among Costa Ricans and seem to have fewer discrimination complaints.

The barriers identified by the 26 cases interviewed during the IRC assessment trip are relatively similar to and consistent with those identified by the UNIICR-UCR Diagnosis cases. The results are provided in the following table:

Table 4. Barriers to Finding Employment Identified by Colombian Refugees During IRC Assessment Trip

\begin{tabular}{|l|l|l|}
\hline Reasons Identified As Barriers to Find Employment & $\begin{array}{l}\text { Total } \\
\text { Cases }\end{array}$ & Percentage \\
\hline $\begin{array}{l}\text { Discrimination for being refugee- employer does not accept } \\
\text { Refugee ID }\end{array}$ & 6 & $23 \%$ \\
\hline $\begin{array}{l}\text { Discrimination for being Colombian } \\
\text { Discrimination for being an immigrant as employer prefers to } \\
\text { hire Costa Ricans }\end{array}$ & 4 & $15 \%$ \\
\hline Lack of Experience & 1 & $35 \%$ \\
\hline Lack of employment opportunities & 1 & $4 \%$ \\
\hline Costa Rican employers want to take advantage of refugees & 3 & $11 \%$ \\
\hline Does not have working papers yet & 1 & $4 \%$ \\
\hline There are no barriers to finding employment & 1 & $4 \%$ \\
\hline
\end{tabular}

During the IRC assessment trip the cases interviewed were asked to respond which was the main barrier to finding employment. Yet, during those interviews refugees tend to mention other reasons as well to justify their inability to find employment. Thus. for the field trip to Costa Rica, the reasons identified during the IRC assessment were given to the families interview to be graded in order of relevance in their own cases from 0 to 5 , with 0 being not relevant at all and 5 being a very important reason for which they 
have had difficulties finding employment. The results from the employment barricrs grading are provided in the following table:

Table 5. Barriers to Finding Employment Identified by Colombian Refugees During Field Trip on February 2005

\begin{tabular}{|l|l|}
\hline Reasons Identified as Barriers to Find Employment & $\begin{array}{l}\text { Grade from 1 } \\
\text { to 100 }\end{array}$ \\
\hline $\begin{array}{l}\text { Discrimination for being refugees as employers do not accept refugee } \\
\text { ID }\end{array}$ & 81 \\
\hline Costa Rican employers want to take advantage of refugees & 69 \\
\hline Lack of references in Costa Rica & 68 \\
\hline Discrimination for being Colombian & 67 \\
\hline $\begin{array}{l}\text { Discrimination for being immigrants as employers prefer to hire Costa } \\
\text { Ricans }\end{array}$ & 67 \\
\hline Colombian employers want to take advantage of refugees & 65 \\
\hline Lack of information and guidance & 49 \\
\hline Lack of employment opportunities & 47 \\
\hline Lack of luck & 8 \\
\hline Total cases interviewed & 17 \\
\hline
\end{tabular}

It is important to note the difference between the results in the Diagnosis and the results from the fieldwork interviews in the area of lack of employment opportunities. The introduction to the economic environment in Costa Rica in the beginning of this chapter explained how the economy has a limited capacity of generating new employments and that the situation gets more difficult as the generation of quality employments is even more critical. The Diagnosis also explains that the majority of Colombian refugees arrived between 2000 and 2001, years in which "Costa Rica was characterized by a worsening of the employment conditions, as the employment rates in the informal sector reached the highest levels of the quinquennium" (UNHCR - UCR Diagnosis, 2003). Yet, even though the unemployment rate has deteriorated even more going from 6.1 percent in 2001 to 6.7 percent in 2003, a comparison shows that while the Diagnosis shows a total 32 percent of refugees said the main barrier to find employment 
was a lack of employment opportunities, only 1 case from the 26 interviewed during the IRC assessment in 2003 identified this reason as a barrier to find employment. Moreover. from the grades given to the nine barriers identified to find employment, the refugees interviewed in the 2005 fieldwork placed this reason in the eighth position.

As explained by one of the refugees interviewed in 2005 , "It has anything to do at all with few employment offers because I read in the paper at least 4 to 5 offers that could fit me but when I apply I'm always rejected, sometimes they say the position has been taken, and then I look at the paper again the following week and find the same positions" (Interview to Arturo, February 2005). This refugee actually explained that even though the Labor Ministry has tried to help him by giving him a refugee registration that certilies the professional areas in which he can work, this paper has not helped him at all to find a job. IJe actually argues the problem seems to be that Costa Ricans prefer to employ other Costa Ricans and one time, he added, a Costa Rican employer even tore apart his resume right in front of him as soon as he noticed he was a Colombian refugee.

But besides this great difference, the results from the Diagnosis surveys and the assessment and fieldwork interviews have an important similarity pointing to the same direction: the reason refugees identified to be the most important barricr to find employment is the refugee ID, and this is not perceived as a legal barrier but as discrimination as they see themselves identified as refugees with the document and therefore rejected as such. The fact is that after talking with the person in the Labor Ministry in charge of overseeing that the refugees' working rights are upheld, he explained the reason why employers reject the refugee ID seems to be a lack of education about this new document rather than discrimination. 
This reason was evidenced by refugees like Ramon, who said that when he shows the refugee ID some employers have told him that it is false and do not even bother calling to verify this is a legal document and work authorization. Other cases like Camilo and Zulani say they have been able to find employment because they actually do not show the refugee ID. In this case Camilo lost his refugee status, as he had to travel back to Colombia because his daughter got really sick. After six months the people who used to persecute him in Colombia found him again and, through the Panama border and without any papers, he had to go back to Costa Rica, where his wife remained. Upon his return he was not able to renew his refugee status and found a lawyer that was able to get him a working permit that Camilo has to renew every three months. Camilo does not know exactly what type of status he has in Costa Rica although he feels he is a refugee. IIe says he has not had a problem with his temporary ID even though it says he is Colombian. He works as a security officer earning the minimum wage. Camilo's wife, Zulani, still has her refugee status but since she has not had luck finding work with the refugee ID, she said she prefers to work independently in domestic services and to avoid saying she is a refugee so that she does not have to show the ID. Moreover, Zulani said she mostly works with Colombians and even with co-nationals she prefers not to say she is a refugee, otherwise they do not call her back.

But the lack of an effective and known refugee work authorization does not seem to be the only reason limiting the refugee's access to the labor force. Judging from the refugees' experiences and as evidenced by the fact that the second most important reason found during the 2005 fieldwork seems to be the perception refugces have that Costa Ricans are trying to take advantage of their refuge condition, it can also be concluded that 
many Costa Ricans may not feel entirely comfortable with so many Colombians trying to make a living in their country. Actually, as explained in the first chapter, the fact that Costa Ricans are not taking well more immigration in their country is tied to the legal barriers imposed on the refugees' right to access residency. As seen before, if refugees were to receive the residency as they were entitled to before the law was changed, then they would have a residency card instead of a refugee ID. Having a residency card would probably change their economic conditions dramatically, as then probably many refugees that explained the refugee ID is the main barrier to find employment because employers don not recognize it, would likely integrate to the labor force easily once they present a residency card. Thus, the legal conditions for refugees, chosen by the Costa Rican government in the best interest of its citizens, are currently affecting negatively the economic integration of refugees instead of contributing to making refugees a productive factor in the Costa Rican economy. It cannot be said that the government has adopted these policies due to xenophobic sentiments of its own or due to the xenophobic sentiments of the Costa Rican population. Yet, as seen in the previous chapter, the problems of the xenophobia felt by refugee populations are not new and although the Colombian population is different than previous Central American waves of refugees in that they receive a working paper within a month from applying for the refugee status once the status is granted, this does not mean that Costa Ricans see Colombians without prejudice.

Hayden (2003) in her book about Salvadoran refugees in Costa Rica explains that in addition to job loss during the 1980s, a period of national unemployment getting expanded, prejudice against refugees was exacerbated by a belief that the country was 
taking care of them. She explains Costa Ricans did not realize many of these expenses were paid by foreign money. So she explained that even beyond the economic burden. the problem in the Costa Ricans mentality seemed to be more related with issues of class. She explained Costa Rica was in danger of losing even the appearance of middle-class character because refugees could form an underclass and the retirees an upper class. Thus, Costa Ricans feared refugees could make inequality more visible in a country that had fought against this inequality and also feared a situation of marginality could create social unrest in the country.

Since refugees have expressed concern about a negative attitude from Costa Ricans, the 2003 Diagnosis also surveyed Costa Ricans to identify how they perceived the Colombian population in their country to therefore have a better idea of these argued xenophobic sentiments. They tested the perceptions of the Colombians both as migrants and as refugees to see if there was a difference in their perception. From 417 Costa Ricans interviewed by phone, 257 people said they had not had any contact with Colombians and 160 people said they have had contact with Colombians, so the results shown below are mainly from these 160 answers. Although this amount of people is not a representative sample of the perceptions of the Costa Rican population in the Central Valley, which is where most Colombian refugees live, it provides at least an introductory idea of what this sample population may believe about Colombians.

Table 6. Costa Rican Population Rates Colombians With Whom They Have Had Contact

\begin{tabular}{|l|l|l|}
\hline Opinion & $\begin{array}{l}\text { Total } \\
\text { Cases }\end{array}$ & Percentage \\
\hline No contact with Colombians & 257 & $61.6 \%$ \\
\hline Problematic & 73 & $17.5 \%$ \\
\hline $\begin{array}{l}\text { Good people, friendly, } \\
\text { communicative. }\end{array}$ & 54 & $12.9 \%$ \\
\hline
\end{tabular}




\begin{tabular}{|l|l|l|}
\hline There's all sort of people & 9 & $2.2 \%$ \\
\hline $\begin{array}{l}\text { Respectful, well educated. descent, } \\
\text { calm }\end{array}$ & 8 & $1.9 \%$ \\
\hline They want to live in peace & 8 & $1.9 \%$ \\
\hline Distrustful, weird & 5 & $1.2 \%$ \\
\hline $\begin{array}{l}\text { They come to exploit, take advantage } \\
\text { and displace ticos }\end{array}$ & 2 & $.5 \%$ \\
\hline Hard workers. honest & 1 & $.2 \%$ \\
\hline Total & $\mathbf{4 1 7}$ & $\mathbf{1 0 0 \%}$ \\
\hline
\end{tabular}

Source: Box 28. UNHCR - UCR Diagnosis About the Local Integrations of the Colombian Refugee Population in Costa Rica, 2003.

When looking at these results, the refugee's claims about discriminatory attitudes towards them are not surprising. As the results were given, most of the people interviewed think Colombians are problematic ( 17 percent), an additional 1.2 percent think they are distrustful, and another .5 percent think they are displacing Costa Ricans from their jobs. This gives a total of 19.2 percent of the cases interviewed giving negative perceptions of Colombians. In contrast 12.9 percent of the Costa Ricans interviewed think Colombians are friendly and communicative, 1.9 percent think the are well educated and respectful, and a .2 percent think the are hard workers and honest. This gives a total of 15 percent of the Costa Ricans interviewed giving positive perceptions of Colombians. The UNHCR-UCR Diagnosis did not include what the 257 Costa Ricans interviewed that have not had a contact with Colombians may think about them. arguing that their opinions would not be as relevant since they have not had any contact. Yet, not having contact does not mean a Costa Rican does not have already a set perception towards the Colombians, based for example on what they may hear from other Costa Ricans. Thus, it is possible that if these questions were asked to those 257 Costa Ricans the percentages of negative perceptions would be higher. 
Moreover, the entire sample of 417 cases were asked if Colombians should have the same rights as Costa Ricans and an alarming 67 percent of the cases interviewed responded Colombians should not have the same rights as nationals while only 33 percent responded Colombians should have the same rights. From the group that responded no equal rights, 52 percent argued that the priority should be given to Costa Ricans. From the group that responded Colombians should have the same rights to nationals, 45 percent said they should be equal in front of the law and God and only 10 percent of this group saw them as deserving of the same rights because they were already part of the country.

It is important to note from this survey as well that when the researchers tried to make a distinction between the perception of Colombian migrants and the perception of Colombian refugees, 52 percent of the 417 cases called said they did not know Costa Rica had Colombian refugees. This is important to note since, as noted by the UNIICR UCR researches, not knowing many Colombians are actually refugees "may difficult that nationals give them an opportunity, a place and the respect refugees deserve as human beings, with the respective rights and duties". Moreover, besides the 233 Costa Ricans. from the 417 sample, that did not respond the questions about their perception of Colombian refugees. 91 cases had a positive perception of the Colombian refugees and 69 cases had a negative perception. This shows that apparently the same sample has more positive attitudes towards Colombians once they are informed Colombians are refugees. Yet, a change in the perception Costa Ricans have of Colombians if they knew Colombians are refugees may be difficult, as from the sample of 417 cases, 59 percent already think Colombians are fleeing due to the conflict in their country and only 27 percent think they arrive to Costa Rica to find employment. Thus, even though many do 
not know Colombians are in Costa Rica as refugees, a high percentage of the sample is already aware of the conflict Colombians are fleeing and that knowledge has not ignited more tolerance towards this population yet. As one of the refugees interviewed during the 2005 fieldwork explained, "being a refugee is the worst thing one can be in Costa Rica. The Community sees refugees as nobody. They know refugees have persecutions problems but they can care less. I realize Colombians are starting to be known as good workers, but most ticos still think that Colombians are involved in bad things" (Interview to Rodrigo, February 2005).

There are some reasons to explain why so many Costa Ricans are prejudiced against Colombians. First of all, springing from the perception regarding previous waves of refugees, particularly Central American ones, there might be a lingering generalized feeling against any foreigner coming into the country. Colombians could thus be the most recent target of a longstanding sentiment. Secondly, perhaps an important additional reason is the tightening labor market described at the beginning of this chapter. It is reasonable to expect Costa Ricans will discriminate against any foreigner threatening to take away from them one of the scarce jobs their challenged economy is making available to anyone these days.

But, going beyond general xenophobic feelings, economic or class issues, another explanation that may contribute to understand the xenophobia of Costa Ricans against Colombians may have to do with the negative media coverage of Colombians in Costa Rica, as explained by officials of the NGO El Productor in Costa Rica. This organization has mostly worked in Costa Rica to uphold the rights of migrants for many years and therefore has mostly worked with Central Americans. In the interview with the IRC 
assessment team in 2003, one official from this organization said Costa Rica had too many sensationalist media and that they had noted an "explosion" of articles reporting Colombians as criminals.

Actually this type of coverage is not only seen in sensationalist media. The fact is that Colombians have been involved in some crimes in Costa Rica, such as the killing of Ivannia Mora, a journalist from the most important newspaper in Costa Rica. Nacion. ("Un año prisión", 2004, "Llamadas vinculas a", 2004, "Sospechosos Ilevaban", 2004, "Refugio abrió", 2004). What was probably more detrimental to the image of Colombian refugees was the fact that two of the three Colombians that apparently participated in this crime were refugees. Thus, the articles covering the crime facts were revealed in a way that raises concern about the integrity of the entire refugee population. not only the integrity of the people involved in the crime. Yet, as explained by Arturo, a refuge who was in the process of resettlement after being followed and threatened several times in Costa Rica, "there is even a worst problem with the media coverage of Colombians in Costa Rica, the problem is that I know of many Colombians that have been persecuted and have made claims of their problems to the OIJ, which is the police intelligence in Costa Rica. But I have never seen in the media coverage of the threats or criminal acts against Colombian refugees here. So the media is only interested in covering news related to Colombians when they are the aggressors, not when they are the victims" (Interview with Arturo, February 2005).

With regrettable events like the killing of this journalist and other reported crimes by Colombians like robberies in Costa Rica, it can be understood why from the UNIICR - UCR survey on the opinion of Colombian refugees, 7 percent of the cases interviewed 
answered Colombian refugees were conflictive, narcotraffickers and illegal while an additional 4 percent said they lie to obtain the legal status. This may seem a very small percentage to account for the feelings of xenophobia. But these answers in addition to the fact that 67 percent of the sample interviewed think Colombians do not deserve the same rights, may lead to conclude that many more Costa Ricans of the sample interviewed have some degree of negative assumptions towards Colombians. Thus, to the fact that Costa Ricans are already seeing their country`s economy as too small and fragile to support this wave of migrants and the fact that Costa Rica has already developed a culture of xenophobia against previous waves of refugees, it is necessary to add the fact that some Colombians are not helping in the projection of a good image but on the contrary are portraying a criminal and not reliable one.

In addition to the already dark scenario for the economic integration of Colombian refugees in Costa Rica it is also important to note that the discrimination towards Colombians is overt and even though the labor law does not allow distinctions for race. employers seem to get away with exclusionary decisions based on nationality. When looking at the employment sections of different Costa Rican newspapers it is common to find adds requesting people for different positions and adding "no Colombians please". In all fairness, it is necessary to say I also found ads specifying that Colombians were preferred for the position. However, I called two of the numbers in the newspaper and found out both positions were for sales on commission only and door-todoor.

Other situations explained by the refugees during the 2005 fieldwork also shed light to discriminatory attitudes to obtain employment, in their neighborhoods. or at the 
job site. Ramon, for instance said that when he tried to apply for Micro credit at the ACAl office they told him he needed to get two co-signers, preferably Costa Ricans, since Colombians had a bad reputation. An employer, he said, also told him he could not employ him because another Colombian had stole from his warehouse and therefore he could not trust people from that country. Eduardo and Doris also said they feel discriminated, especially in their neighborhood. They said when they arrived they tried to make friends and started greeting their neighbors in the mornings. After some time they stopped greeting people as they never replied to them or even looked at them. like ignoring them completely. Sofia for instance had a bad experience when she went to rent an apartment with another Colombian friend. The landlord, she claims, told them directly he would not rent to them because they were Colombians.

But not all cases have felt discriminated against and as Rocio, other refugee interviewed. it all depends on each person. Before the interview she used to have her own business and has always been very involved with public relations in San Jose. As such, she has been able to develop strong relations both with Colombians and with Costa Ricans. In regard to the perceptions of Costa Ricans towards Colombians she said, "I never say that I have been persecuted because that would change my image in people's mind and that would affect me. I never say I am a refugee; I do not like to put myself in a separate group. I have always said I am a resident, even when I have to show my ID. I think some refugees have created their own stigma and I do not want to alicnate myself" (Interview with Rocio, February 2005). Thus, although Rocio has been able to overcome the discrimination by disguising her refugee status, as the previously mentioned case of Zulani, who also hides her status and actually prefers to work under the table, this 
alternative has not worked for others. Arturo for example also said he rather says he is not a refugee to avoid inconveniences. Yet, he has never been able to find an occupation in Costa Rica. not even in the informal sector. It is possible that the difference between Arturo and cases like Rocio and Zulani is that Arturi has not able to develop the relationships with Costa Ricans and Colombians that refugees like Zulani and Rocio have been able to develop, and this may be an important factor in the successful economic integration of Colombian refugees.

I will go in depth on how the relations refugees develop in their new community may affect their overall integration. Yet before moving on, another interesting finding is evident from talking to the refugee cases at length. It is important to learn than in some cases the refugees" vulnerable economic situations and unemployment are not necessarily caused by not being able to find an occupation but instead by fears of persecution. Two of the cases who were unemployed by the time of the interview had actually good jobs before being unemployed but lost their stability due to fear of persecution. One of these cases, Karen, a single mother of an eight-year-old girl, considered herself lucky to find a job in a financing firm and to receive a salary of $\$ 250,000$ colones ( $\$ 500$ US). The first job she got in Costa Rica was at a retail shop owned by a Colombian, although earning only $\$ 18.000$ colones a week ( $\$ 36$ US). Then, she moved on to selling clothes in different cities of Costa Rica with two partner friends. but at that time Karen started to be threatened. Karen participated with other refugee friends in a video that was transmitted in Colombia and denounced the situation of refugees in Costa Rica. She explained the people who used to persecute one of the refugees who participated in the video identified her this refugee and started to threat all the participants in the video to find her. Karen's 
friend was resettled to the U.S., but the other friends of the video remained in Costa Rica and had to face threats that eventually made them also look for resettlement options in other countries. Karen's daughter became extremely nervous and depressed from the threats and seeing men following her and her mother. The girl could not continue going to school and Karen had to quit her job in Alajuela as a credit promoter in the financing firm to take care of her daughter and take her to therapy in San Jose. While the resettlement case was being processed $\mathrm{ACAl}$ offered the psychological support to Karen`s daughter and also provided emergency cash assistance. Karen also received financial assistance from her sisters in the U.S. while she was unemployed in Costa Rica and after some months of waiting she and her daughter were eventually resettled to the U.S. where she met with her sisters and started to rebuild her life all over again.

Another case interviewed did not enjoy the luck of the resettlement option and unemployed, was running out of her savings by the time of the interview. Rocio fled Colombia due to paramilitary persecution and arrived to Costa Rica in 2002. After she started working in a company owned by Colombians serving coffee, she moved on to sales in this company and then to independent real estate sales. She was able to save enough money to start her own business, a beauty salon in one of San Jose's most important malls, even without the support of the micro credit loans for refugees from ACAI. After opening a stable business on her own and becoming an employer with net monthly incomes between $\$ 250,000$ and $\$ 300,000$ colones $(\$ 500-\$ 600$ US), Rocio`s success came to a halt when she bumped into the right-hand man of the paramilitary commander that had ordered to kill her in Colombia. This person recognized her and told her "Mrs. Carmen, how small is the world, and we thought you were in the US" 
(Interview with Rocio, February 2005). Even though the person did not even remembered her name correctly, Rocio has been sure he recognized her and from that moment started feeling extremely nervous and paranoiac. She changed the color of her hair after seeing him walking around the mall where she had her salon. Then, she could not control her anxiety and ended up closing her salon and selling everything as she feit too exposed in the mall.

Rocio then started working taking care of an elderly man, "in a house without the need to be seen in the streets" as she said, while her resettlement case was being processed. She was never called back for an interview and that meant her case had not been taken into consideration. It was actually weak, as she never received a direct threat. they never followed her, and they never looked for her directly as many other refugees in a resettlement process claim. Thus, even though seeing people who had persecuted her is not argued, the fact is she became very vulnerable due to the insecurity environment some refugees claim to feel in Costa Rica. This feeling of insecurity drove her to loose her economic stability and join the group of unemployed refugees. By the time of the interview, after her hopes for resettlement had faded. Rocio was starting to rebuild her life yet again. She was helping a Costa Rican friend in an exporting business without a pay and once again, hoping to get the chance of proving her selling abilities to join her friend's company formally.

\section{Conclusions}

After exploring in this chapter the fragile labor market in Costa Rica. the mostly precarious economic conditions of Colombian refugees, and examining the barriers they 
identify to linding employment, it is fair to support our hypothesis 2 and affirm that the negative conditions of the labor market in Costa Rica inhibit the economic integration of Colombian refugees. It has been found that the labor market for Colombian refugees in Costa Rica is characterized by a vulnerable economic situation for most of the families interviewed and from which many do not seem to find an exit option: by a weak labor market that has mostly affected the poorest sectors in the country for the past years due in part to its incapacity to generate quality employment and despite being a relatively stable economy compared to others in the region; by some cases of persecution and insecurity in the country that affect the refugee"s employment attainment and stability; and by an alarmingly high degree of xenophobia ${ }^{25}$ towards the Colombian refugee population.

Only very few of the cases interviewed felt they had hopes in the future or chances for a new life. Actually from the 43 cases interviewed in both trips to Costa Rica, 29 cases or 67 percent wanted to leave the country and while 15 cases had initiated a process of resettlement, mainly due to security reasons, another 9 cases said they were interested in starting such process.

Some of the barriers to finding employment proposed by Portes and Raumbat (1990) in their model of immigrant modes of incorporation included the lack of education, job experience in the host community, or low job skills among the refugee population. Yet, as evidenced by the surveys conducted during both trips and the surveys completed by the 2003 Diagnosis researchers, none of these barriers seemed to be

\footnotetext{
25 In addition to the percentages of Costa Rican's that had a negative opinion about colombians provided by the Diagnosis and explained in this chapter, a technical report from the labor Ministry prepared in 2002 concludes there is approximately a $40 \%$ of xenophobia against colombians. The report does not explain how such number is found. However, given the official source of the information it is worth noting this data.
} 
relevant in the case of the Colombian refugee population in Costa Rica. An additional variable introduced by Portes and Rumbaunt as a possible advantage for the economic integration of refugees is their spatial concentration. In this respect Colombian refugees do not seem to have the potential to create an enclave economy as even though they concentrate in San Jose and towns surrounding the Central Valley like Nlajuela and Heredia, from the surveys regarding their employment and the surveys that will be explored in the following chapter regarding the social connections, it does not seem that Colombian refugees live in a specific geographic area within the cities where they live.

Thus with the rather negative conditions in the Costa Rican labor market faced by Colombian refugees, as I repeatedly heard the refugees' unlucky accounts of their lives in Costa Rica I kept asking myself, what is the difference between the successful cases and the unsuccessful ones? The background seems similar in many of these cases, yet can it be that some just have more luck than others? The receiving environment in Costa Rica is also constant for all of them, so why do some cases seem to overcome this overall negative stereotyping while other cases seem to get stuck with it? Luck is not a valid academic reason to account for this difference. Therefore, in the next chapter I will examine the social integration of Colombian refugees to get a better insight on what can be the reason behind a positive or negative integration of refugees. 


\section{SOCIAL INTEGRATION}

Having already reviewed the variables related to the economic and legal integration of Colombian refugees in Costa Rica, this final chapter is going examine the variables pertaining to the social integration of this population. The theoretical overview of chapter 1 allowed us to draw two sets of variables to explore the social integration of this group of refugees. The first set of variable derives from Portes and Rumbaut's model of immigrant modes of incorporation (1990). The variables in this group have to be studied after establishing if there was an ethnic community already living in Costa Rica by the time the refugees started to arrive. If it is established that such community existed. then the authors explain the social integration is entirely network driven, which means that networks would provide information about outside employment, jobs inside the community, and sources of credit and support for entrepreneurial ventures. If, on the contrary, there is not sufficient proof of the existence of a Colombian community by the time refugees started to arrive, then the authors explain the social integration will depend mainly on the host labor market, which was already explored in the third chapter of this thesis.

In addition to looking at the variables from Portes and Rumbaut's (1990) model. this chapter will also explore the social cohesion of the Colombian refugee community in Costa Rica by looking at the sources of social capital within the refugee community. To start it is important to take a look at the levels of social capital in Colombia to identify general characteristics brought from home. Then, in order to analyze the sources of social capital it is necessary to explore the nature of groups and networks within the refugee 
community and the Colombian community in general, and specifically look at the refugees" membership and interactions in such networks and groups. as these are the space where the social capital can develop in the form of bounded solidarity. Then. it is necessary to look at the levels of trust in the community and their adherence to norms to detect the presence of enforceable trust as a source of social capital. Finally, it is also indispensable to look at the potential for collective action among the refugee community as an output measure of social capital. By looking mainly at these three areas it will be possible to identify the presence of bridging or bonding social capital. While Portes and Sensenbrenner (1993) identify bounded solidarity and enforceable trust as the sources of social capital mostly found in groups of immigrants, this chapter will also explore the possible presence of bridging social capital. As other authors, such as Robert Putman (2003). explain that bridging social capital may be of greater effectiveness for the development of a community than bonding social capital.

\section{Receiving Colombian Community}

The model of immigrant modes of incorporation developed by Portes and Rumbaut (1990) explains that the economic integration of immigrants depends in part on the absence or presence of an equal ethnic community already integrated in the host country. In the case of Colombians in Costa Rica, the interviews with refugee families and field research provided a general picture of this scenario at the beginning of the 2000 s, time in which Colombian refugees started to arrive massively in Costa Rica.

From the 17 refugee families who answered questions regarding the knowledge of a Colombian community living in Costa Rica before the year 1999, only one person 
admitted knowing about Colombians who had lived in Costa Rica for over 30 years. This timeframe corresponds to the Colombian wave of economic migration during the 1970s. Yet, Costa Rica did not seem to be the preferred destination of Colombians at that time. Another of the cases interviewed responded she knew Colombians who had migrated since 1997, but not before that year. The other 15 cases interviewed had not heard about a community formed by Colombians that migrated before 1999 .

From the descriptions by the only refugee interviewed that knew about Colombian migrations to Costa Rica before 1999 and an interview with the Colombian Ambassador in Costa Rica, Mr. Julio Anibal Riaño, apparently a very small group of Colombians settled in Costa Rica in the late 1970s. From that original migration there is today a group of approximately thirty people that frequent the Colombian Consulate and participate in cultural activities organized there. The refugee interviewed explained the ladies from this group of Colombians get together and organize charity events among other social activities. However, besides getting together for social activities, there is no evidence of this group of Colombians ever organized formally in any type of association. Moreover, in reference to the interactions between these ladies and Colombian refugees. the person interviewed explained the ladies were a very closed group and rather elitist. She then added that the ladies helped families of Colombian refugees they found in need sometimes, but besides the charity interactions with refugees she never knew of other activities with this population ever taking place.

In addition to the lack of any oral evidence concerning the presence of a Colombian community in Costa Rica prior to 1999, there is not any other type of evidence pointing in that direction. Newspaper articles, periodical publications, and 
monographs are inexistent on the subject. It was not possible to establish, therefore. if there is a strong community of Colombians that migrated before the wave of Colombian migrants and refugees that started to arrive to Costa Rica in 1999. Since this community does not seem to have been present by the time the wave of our interest arrived. following Portes and Rumbaut (1990) the economic integration of a group of migrants like the one under consideration may depend therefore on the host labor market. The authors move on to explain that the ideal scenario for the successful integration of refugees would be if employers do not discriminate against immigrants for their education, resources, or the efforts of voluntary agencies resettling refugees. In the chapter relating to the economic integration of Colombian refugees it was concluded that the integration of Colombian refugees was quite difficult due in part to a weak labor market in Costa Rica that does not even generate quality employment for its national population. The host labor market is also characterized by alarming xenophobic sentiments towards the Colombian refugee population specifically, as well as toward other immigrant groups. Finally, among other characteristics identified in the third chapter. the host labor market is also negative due to the refugees' precarious economic and employment conditions, which by themselves are an additional barrier to their economic integration.

Thus, if Portes and Rumbaut's (1990) model explains that in the absence of a receiving community the social integration will be determined by the nature of the host labor market, it would be fair to conclude that the Colombian refugee community also experiences negative conditions for its social integration. Yet, before rushing to such conclusion it is also important to explore the presence of sources of social capital among 
Colombians to have a more complete picture of their potential for social integration in Costa Rica. After looking more closely at the refugee's levels of social interaction and potential for developing positive social capital, it would therefore be appropriate to test the hypothesis number 3 .

Finally, one of the most important factors when looking at how some immigrants "make it" in America, Portes and Rumbaut (2001) argue, has to do with the human capital, the motivation, and the resources migrants bring with them. Professionals, on one hand, might have a tough time in the beginning due to language barriers and lack of jobseeking experience, yet over time they have a high chance of obtaining better-paid jobs. Immigrants with previous entrepreneurial experience, on the other hand. would most likely take the road of self-employment, although also after they overcome some barriers through time. For refugee groups, however, the two academics make a distinction. As seen in chapter 1 of this thesis, the authors explain that for refugees time does not necessarily transforms into better income, as is the case of regular migrants. They attribute this to the fact that many refugees come from a declining sociocconomic background. Thus, in most cases the fate of lower income refugees depends on the kind of community built by co-national higher-income refugees who usually are the first wave that migrates. Since the fate of refugees is proven to depend more on their interactions with higher-income co-nationals than on their human capital, and there was not a community of Colombians by the time of the refugees massive arrival, then it is necessary to look more closely at the nature of their community to identify whether or not there is some support from other groups within the Colombian community. 
Since the refuge community in Costa Rica has recently migrated from Colombia and they arrived with pre-determined attitudes towards co-nationals based on their previous experiences, it is helpful to have an insight on the characteristics of social capital in Colombia. John Sudarsky (2001) measured the social capital in Colombia through the development of a barometer called the BARCAS. This study was geared mainly at measuring the social capital in dimensions related to the Civic Society and their trust, participation. and interactions with the State, its institutions and the different segments in the society of political participation. Although this measurement of social capital is highly concentrated in scenarios of political interactions, there are still useful insights on the type of social capital that predominates in Colombia's society.

From the comparison of trust in strangers and perceived corruption. Sudarsky (2001) concluded, through the BARCAS that Colombia's social capital is weak. This phenomena, he argues, is proved with the crime, violence, and lawlessness that abounds in the absence of social capital in the society, as it is commonly seen in Mafiosi societies. He found a relatively higher trust in the Fiscalia than in other institutions tested and highlights this finding as a valuable source of social capital. Yet, trust in other public institutions, such as in the parliament, the political parties, the labor unions, and the guilds. is fragile and calls for an improvement in transparency to increase civic participation.

Sudarsky (2001) also concluded with a very clear message regarding the social capital in Civil Society: "Civil Society is the reservoir more important for the generation of social capital and its development through increased membership in secular non 
religious organizations is a clear path to do so" (pp. 42). The fact is that when Sudarsky tested the participation in intermediary organizations, higher levels of trust and membership were found in the Church than in guilds. labors unions, or political parties. The complexity here is that in the Case of Colombia, there is not a negative relationship between going to mass and civic participation. as was found by Putman in Italy, and membership in a religious organization was not found to have a negative effect on social capital either. Actually the membership and trust in this arena does no seem to have anything to do with social capital. Thus, the potential for social capital found in the form of trust and membership in this civic participation does not contribute to the actual generation of social capital and therefore Sudarsky suggests the civic action should be done in the non-secular arena. A more recent study about the political culture of democracy in Colombia suggests that participation in church activities continues to be the most common in Colombia, along with participation in teacher-parent associations (Rodriguez-Raga and Seligson. 2004).

In addition to Sudarsky's measurements of social capital and evidence of its weakness, other authors such as Mauricio Rubio (1997) and Maria Mercedes Cuellar (2000) actually were arguing that the levels of social capital in Colombia were high, but were of the perverse type. In Chapter 1 of this thesis it was explained that just as social capital has been related to the development of some communities, it could also be characterized as negative, or perverse as these authors denote it.

Cuellar (2000) explains that the levels of social capital are high, as measured in the participation of Colombians in different associations and in comparison with international standards based on income levels. Yet, she also notices that the foundation 
for this social capital has levels of trust unusually low among the members that associate with each other. She finds alarming the fact that those who present higher levels of participation in associations and group activities have less respect for norms and are more prone to get involved with illegal activities such as drug trafficking. Thus, she concludes,

...It seems that the country"s institutional structure, not responding to the population's demands, has open the space for the appearance of ample networks of associations that, on one hand, include those of the criminal type that resort to murder, kidnapping and extortion, that operate informally, and that allow its members to obtain, through diverse ways, what they could not obtain in these association"s absence, and on the other hand, include those organization that form to defend and substitute formal institutions and that have adopted great strength (pp. $873-873$ ).

Mauricio Rubio (1997) also concludes that the levels of violence and criminality are not the result of absence of social capital, but on the contrary, the result of high levels of social capital of the perverse type. To support his argument Rubio provides an analysis of the strength of social capital in regions like Antioquia, which have been traditionally considered genuine examples of "good" social, cultural and economic development. Rubio pointed out two factors in the region's history that favored the development of social capital: "1) the level of trust between strangers taking part in the economic exchange process; and 2) the ability of the family institution to "open up to" or "adopt" outsiders, thus facilitating the configuration of associations beyond the family nucleus" (pp. 7 -8). It is important to highlight that this second factor actually can be related to the creation of bridging social capital, which as seen in the first chapter is believed to be more efficient for the economic development of a community. Yet. in addition to the development of these two factors, Rubio also explains that detrimental "rules of the game" also developed in the region and "led to the consolidation of informal institutions that, it is now acknowledged, facilitate rapacious behaviors and rent-seeking" (pp. 9), 
The author explains these "rules of the game" come from a history of informal activities in the region, especially in the mining industry unrelated to existing colonial legislation and the commercial trade, that "could have had the consequence on the Antioquia institutions of an increase in threats and the use of force as mechanisms for maintaining public order and enforcing property rights" (pp. 10). Thus, despite the first two positive factors developing in this community, the weakness of the institutions and specific cultural characteristics that also developed in the community provided the foundation for the rise of a perverse social capital in which.

The networks, the contacts, the power relations, the legal system, the informal norms of behavior, the political activities, the reward system established in this society, inspire rent-seeking, or criminal behavior, to the detriment of productive activities an technological innovation. The organizations that develop successfully in this environment privately become more efficient and powerful and they reinforce socially unproductive rules of the game, given that they progressively restrict the overall opportunities for economic growth (pp. 17).

On one hand, Sudarsky (2001) argues that there is a weak social capital in the country and that the high levels of violence are a consequence of its absence as seen in Mafiosi communities. On the other hand, Rubio (1997) actually argues that it is precisely due to the high levels of perverse social capital that certain communities such as Antioquia allow for the development and strengthening of criminal organizations like the Medellin Cartel. Sudarsky also suggested that the civil society in Colombia was a good reservoir of social capital but that the associations and activities should be encouraged in a non-secular environment. Yet, from the evidence in Antioquia suggested by Rubio, it was actually in a non-secular arena that the positive factors of the social capital developing in the region were corrupted, as it was within a commercial arena that the social capital became perverse. With Sudarskys" views opposing Rubio and Cuellars" 
(2000) views it is difficult to conclude what is the specific nature of social capital in Colombia. It is possible to conclude, however, that the social capital in Colombia is either weak or perverse and therefore not good for the healthy development of the community. Also it is possible to see that in all the studies the levels of trust of the civil society in Colombian institutions is low, with exception of the Fiscalia and as found more recently the Procuraduria and the Defensoria del Pueblo (Rodriguez-Saga and Seligson. 2004). Therefore the society tends to evolve more comfortably in an informal set of rules.

The next section will provide a close look at the nature of the Colombian community in Costar Rica, the existence of groups and networks and the participation of refugees in such networks. From the previous analysis of social capital in Colombia it is possible to see already that social capital does not seem to be a factor favoring the development of a Colombian community. Thus, after establishing if it is possible for the Colombian community in Costa Rica to develop social capital, it will be important to assess if such capital actually helps the integration of refugees or if it is detrimental to their integration.

Social Capital Among Colombians in Costa Rica

As seen in the theoretical framework presented in Chapter 1. social capital has been used often to determine some communities and countries potential for development. Therefore, analyzing its nature among the Colombian refugee community can be useful to determine if this community has the potential to integrate socially in Costa Rica. Two approaches were identified for the study of social capital; the lirst led by Rohert Putman (2000) and the second led by authors such as Alejandro Portes (1993). On 
one hand, Putman explores social capital as the extent of the people's involvement in groups and networks. Then, based on the level and nature of these involvements, the health of the civic community is assessed, assuming that social networks have real value both for people in those networks as well as for bystanders. On the other hand, authors such as Portes explore social capital from the perspective of the resources that individuals are able to obtain from their interactions within the groups and networks they are a part of. Despite the different approaches to study the subject, one analyzing the interactions and the other the resources gained from such interactions, both approaches agree on a number of things. They concur that to study social capital in different communities it is important (1) to look at the groups and networks formed in the community, (2) at the perceptions of trustworthiness among the members of the community, and (3) at the norms of cooperation and potential for collective action that can result from the existing social capital. These three levels of study will be explored within the Colombian community in Costa Rica as the sources to identify the existence of social capital. Yet, before looking at each variable closely, it is important to provide an introduction to general social characteristics of the Colombian community in Costa Rica.

Colombian community in Costa Rica. After interviewing 17 families of Colombian refugees in Costa Rica and talking to several other Colombians living in this country without refugee status, it was possible to get a fairly good understanding of the nature of the Colombian community in this country. Overall, the results show a wide gap between the refugee community and the community of Colombians that migrated to Costa Rica also around the year 2000 as investors and entrepreneurs. Behind this apparent lack of unity there are also noticeable sentiments of distrust and general 
characteristics of alienation among refugees, which provide a very weak foundation for the development of social relations and networks.

The entrepreneurial class of Colombians in Costa Rica seems to have a healthy and encouraging environment for the development of businesses. From descriptions provided by some refugees, there are approximately 300 businesses owned by Colombians, although mainly in partnership with Costa Ricans. It was not possible to find a directory of Colombian businesses like the ones existing in the United States. Yet. it was possible to identify different businesses owned by Colombians during the fieldwork. There is for example a chain of bakeries called "Panaderia Santa Clara" that has become one of the best-known bakeries in San Jose, and a firm of engineers called "HL Ingenieros" that is constructing several public projects in Costa Rica. There are also two radio stations operated mainly by Colombians, "Radio Reloj" and "La Voz Dial", a cultural magazine called "Colombia Tica", and a community newspaper called "Renacer". There are as well different important Colombian companics operating in Costa Rica including Carvajal S.A., Metalco, and Socoda. Additionally, from the paid advertising found in the cultural magazines mentioned above, it is also possible to see an ample array of businesses owned by Colombians ranging from medical services, to beauty shops. restaurants, consulting services, construction services. and telecommunication services, among others.

Yet, despite this fairly significant number of businesses owned or operated by Colombians, the refugee community does not seem to have an active interaction with the entrepreneur community. Most of the businesses found were started in the late $90 \mathrm{~s}$ and early 2000s. This means that this entrepreneurial class is just forming and was not 
established by the time refugees started to arrive. Since the business community is just starting to consolidate in Costa Rica, it is probably not easy for them to become a support base for the refugee community. Actually six of the refugee families interviewed said they know about the existence of several Colombian companies in Costa Rica and only one refugee said he knew very few companies. One of these cases explained that some of the reasons why the Colombian entrepreneurs are not able to become a support base for refugees include the fact that most of these businesses are owned in partnership with Costa Ricans and therefore they cannot give preference to fellow Colombians for employment. Also, a couple of refugees, including Rocio, who had previously established her own business in Costa Rica, explained that according to the Costa Rican labor law, businesses owned by foreigners must employ a high percentage of nationals and cannot operate only with employees of their country of origin. Finally, another refugee said Colombian entrepreneurs prefer to employ close relatives and friends rather than refugees since Colombian entrepreneurs have a negative perception of Colombians with refugee status in Costa Rica.

In relation with this stereotyping actually it is worth mentioning the perception of a couple of Colombian entrepreneurs interviewed during the fieldwork. One of them, an owner of a small bakery, said she did not like refugees because she thought those were Colombians who were mostly taking advantage of the welfare system in Costa Rica. Another entrepreneur interviewed, also owner of a small coffee house, mentioned refugees are dangerous and actually warned me about them saying that many glerrilleros and paramilitares were disguised in Costa Rica with the refugee status. 
To make the interactions between refugees and entreprencurs even more complicated, distrust towards Colombian entrepreneurs also became noticeable among the refugees. From the 17 families interviewed 8 said Colombian entreprencurs tend to exploit other Colombians in less favorable conditions. Some argued Colombian entrepreneurs pay less than what they are supposed to pay as they recognize the needy condition of refugees. Others argued that Colombian employers usually force fellow Colombians to work longer hours without pay and with no benefits. One of the respondents also argued Colombian entrepreneurs tend to be very arrogant. as they have a more favorable position, and prefer to employ Costa Ricans instead of Colombian relugees.

In addition to these eight cases that do not have a positive image of Colombian entrepreneurs another four families also recognized that Colombian entrepreneurs tend to pay less to Colombian refugees. Yet, these cases argued Colombians pay low to be competitive and also recognized some Colombian entrepreneurs would prefer to employ Colombians if the salary conditions were similar to Nicaraguans, for example, and that although paying low at least these entrepreneurs give an opportunity to Colombians. These results from the interviews in regard to the perceptions between the refugee and the entrepreneurial community are therefore not alleviating. From the 17 families, 8 felt they were exploited by Colombian entrepreneurs; another 4 recognized the advantage taken by Colombian entrepreneurs but also recognized they at least try to give a helping hand when they can; another 4 families recognized Colombians entrepreneurs cannot help Colombian refugees and gave different explanations for this behavior: and the last case said he did not know about the existence of many Colombian entrepreneurs. 
(1) Groups and Networks in the Colombian Community: To understand the nature of groups and networks within the Colombian community in Costa Rica the analysis in this section will rely on the definitions used in the World Bank Working Paper on "Measuring Social Capital" (Grootaert, Narayan, Jones, Woolcock, 2004). This document describes groups along different dimensions including the density of the membership, the diversity of the membership, and the extent of democratic functioning. By looking at these characteristics it will be possible to examine if the nature of these memberships can be a source of social capital of the bonding or the bridging type. As seen in Chapter 1 the bonding social capital is the type where networks are created by kin or by people who are linked by crucial similarities, such as ethnicity, and is more inward looking. The bridging social capital is the hardest to create, as it is conformed by networks of different types of people who are more outward looking, and it is apparently more efficient for the development of a community.

To start looking at the participation of Colombians in groups and networks it is helpful to provide an overall glance at the type of social relations refugees seem to engage in. In this respect one family said they do not know anybody outside their family nucleus and do not go out at all. They just go to work and back to home. Eight families said they know people mainly from work but do not go out much or have many social relations with people outside their family nucleus. Some of them actually attributed this behavior to the feeling that they do no have real friends. From this group of people it is worth noting, however, that three of these cases have been able to develop enough contacts to keep themselves employed at least in their informal activities. Another five families said they have a group of friends mainly from Colombia and go out to social 
gatherings every once in a while. Finally, three cases considered themselves to be very active socially since they know a lot of people, have a fairly active social life, and have been able to make connections that have helped them obtain employment. For the purpose of analyzing social capital it is important to see if, although limited, some of these social interactions are done within a formal group or association. in which case the analysis of their membership can provide a better description of the type of social capital these refugees are developing.

Grootaert. Narayan, Jones, and Woolcocks' document (2004) classify the density of membership by the prime objectives and the scope of the group, meaning the extent of connections to other groups. The diversity of membership is based also on different criteria including kinship, religion, gender, age, ethnicity, occupation, education, political affiliation. and income level. Finally the extent of democratic functioning is defined by this document as a measure of participation on the decision-making process within the organization.

Unfortunately during the interviews the refugees mentioned very few groups and very few cases actually knew about the existence of groups or organizations. making the analysis of these groups then very limited. Eleven families of the 17 interviewed responded they did not know about the existence of any type of organization or group formed by Colombians, Costa Ricans, or both. Another four cases said they knew about the existence of a Colombian organization named ASDECOR, which had been dissolved by the time of the interviews. Rocio, one of the refugees interviewed and one of the three cases considered socially active. was actually cofounder of this organization. She explained the organization was initially formed to become a base of support to all the 
refugees arriving to Costa Rica as in the beginning the processing of their status was very slow and they did not have access to many rights. Yet, the organization dissolved shortly after due to power struggles within its board of directors, which can also give a sense as to the limited democratic functioning of the group. Rocio explained she abandoned the board of directors before the group dissolved because her opinions were not taken into account and the president of the organization was trying to impose his personal agenda. She also explained the members of the organization were all Colombians but with mixed income levels. The other three cases that knew ASDECOR, however, said the members of the organization were mostly refugees and all of low-income levels. These refugees said they attended some of ASDECOR meetings, although never became members. One of them said he stopped attending the meeting because he saw too much lack of organization and he realized he needed to concentrate on finding employment.

Rocio also mentioned other organizations formed by Colombians or were she has seen Colombians participating. One of them was an organization led by a Colombian lady and formed with her friends to do charity work in Costa Rica, although not necessarily to help Colombian refugees in the country. Rocio also mentioned an organization of Catholic Professionals and an informal public relations group where both Colombians and Costa Ricans, although Colombians in less proportion, do networking. In addition to these professional groups Pilar, another refugee interviewed, also mentioned other groups including FOCUSIN and the Association of Professionals in Alternative Medicine. She also described these groups as professional in nature where members were mostly interested in receiving trainings and opportunities in their professional field. Both Rocio and Pilar described these professional groups as very closed and elitist. In regard to the 
scope of the groups they explained that members usually did not seek to develop relations with members of different groups or with members of similar groups in other cities. Thus the groups are probably limited in their potential for developing bridging social capital. It is likely members of these groups could only be able to develop bonding social capital due to their common professional interest.

Another group described during the interviews was a group of socecr players. The only refugee who knew about such group was Francisco; actually one of the only refugees interviewed who had a formal employment and economic stability. Ile described the group as diverse, with players both from Colombia and Costa Rica. He also mentioned they are all from similar social levels although economically he explained some members are doing better than others. Additionally, he explained the group tends to be closed, since they have a limited number of players and the only interactions outside the group is when they play with other teams. Yet, he joined the group within the first months of arrival and explains that Colombian members of such group actually became creditors when he was at his first job, which allowed him to sustain the business he was in for some time. Thus, this group can be identified as one of the few examples of groups that create actual social capital since its members have been able to develop resources from their interactions and since the group has allowed this member in particular to find a social space for development.

In addition to the few groups mentioned by refugees, the networks are also another space where they can develop social capital. $\Lambda$ ccording to Grootaert, Narayan, Jones, and Woolcock's document (2004),

a network is seen as a circle of "close friends" - that is, people one feel at ease with. can talk to about private matters, or call upon for help. The size of the 
network then is captured by the number of such close friends. The usefulness of the network is assessed by asking the respondents whether they could turn to the network in a series of hypothetical emergency situations." (pp. $11-12$ ).

The first section of the following table will provide the results from the interviews needed to measure the networks and their effectiveness. This section measures the number of friends, the number of people willing to lend money to the refugees, and the number of people actually able to lend money to refugees. Each refugee responded with the number of friends in each case. The second section of the table will provide the number of social interactions reported by refugees. which will help verify the strength of such networks. This section measures the number of social interactions in different scenarios, including number of visits to friends or neighbors, number of calls to friends and neighbors. number of weekend social activities, and number of times refugees bump into friends or acquaintances when they go out. The measurements in the second section of the table where given by the refugees in a scale of 0 to 5 with 0 being no social interactions at all and five being several social interactions.

Table 7. Number of Social Interactions in Networks of Colombian Refugees and Networks Usefulness

\begin{tabular}{|l|l|l|l|l|}
\hline & $\begin{array}{l}\text { Higher } \\
\text { Number From } \\
\text { Respondents }\end{array}$ & $\begin{array}{l}\text { Lower } \\
\text { Number from } \\
\text { Respendents }\end{array}$ & Mean & $\begin{array}{l}\text { Number of } \\
\text { Families } \\
\text { lnterviewed }\end{array}$ \\
\hline \hline Number of close friends & 15 (2 cases) & 0 (2 cases) & 5.3 friends & 16 \\
\hline $\begin{array}{l}\text { Number of people willing to } \\
\text { lend her/him money }\end{array}$ & $15(1$ case $)$ & 0 (4 cases $)$ & 3.18 people & 16 \\
\hline $\begin{array}{l}\text { Number of people able to } \\
\text { lend her/him money }\end{array}$ & $15(1$ case $)$ & $0(6$ cases $)$ & 2.75 people & 16 \\
\hline \hline $\begin{array}{l}\text { Number of social } \\
\text { interactions with neighbors } \\
\text { or friends during week } \\
\text { hefore interview }\end{array}$ & $5(10$ cases $)$ & 0 (6 cases $)$ & $\begin{array}{l}3.05 \\
\text { interactions }\end{array}$ & 17 \\
\hline $\begin{array}{l}\text { Number of social } \\
\text { interactions measured by }\end{array}$ & $5(10$ cases $)$ & 0 (4 cases $)$ & $\begin{array}{l}3.31 \text { phone } \\
\text { calls }\end{array}$ & 16 \\
\hline
\end{tabular}




\begin{tabular}{|l|l|l|l|l|}
\hline $\begin{array}{l}\text { phone conversations during } \\
\text { week betore interview }\end{array}$ & 5 (1 cases) & 0 (4 cases) & 2 activities & 16 \\
\hline $\begin{array}{l}\text { Number of social } \\
\text { interactions measured by } \\
\text { activities during weekends }\end{array}$ & 5 (7 cases) & 0 (2 cases) & 3.56 times & 16 \\
\hline $\begin{array}{l}\text { Number of social } \\
\text { interactions by limes } \\
\text { refugces sec friends or } \\
\text { acquaintances in the street }\end{array}$ & & & & \\
\hline \hline
\end{tabular}

These results show that most of the families interviewed have people they considered close friends, as only two families saw themselves with no real friends. Actually live cases responded they have between 9 and 15 friends, which can be seen as rather large networks of friends, given the fact that they are out of their country of origin and have had only few years to develop these networks. Then another four cases said they have between 4 to 5 friends and another five cases said they had between 1 to 3 friends. This means the networks of friends exist and although not all cases may have large networks, it seems many cases have at least a network to be supported by. Yet. when looking at how well such networks could be functioning by assessing the refugee's responses in case they need help, it is also interesting to note that from the five cases that reported to have over 9 friends, only two cases said their friends would be willing and able to lend them money. One of these two cases actually specified such help could not exceed horrowing $\$ 5$ US. Most of the cases who had networks of 1 to 5 friends said all of their friends would be willing to lend them money, although much less would be able to do so. This means that despite the existence of networks, their functionality seems weak and not too reliable. 
Is it important also to note that the cases with higher number of friends are not directly proportional to better economic conditions among the respondents. For example Francisco, who has a stable economic condition, says he has 10 close friends, while other unstable cases like Camilo or Pilar responded they have approximately 15 close friends. These two cases have informal employments and one even resettled to the United States already due to lack of security conditions in Costa Rica. Also, it is interesting to note complex cases like the one of Rocio. She feels that she is very active socially, while reporting she only had 1 friend and explaining she almost never goes out for fun on weekends. Still, she responded with high numbers when measuring her social interactions by phone calls, visits to other friends or neighbors, or seeing known people in the street.

It is also possible to see that refugees seem to have a high number of social interactions from the second section of the table. The scale measures the interactions from 1 to 5 and most interactions means are above 3 , with only the interactions on weekends, which were considered mostly entertainment activities, with a mean of 2 . These results confirm indeed the fact that many refugees may have informal networks large enough to allow for several social interactions. Yet, the interactions in these networks are not necessarily leading to the development of bonding social capital since the efficiency of such networks seems to be low.

Another variable that can be used to measure the efficiency of such networks is the support perceived by refugees from both Colombians and Costa Ricans. If refugees perceive other Colombians and/or Costa Ricans as supportive, this can indicate that they have had good experiences with these groups within their networks and therefore that the network is strong. Yet, in the 0 to 5 scale used to measure the refugee's responses, the 
mean measuring the support from Colombians is only 2.8 while the mean measuring the support from Costa Ricans is only 2.1 . Actually when responding about the nationalities of their friends only two cases responded they had friends from Costa Rica, everybody else had friends mostly from Colombia. Thus, even though the closest friends were mostly Colombians, the perception refugees have of their fellow nationals seems to be similar to the perception they have of Costa Ricans, who they recurrently complaint about during the interviews. It is important to note here that due to the fact that most refugces responded their friends were mostly from Colombia, the social capital that could develop would be of the bonding type. The factor uniting these networks of friends, although weak, seems to be the nationality and even though they engage in several social relations with Costa Ricans for work purposes, these refugees do not seem keen to have Costa Ricans as close friends.

The results about groups and networks actually show that the majority of the refugee families interviewed are part of networks where they are able to sustain social relations: only one family said they do not know other people or go out at all, and just two families said they do not have friends at all. Yet, since the networks have low levels of functionality the fact that the majority of these families have social relations does not mean that their participation in them would always provide a basis for the formation of social capital. Thus, even though they may have the potential of developing networks because at least they seem to have many social relations, there seems to be an additional variable that inhibits their strengthening of friendships and indeed the creation of networks and participation in groups -namely their trust levels. 
(2) Solidarity and Trust: To better understand the reasons why refugees are not able to develop social capital from their interactions within networks and groups it is indispensable to look at their trust and solidarity levels. These variables provide the foundation for healthy interactions within such groups and networks. First, it is important to understand if Colombian refugees believe there is solidarity among them and with other Colombians who are not refugees. Portes and Sensenbrenner explain in their model that if migrants face conditions such as (2.1) outside discriminations hased on cultural differences, (2.2) blockage on an exit option, and (2.3) the preservation of a cultural repertoire hrought from home, then it is more likely to see the presence of bounded solidarity. This bounded solidarity, they explain, is then considered a source of social capital along with enforceable trust.

Before examining if these three factors exist, it is important to address the current perceptions refugees have of the solidarity levels among Colombians in general. The picture that can be drawn from the interviews is not very positive, though. From the 17 families interviewed 10 believe there is no solidarity among Colombians at all and that Colombians are not united since usually they tend to act in self-benefit only. Another 2 families said they prefer not to be united with Colombians since there are many criminals among Colombians in Costa Rica. The other 5 families said there is some solidarity among some Colombians, or at least that there is more solidarity from fellow Colombians than from Costa Ricans.

To have a more detailed picture of their levels of solidarity, the refugces also answered six different questions from statements given to them and hypothetical 
scenarios. Their answers were also be tabulated since they were given in a 0 to 5 scale and are provided in the following table.

Table 8. Solidarity Among Colombians in Costa Rica

\begin{tabular}{|c|c|c|c|c|}
\hline & $\begin{array}{l}\text { Higher } \\
\text { Number From } \\
\text { Respondents }\end{array}$ & $\begin{array}{l}\text { Lower } \\
\text { Number from } \\
\text { Respondents }\end{array}$ & Mean & $\begin{array}{l}\text { Number of } \\
\text { Families } \\
\text { Interviewed }\end{array}$ \\
\hline $\begin{array}{l}\text { Perception of solidarity and } \\
\text { unity among Colombians }\end{array}$ & $5(1$ case $)$ & $0(3$ cases $)$ & 2.5 & 16 \\
\hline $\begin{array}{l}\text { Individual solidarity with others } \\
\text { (not only Colombians) }\end{array}$ & 5 (11 cases $)$ & $0(1$ case $)$ & 4.3 & 16 \\
\hline $\begin{array}{l}\text { Solidarity in action through } \\
\text { volunteering and helping others }\end{array}$ & $5(4$ cases $)$ & 0 (10 cases $)$ & 1.56 & 16 \\
\hline $\begin{array}{l}\text { Solidarity with others in } \\
\text { scenario of someone's car } \\
\text { getting damage in front of } \\
\text { respondent's house }\end{array}$ & 5 (7 cases $)$ & $0(2$ cases $)$ & 3.4 & 16 \\
\hline $\begin{array}{l}\text { Fthnic solidarity through } \\
\text { scenario of helping unknown } \\
\text { Colombian in problems }\end{array}$ & 5 ( 15 cases $)$ & 0 (1 case) & 4.7 & 16 \\
\hline $\begin{array}{l}\text { Ethnic solidarity through } \\
\text { scenario of giving preference to } \\
\text { Colombian for employment }\end{array}$ & 5 (14 cases) & 0 ( 1 case $)$ & 4.4 & 16 \\
\hline
\end{tabular}

These results are very helpful to see the great gap between the refugee's willingness to help and their actual involvement in activities to help others. When asked about their belief on the need to help others, most respondents expressed they believe helping others is positive and only one case responded such help depended on who was receiving it while other refugee said it was hard for her to trust others and indeed to help them. Yet. when asked about actual examples of helping others and their involvement through volunteering activities most cases could not give an example. two cases said they have helped other Colombians just a couple of times, and only four cases said they have helped others many times. Regarding this lack of involvement refugees like Lucas and Rodrigo said for example they do not have time or money to get involved in any 
volunteering activity although they would want to be more involved. Other refugees like Sofia said she thinks Colombians in particular would like to help other Colombians and that the lack of help among them is not a problem of lack of willingness. She explained that the actual problem is the lack of capacity to help since most Colombians have the same problems and therefore each one needs to look out for him/herself before looking out for others, or even wanting to do so.

This argument may explain why when given potential scenarios of helping other Colombians in different situations, most refugees answer with the higher score, meaning they would always be willing to help other Colombians if they can. Yet, when answering about their perception of solidarity among Colombians, only one case responded he thought there was solidarity among Colombians and actually 10 out of the 16 families interviewed gave a score below 3 to this question, meaning most refugees do not believe there is solidarity or unity among Colombians in Costa Rica.

(2.1) Outside discriminations based on cultural differences: The different responses between the scenarios of helping other Colombians and the scenario of helping anybody, not necessarily Colombian, contributes to understand the response to common adversities faced by refugees. The scenario of helping a stranger with a car broken in front of their house had a mean of 3.4 while the scenario of helping an unknown Colombian either by paying a lawyer or by giving this person employment got means over 4.4. In general most refugees throughout the interviews complained about the limited support provided by Costa Ricans for their integration. Their perception of xenophobia was explained in Chapter 3 and can also be seen from the low mean measuring the support of Costa Ricans in the previous section. Thus the fact that most 
refugees are willing to help other Colombians if they had the power or capacity to do so, even more than they have the willingness to help anybody else, proves that at least there is the potential for a positive response to the common adversity of discrimination faced by many of these families, even if not all have suffered such discrimination directly. Yet, it is important to note here that as proven by the refugees' actual involvement in helping others, the good willingness they may have to face a common adversity, in this case discrimination, does not always transforms into actions. Thus, it is hard to establish. in the case of these families of Colombian refugees in Costa Rica, that facing common adversities will necessarily transform into bounded solidarity as a source of social capital.

(2.2) Blockage of an exit option: In the case of Colombian refugees in Costa Rica, the blockage of an exit option is not a variable contributing to the generation of bounded solidarity either. The problem in this case may be the knowledge the families interviewed had about the resettlement option for refugees. From all the families interviewed 10 applied to be resettled, and only 3 were actually granted resettlement after the fieldwork was completed. Another 2 families were interested in applying for resettlement and although the other 5 families knew about this option, they were not interested in applying by the time of our interview. The word about this option spread very fast among Colombian refugees in Costa Rica and since the UNHCR or the ACAI officials gave no clear information about this option to refugees, most refugees had misleading information about resettlement. On one hand, officials do not disclose the criteria for resettement provided by the countries taking these refugees to avoid fraudulent cases to be receiving this benefit. On the other hand, since refugees are not aware of these criteria they go through the process of applying or have this option constantly in their mind. This 
sometimes creates more instability in their processes of integration. For example some cases had been waiting for over three months to hear a response about their application. Instead of concentrating on obtaining employment these cases preferred to stay home leaving out of savings, charity, or the profit of sporadic sales in the strect. One of these cases was actually striking since during the interview, as she was telling her story, she actually realized how fool she had been for having lost so much time waiting for such response. In the beginning she felt very angry and cried out of frustration with the agencies that had left her waiting for so long. Then her reaction was full of energy. She seemed to have gathered the courage to say that instead of leaving the country she would stay to speak out about her case and to make a good.

(2.3) Culural repertoire brought from home: The last variable that requires exploration to identify bounded solidarity, as a source of social capital among Colombian refugees in Costa Rica, is the cultural repertoire brought from home by refugees. This variable was defined by Portes and Sensenbrenner as needed for the refugees to construct an autonomous portrayal of their situation and therefore as a catalyst for them to unite. Most of the families identified the existence of a cultural repertoire and expressed they enjoyed sharing their Colombian culture in Costa Rica with other Colombians. One refugee said she enjoyed seeing Colombians overcoming their challenges and demonstrating the best qualities that characterize them, such as their hard work, their positivism, and their good spirit. Most said they talk a lot about Colombia. the good things they left behind, and they also enjoy talking about the good things of the country to project a more positive image. From the families only two cases said they do not recognize a cultural repertoire and that actually Colombians do not try to preserve their 
culture, while one case actually said "The paisas talk a lot about Colombia and they have a very strong cultural repertoire, but I get desperate with so much talking, it is like they are already here and they do not want to recognize it".

In fact, when responding about the existence of a cultural repertoire, most of the families interviewed talked about the positive things in Colombia and how much they like to share their home culture in their new country of residency, through attending cultural events if they can or just sharing with other Colombian friends. Yet, none of the cases connected this very positive cultural repertoire with the challenges they face in Costa Rica. It seems, rather, that the cultural repertoire serves effectively to bring together Colombians into a space of entertainment and pleasant sharing of memories. Yet, that within such space there is no place to discussions about possible actions to face their challenges. At least eight refugees did mentioned that in such spaces they at least get to share their problems with others that may be going through similar issues. Yet, there was no evidence from these interviews to prove that the spaces of cultural repertoire sharing have led to construct and autonomous portrayal of the situations they face in Costa Rica, meaning that besides sharing their problems they do not come together due to common challenges. Rather, the cultural repertoire helps them keep alive the memories and cultural values brought from Colombia.

In addition to assessing solidarity, it is also necessary to look at the trust levels among Colombian refugees in an effort to find enforceable trust as a source of social capital. As defined by Portes and Sensenbrenner and explained in Chapter 1, enforceable trust as a source of social capital is based on the internal sanctioning capacity of the community itself. Thus, members of a group behave according to expectations out of 
fear of punishment or in anticipation of rewards. Areas of such punishment or reward usually include financial networks or business networks in enclaves. For the existence of enforceable trust these authors identified the existence of three factors: $(2.4)$ the blockuge of outside social and economic opportunities, (2.5) the availability of in-group economic resources, and (2.6) the community's capacity of monitoring and sanctioning.

Before looking at these three factors it is important to examine the actual levels of trust among Colombian refugees and their actions based on trust through hypothetical scenarios. The following table provides a close look to the levels of trust among the Colombian refugee families interviewed.

Table 9. Trust Levels Among Colombian Refugee Families

\begin{tabular}{|l|l|l|l|l|}
\hline & $\begin{array}{l}\text { Higher } \\
\text { Number From } \\
\text { Respondents }\end{array}$ & $\begin{array}{l}\text { Lower } \\
\text { Number from } \\
\text { Respondents }\end{array}$ & Mean & $\begin{array}{l}\text { Number of } \\
\text { Families } \\
\text { Interviewed }\end{array}$ \\
\hline $\begin{array}{l}\text { Lack of trust among community } \\
\text { members in relation to money } \\
\text { issues }\end{array}$ & $5(7$ cases $)$ & $2(1$ case $)$ & 4.06 & 16 \\
\hline Trust in other Colombians & $4(3$ cases $)$ & $0(7$ cases $)$ & 1.68 & 17 \\
\hline Trust in Costa Ricans & $4(1$ case $)$ & $0(9$ cases $)$ & 1.05 & 17 \\
\hline $\begin{array}{l}\text { Lack of trust in others - you need } \\
\text { to be alert because others would } \\
\text { try to take advantage of you }\end{array}$ & $5(8$ cases $)$ & $0(2$ cases $)$ & 3.58 & 17 \\
\hline Trust in Costa Rican government & $5(1$ case $)$ & $0(9$ cases $)$ & 1.06 & 15 \\
\hline Trust in strangers & $3(2$ cases $)$ & $0(9$ cases $)$ & .88 & 17 \\
\hline $\begin{array}{l}\text { Trust in neighbors through } \\
\text { scenario of having them watch } \\
\text { over your child in case of } \\
\text { emergency }\end{array}$ & $5(1$ case $)$ & $0(8$ cases $)$ & 1.37 & 16 \\
\hline $\begin{array}{l}\text { Power of exclusion within } \\
\text { Colombian community }\end{array}$ & $5(7$ cases $)$ & $0(2$ cases $)$ & 3.43 & 16 \\
\hline
\end{tabular}

These results provide a clear picture of the lack of trust the families intervicwed have towards other Colombians, toward Costa Ricans, toward strangers, toward neighbors, and toward the Costa Rican government. The means for trust in Colombians and Costa Ricans 
are very low compared to the mean in the scenario of other people trying to take advantage of them. This may be related to the fact that some of the refugec families interviewed are not entirely distrusting of others, especially in relation to issues of employment since most understood this scenario in relation to their work life.

Yet, besides this relatively positive attitude in not believing other people are always trying to take advantage of them, the extremely low means in all the other questions testing trust are a rather negative foundation for the creation of any type of social capital. The lack of trust towards Colombians can be founded in the fact that refuges come from environments of crime, kidnapping, and killings perpetrated by other Colombians sometimes directly against them. Also it derives from the fact that many refugees see themselves vulnerable in Costa Rica due to the apparent presence of guerrilleros and paramilitares in the streets of the main cities, many times even disguised as refugees and businessmen. As explained by Eduardo and Doris, "coming from a culture where you cannot trust anybody you cannot just open the doors of your house to strangers. If you want, you need to try to help someone else in ways that would not put you at risk, and that is usually very hard".

Other refugees like Adrian, who worked as a security manager in a hotel in Costa Rica, even said "I cannot trust Colombians because at least 50 percent of the Colombians here are thieves and when I was working in the hotel they would always come to me to offer me partnership in criminal activities since I had access to the security code in the hotel". Adrian's trust levels were so low that when I got the chance of introducing him to another refugee during the fieldwork he introduced himself with a different name in an 
effort to disguise himself in case the person he was meeting was just a criminal like the many he thought there were around.

Cesar, another of the refugees interviewed also has a strong reason for his lack of trust. which was not common in the refugee's accounts but still interesting to note. Although Cesar was able to start his own independent activity in the construction business after receiving several referrals from another Colombian. he also said he does not trust Colombians at all. Ilis lack of trust comes from the time he referred a Colombian friend to work in the financial firm where he was working before he got into construction. This friend he referred ended up robbing the company for a large quantity of money and going to jail. Since Cesar was the person who referred her, then he got in problems too and from that time he prefers to avoid helping other Colombians. Ilis trust in Costa Ricans is actually a couple of points higher than the trust in Colombians since he works with many Costa Ricans and they gave him an employment opportunity when he did not even had the refugee papers. He still commented Costa Ricans are not sincere and therefore he does not feel he could trust them entirely either.

In regard to the perception the other refugee families interviewed have of Costa Ricans the negative results were also founded in many fears. Some families would for example complain about the insecurity in San Jose; about the child abusers in the street: or about the fact that Costa Ricans envy Colombians for their level of professionalism and hard work to the point of confabulating against them. Other refugees like Karen say Costa Ricans are interested persons and they are not sincere, so that it is actually better to trust Colombians even though they would also try to take advantage of you if they can. Actually, the only refugee who had high trust levels for Costa Ricans was Rocio, and 
even higher trust than towards Colombians. This may be due to the fact that despite all the people she knows and has had social relations with, the only friend she said she had is from Costa Rica.

(2.4) Blockage of outside social and economic opportumities: Chapter 3. where the economic conditions of the refugee families were explored, provides a general picture of the perception refugees have regarding their outside social and economic opportunities. which is the first factor identified by Portes and Sensenbrenner for the existence of enforceable trust. In this chapter it was possible to see that most refugees interviewed feel very frustrated due to the lack of employment opportunities. It was also established that while few cases felt more comfortable with the opportunities ahead of them. most of the people interviewed felt vulnerable due to security conditions in Costa Rica and therefore were also interested in leaving Costa Rica to rebuild their lives. Since only one case from the 17 interviewed felt there were outside social and economic opportunities, it is therefore appropriate to assume that for the group interviewed there seems to be a blockage of such opportunities.

(2.5) Availability on in group economic resources: Chapter 3 along with the first section of this chapter where the Colombian entrepreneur community is explained from the refugee`s perspective. can provide a picture of the second factor identilied by Portes and Sensenbrenner, which in this case is a lack of in-group economic resources. The existence of an entrepreneurial class was established and within this group of people there may be enough economic resources to strengthen the sanctioning capacity within the Colombian community. Yet, most refugees' accounts evidence the entrepreneurial class is very distant to the refugee community and only two of the 17 refugee families 
interviewed argued that entrepreneurs actually would like to help refugees. Rocio is one of them. She claims she has helped 4 or 5 families of refugees by connecting them to entrepreneurs that wanted to help. She said these entrepreneurs prefer to stay away from organizations like UNHCR and ACAI because they pereeive these organizations as too bureaucratic and corrupted. Thus, the main barrier she finds for the refugees to be helped or supported by entrepreneurs is not the lack of willingness but the absence of connecting channels between these two communities of Colombians. These explanations for the lack of unity between Colombian entrepreneurs and Colombian refugees, along with the mostly negative perceptions refugees have of Colombian entrepreneurs help understand the reasons behind the lack of economic resources within the refugee community.

(2.6) ('ommunity's capacity of monitoring and sanctioning: The last factor needed for the existence of enforceable trust, as a source of social capital, is the community"s sanctioning capacity. The results for this question were also provided in the last row of table 3 and show that seven cases believe the community has the power of exclusion, especially for commercial purposes, and only two families believe the Colombian community does not have any power at all. These answers can be related to the fact that many of the families interviewed are aware of the capacity of the Colombian entrepreneurial community, as evidenced in their descriptions of these communities in the first section of the chapter. The answers can also be related to the fact that other Colombians in terms of employment have actually excluded many of these refugees, as some entrepreneurs have not supported them through employment.

This capacity is also tested through the existence of financial or business networks, as explained by Portes and Sensenbrenner (1993). In the previous network 
section it was established that most of the networks created by refugees are fragile and mainly considered a space they have created to share their culture and Colombian customs. There is very little evidence of financial networks within the community, as only two families said they have borrowed money from other Colombians and this is no evidence of the existence of a network but of isolated solidarity actions. In the case of the business networks at least the eight families who said that they know many people from work seem to rely on such social interactions for the maintenance of their activities in the informal sector. Yet, as shown already since only very few of these social interactions are actually performed within a network of people trusting each other, then it is difficult to conclude there are consolidated business networks within the Colombian community. Some of the refugees interviewed like Cesar, Rocio, or Adrian, would argue they are part of business networks since their activities in the construction, sales and marketing, and handcrafts sectors respectively, are sustained mainly by knowing both Costa Ricans and Colombians and interacting with them. Yet, all these cases also claim to have very few real friends while also tending to have low levels of trust towards others.

From the refugees ${ }^{\circ}$ answers regarding their trust levels and exploring the presence of blockage of outside social and economic opportunities, economic resources within the Colombian community and presence of a sanctioning capacity in this community, it is difficult to conclude that enforceable trust exists as a source of social capital within the Colombian community. First, despite the fact they seem to have more trust towards Colombians than towards Costa Ricans or strangers, the trust levels of refugees towards other Colombians is in any case very low. The blockage of outside social and economic opportunities seems to exist judging to the repeated frustrations expressed by refugees 
when responding about their employment and economic conditions. Yet. despite the existence of this factor and the existence of resources owned by Colombian entrepreneurs in Costa Rica, refugees do not have access to these resources and both communities are separated by a wide gap filled with lack of trust and solidarity. Thus, regardless of the blockage of outside opportunities, refugees do not find resources within the community and therefore the development of enforceable trust may be inhibited. Finally, despite the fact that refugees perceive the Colombian community as powerful and endowed with a sanctioning capacity, the lack of business and financial networks within the entire Colombian community make this sanctioning capacity inefficient as entrepreneurs are not connected to refugees and therefore are not able to exercise their power.

(3) Potential for Collective Action Within the Colombian Community: To complete the analysis about the existence of social capital among Colombians in Costa Rica it is also necessary to look at the potential for collective action among the refugee community, as an output measure of social capital. In addition to the perceptions refugees have on this subject it will also be helpful to look at some responses they gave regarding their reasons for participating in groups and networks. These responses may bighlight the potential for collective action.

First the families were asked to give examples of Colombians coming together to face common challenges. Then they were asked about Colombians coming together due to having a common identity. These questions helped to further understand the nature of their interactions and whether or not these interactions can be considered an output of bounded solidarity as a source of social capital. The responses confirmed that the force uniting these refugee families with other Colombians is the interest of sharing their 
culture to feel closer to home and that these families do not perceive Colombians have had the ability to organize and come together to face common challenges.

It is important to note that from the 17 families interviewed 5 families mentioned the organization ASDECOR as an example of Colombians coming together to face common challenges. However, since this organization dissolved itself, all of these families (and another nine families that did not know about the existence of $\triangle$ SDECOR), believe that Colombians are not able to organize themselves; that they talk about their issues but never talk about solutions: and that one of the reasons why they cannot come together is their lack of trust among each other. On a more hopeful note, the remaining three families believe that Colombians are uniting now and there is a strong sense of brotherhood among them that many may not recognize. Yet, even these families that see a more positive side of the Colombian community believe Colombians are not able yet to face challenges together.

Since the only example of Colombians coming together is ASDECOR, it is important to take a look at this organization. Refugees around the year 2001 formed the organization. Andres Ramirez, Director of UNHCR in Costa Rica by the time of the interview in the year 2003, explained that a group of refugees came together and started demanding the resettlement option claiming that paramilitaries were present in Costa Rica and referring to killings of Colombians in the country that had not been originally reported. Mr. Ramirez explained that by that time the UNHCR was very involved in speeding up the process of refugee status approval for Colombians and then suddenly this group of refugees organized a protest in front of the Spanish Embassy in San Jose. The refugees were demanding a letter from Costa Rica`s Foreign Minister acknowledging the 
country was not able to provide protection to Colombians and requesting the help of the UNHCR to initiate the resettlement program. After this protest, the UNHCR started a small resettlement program with Canada and the United States as receiving countries. After this common action Rocio, who was co-founder of ASDECOR. explains that the organization started to disintegrate because its president continued the allegations against both the Costa Rican government and the UNHCR and adopted positions not all members of the organization agreed with. Eventually, the Costa Rican Department of Migration cancelled the refugee status of the president of the organization and none of the people interviewed who knew about him were able to say if he stayed in Costa Rica or went to another country.

This example shows, as few of the families interviewed are able to notice, that Colombians are able to come together when facing common challenges and they are able to achieve results. However, not many of the refugees interviewed were aware of this example and it is likely that a refugee like Rocio, who was close to these developments. is exceptionally aware of the capacity of Colombians and therefore continues to develop relations with them as much as she can. However, It is also possible to assume that precisely due to the inability of this organization to continue working for Colombians, the other refugee families who knew about this organization became skeptical about the capacity of Colombians to organize again and unite effectively to face common challenges.

The fact is, this organization can be considered an example of collective action from bounded solidarity as a source of social capital. Through it Colombians came together, trusting each other, to face a common challenge. They actually succeded by 
pushing the UNHCR to start the resettlement program. Yet. by the time of the interviews maybe these families did not see a challenge they could face together. Also, their informal networks are formed mainly to just share their culture, which does not require much trust. Actually, when responding to the reasons why they were part of groups or informal networks, just five families recognized this participation could improve their living standard while nine said they participated just for recreation and entertainment and 12 said they participated just to stimulate their memories about Colombia. Thus. most of these refugees may not be even close to realizing that they have the potential for acting together if they could overcome their lack of trust and fears toward other Colombians.

Judging from their answers to the reasons for their lack of participation in informal networks or groups, the potential for collective action might not have existed by the time of the interviews but could be developed at some point. It is interesting to see that when responding to these questions seven families answered they do not participate due to lack of trust in Costa Ricans while only three refugees said they do not participate in these groups or networks due to the lack of trust in Colombians. Actually out of the 16 families responding to these series of questions a total of 11 families said they would like to participate in groups or formal networks but they just do not have information about them and therefore are unable to join. These responses are important to highlight because, despite the lack of trust they have expressed. they demonstrate that most of the families interviewed are still willing to participate in groups or formal networks. Thus. even though most do not show interest in becoming community leaders, they still show the capacity of becoming followers in case someone else decides to start something they can join. 
To have a better understanding of the capacity Costa Rica's Colombian refugee families may have to integrate socially, the main purpose of this chapter was to analyze their community and identify the variables needed to be present for their integration. From this analysis it is possible to support the third hypothesis of this thesis and affirm that due to the negative conditions of the host labor market. the lack of bounded solidarity and enforceable trust within the Colombian community, and the lack of potential formation of social capital among Colombian refugees. the success of their integration process is inhibited.

First, based on the model of immigrant modes of incorporation developed by Portes and Rumbaut (1990) it was necessary to identify if the Colombian refugees had arrived to the Central American country having there a pre-existent and higher-income community of Colombians willing to support them. Since this community was not present by the time of their arrival, these authors argued that the fate of the refugee population would depend on the conditions of the labor market. Chapter 3 showed that the conditions of the labor market were not appropriate for their integration. Then, following Portes and Sensenbrenner"s (1993) ideas about the potential of an immigrant community to benefit based on the development of social capital, it became necessary to analyze this issues.

The focus thus turned on the presence of bonding social capital (rather than bridging social capital), since in studies about this phenomenon done by Portes and Sensenbrenner (1993) such variety of social capital was found to be more likely to 
develop among immigrant communities. The results show evidence of Colombians tending to come together in informal networks and having the potential of developing bonding social capital. However, since the sources of social capital are absent, neither bonding nor bridging social capitals can be considered present among Colombian refugees in Costa Rica, even though there has been potential for collective action.

To identify the presence of social capital of any type it was important to look at its levels in Colombia itself, as refugees may have brought those assets from home. Yet, the studies of social capital in Colombia show that social capital there does not seem to be a factor favoring the development of the community. Some studies concluded that social capital in Colombia is weak while others concluded social capital in Colombia is rather perverse and therefore favored the emergence and sustainability of illegality. Ilowever. based on the results from the analysis of the potential generation of social capital among Colombians in Costa Rica, it is not possible to conclude that the potential formation of social capital among this population would be perverse. Yet, it is possible to conclude that the low levels of trust and membership participation in civic activities in Colombia were transferred to Costa Rica.

Moreover, the absence of sources of social capital in the form of bounded solidarity and enforceable trust lead to the conclusion that unless Colombian refugees start trusting each other and therefore start participating more in activities of mutual interest, it would be very difficult for this community to evolve and enjoy the development that social capital could bring them.

From the refugees interactions in groups and networks it was possible to see that most of their interactions are within informal networks formed with mainly other 
Colombians and that due to lack of information most families do not participate in groups or organizations. From the type of memberships of the few cases that participated in groups it was also possible to conclude that there is no potential for the development of bridging social capital, as the memberships were usually based on their nationality and the groups did not seem open for interactions with other organizations. For the informal networks the level of participation was rather high and the families interviewed seemed willing to support other Colombians if needed. Yet, since the actual support and solidarity perceived from other Colombians and other Costa Ricans is rather low, while most of these refugees claim to have very few friends, then the functionality of these networks for the generation of social capital would be very low and not reliable.

With a vulnerable foundation for the existence of social capital given by the weakness of their participation in groups and the inefficiency of the networks created by these families, it was also necessary to loot at enforceable trust and bounded solidarity as sources for the creation of social capital. First of all, the results show that most refugees do not believe there is solidarity or unity among Colombians in Costa Rica. Even though they may claim to be willing to help other Colombians their actual involvement in voluntary or helping activities is very low. Additionally, despite the presence of outside discrimination established in Chapter 3, the results in this section do not show that refugees see this discrimination as a common challenge. Rather, many families alienate themselves from the group of refugees and justify in some cases the discrimination they perceive towards Colombian refugees by admitting there are good and bad Colombians within their community. Thus, the factor of outside discrimination does not contribute towards the generation of bounded solidarity either. Neither do the last two factors, the 
blockage of an exit option and the cultural repertoire. On one hand, the blockage of an exit option is weakened by the knowledge refugees have of resettlement. On the other hand, the cultural repertoire brought from home by refugees is used for the maintenance of their identity as Colombians but has not served as a factor bringing them together to face some of their common challenges.

For the existence of enforceable trust the presence of another three factors was tested, (a blockage of outside social and economic opportunities, resources within the community, and a sanctioning capacity within the community). In this respect while there was evidence of a blockage of outside social and economic opportunities, given by the frustrations expressed by the refugees interviewed in regard to employment opportunities. there was no evidence of the existence of resources or a sanctioning capacity within the community. The absence of these two factors can be attributed to the fact that the refugee community is not integrated with the community of Colombian entrepreneurs. Thus, even though refugees may perceive that the community of entrepreneurs may have the power to exclude them, the fact is that since there are no channels of communication or interaction between these two communities then refugees do not have access to their resources and the entrepreneurs cannot support them or sanction them. These results, along with evidence of the low levels of trust these Colombian refugee families have towards other Colombians, lead to the conclusion that there is not a strong foundation for the development of enforceable trust as a source of social capital.

Despite this rather negative scenario for the development of social capital among the Colombian refugee community in Costa Rica at the moment, there are some aspects that could lead to its development in the future. First of all, the foundation of ASDECOR. 
created when refugees needed the resettlement option, is a significant precedent of collective action. The goal of obtaining resettlement had enough strength to pull the forces of a group of people willing to unite for their own benefit and the benefit of other Colombians. It is probable that the absence of a common cause contributes to the lack of unity among refugees now. By the time of the interviews, for instance, refugee families seemed to seek very diverse goals. Some were interested in better security conditions: others in securing an employment in their professional field; others in securing any type of employment; and yet some more in living without having to face discrimination.

Despite the lack of groups and formal networks, enforceable trust, bounded solidarity, and collective action, it is also important to highlight that the Colombian refugees interviewed have a strong willingness of helping each other based on their common identity as Colombians. This may lead to the generation of strong cthnic solidarity if these refugees are able to trust each other. It is also important to see that some of the factors missing for the presence of enforceable trust and bounded solidarity have to do with the lack of connections between the Colombian entreprencurial community and the refugee community. Even with many refugees believing entrepreneurs just want to take advantage of them. evidence from the arguments presented by some of the refugees interviewed shows that entrepreneurs would be actually willing to support refugees. One of the refugees participating in the survey, for instance, took me to the bakery of the Colombian entrepreneur that I interviewed. The interesting scenario comes from the Colombian entrepreneur actually telling me she did not like refugees and preferred to stay away from them because they tended to abuse the system. while simultaneously offering a referral for employment to the refugee that took 
me there. She actually told him "It's so good to see you Adrian, I had you in my mind a lot. Have you found employment yet? Because I have a very good referral for you and it's in the field of security where you have worked before". Thus, while on one hand the entrepreneur was being very negative towards refugees, on the other hand she was actually helping one of them. This example is useful to see how despite the absence of strong networks and even the existence of a wide gap between refugees and their conationals in Costa Rica, there is still an apparent solidarity foundation for the improvement of the community as a whole. The fact remains that if these two communities do not come together, then it would be hard for the refugee community to develop any type of social capital. Their social integration would thus continue to be inadequate. 


\section{RECOMMENDATIONS}

- In order to strengthen the integration of Colombian refugees in Costa Rica, not only from the legal but also from the economic and social perspective, the government of Costa Rica should give back to refugees the right to apply for residency 2 years after receiving their refugee status approval. The efforts of the UNIICR legal department to strengthen the national legislation and advise the Costa Rican government in the drafting of the new migration law does not include recommendations to reinstate this right to refugees. The refugee ID has been inefficient as an employment authorization, as many employers do not recognize it. Moreover, the ID serves to identify refugees as such and while such characterization gives them access to some social benefits, it also places individuals in a category that has been negatively typified in Costa Rica. The UNHCR and the University of Costa Rica are currently developing and implementing a campaign to educate the Costa Rican population about the Colombian refugee community with the goal of reducing the xenophobic sentiments. Yet, the limited funds assigned for these efforts may be wasted in face of such an overwhelming goal; educating a community that for over 20 years has seen refugees as a burden to the country and as lower class individuals. Thus, to reduce xenophobia towards Colombian refugees. UNHCR and $\mathrm{C} A \mathrm{Al}$ officials should instead focus on fighting for bringing down the Executive Decree that in 2003 limited the right for refugees to apply for permanent residency.

- Another area that needs great attention is the efforts currently underway to integrate Colombian refugees into the Costa Rican labor market. Chapter 3 provided enough 
evidence about the limited capacity of the employment program established in 2003 . None of the refugees interviewed who had attended the employment orientation meetings prepared by the ACAI with help of the Labor Ministry had found employment from a referral from this program. By February of 2005 only two people at the Labor Ministry and another two people at the ACAI office where in charged of rumning the employment program. This personnel is not sufficient to research the labor market in Costa Rica, meet with unemployed refugees, meet and educate employers about the refugee population, and find employments for the great amount of refugees who seem to live under precarious conditions. The employment programs managed by different resettlement agencies in the U.S. should be used as example for the management of the employment program in San Jose. The quality of the employment program in San Jose should be judged as some programs are judged in the U.S., by the number of employments found and by making the refugee family self-sufficient within a determined period of time. Refugee families should not only be receiving counseling and emergency cash assistance when needed, as this tends to make refugees dependent on aid. The programs to help refugees in Costa Rica should be based on finding an employment or an economic activity that would make refugees self-sufficient and therefore able to integrate economically into the host labor market and the host economy.

- The Colombian community in Costa Rica seems to have the potential to develop social capital and therefore to rise as a strong community as refugees seem to have more interactions with Colombians than with Costa Ricans and there is precedent of collective action in the refugee community. Yet, this potential is truncated mainly by 
the fact that Colombians have very low trust levels among them and therefore the networks they form are weak and vulnerable. Additionally by the fact that there is lack of unity between the Colombian refugee community and the Colombian entrepreneurs. The gap between these two communities affects the resources both parties could have available for them if more networks were to exist among them. Finally the potential to generate social capital is truncated by the fact that formal networks where Colombian refugees could interact with Colombian entrepreneurs or even Costa Ricans are inexistent. In this area the Colombian Embassy, as well as the ACAI office and the UNHCR in Costa Rica should take a stronger role. The ACAI office organizes fairs where refugees meet and present their businesses. These efforts are not sufficient though. These agencies should take an active role in helping refugees to organize in professional groups with Costa Rican or Colombian mentors that have succeeded in each professional activity. While refugees seem to lack information on any type of groups, most of them expressed. however, willingness to attend and participate in groups if they knew about their existence. Thus, if the refugees have the willingness to participate in formal networks, the agencies in charged of making their integration efficient as well as the Colombian Embassy in Costa Rica should support them in this arena.

- Finally refugees should also be led into a change of attitude towards other Colombians. Making Colombians trust each other is not an easy task and it may require many decades to change the negative stereotyping Colombians seem to have of their own co-nationals. This thesis will not go into recommendations for this monumental educational task. Yet, it hopes to contribute towards the general 
understanding about the great opportunities Colombians can be missing for their lack of trust and solidarity. It is ironic to find that Colombians abroad seem to have such high regards for the country they left behind, yet that some have other Colombians in such negative terms. Thus, now that so many communities of Colombians are forming in different countries it may be helpful to start educating. not only forcigners about the positive aspects of Colombians, but to start educating Colombians about the positive face of the Colombian people as well. 


\section{REFERENCES}

Alba, Richard D.. Douglas S. Massey, Ruben Rumbaut. (1999). The Immigration Experience for Families and children. Washington DC: American Sociological Association.

Alud de Colombianos aqui. (Domingo 16 de septiembre. 2001). Nacion. (Costa Rica). Retrieved July 14,2005 from www.nacion.com

Basok. Tanya. (1993). Keeping Heads above Water: Salvadoran Refugees in Costa Rica. Montreal: McGill-Queen's University Press.

Bonacich, Edna and J. Modell. (1980). The Economic Basis of Ethnic Solidarity: Small Business in the Japanese American Community. Berkley and Los Angeles: University of California Press.

Bonacich, Edna. (1973). A Theory of Middleman Minorities. American Sociology Review $38,583-594$.

Casey Cristyn, (2002). The Colomhian Migration to South Florida: The Effect of Social Capital on the Formation of immigrant Communities. Miami. Florida: Florida International University.

Collier Michael W. (2004). Colombian Migration to South Florida: A Most Unvelcome Reception. Miami, Florida: Latin American and Caribbean Center, Horida International University.

Constitucion Politica de la Republica de Costa Rica. (2004). San Jose. Costa Rica: Litografia e Imprenta LIL. S.A.

Costa Rica: ACNUR llama a revisar la nueva Ley de Migracion. (Agosto 12, 2005) Nacion (Costa Rica). Retrieved February 5, 2006 from www.nacion.com

Costa Rica ocupa tercer lugar del continente en migracion. (Jueves 10 de junio, 2004). Nacion (Costa Rica). Retrieved July 14, 2005 from www.nacion.com

Crisp, Jeff. (April 2004). The local integration and local settlement of refugees: a conceptual and historical analysis. New Issues in Refingee Research. Working Paper No. 102,1-8.

Cuellar. Maria Mercedes. (2000). Colombia, un proyecto inconchuso: valores, instifuciones y capial social. Bogota, Colombia: Universidad Externado de Colombia. 
Defensoria de los Habitantes (2003). Informes Anuales 1998 2003. San Jose. Costa Rica: Direccion de Proteccion Especial en material de Poblacion Migrante.

Diputados aprueban nueva ley migratoria. (28 de Octubre, 2005). Nacion (Costa Rica). Retrieved February 5, 2006 from www.nacion.com

Dryen-Peterson Sarah and Lucy Hovil. (September 2003). Local Integration as a durable solution: refugees, host populations and education in Uganda. New lswues in Refugee Research. Working Paper No. 93.1-27.

Ecuador, EEUU, Canada y Costa Rica es refugio para Colombianos. (19 de Junio, 2005). Nacion (Costa Rica). Retrieved July 14, 2005 from www.nacion.com

Exodo Colombiano toca a Costa Rica. (Domingo 25 de marzo, 2001). Nacion (Costa Rica). Retrieved July 14, 2005 from www.nacion.com

Franco, Nathalia. (2002). The Colombian Migration to South Florida: Expectations and Experiences. Miami, Florida: Florida International University.

Global Policy Network. (2004). Recent Development of the Labor Market in Costa Rica. Retrieved November 2, 2004 from http://www.gpn.org/

Grootaert. Christiaan, Deepa Narayan, Veronica Nyhan Jones, Michael Woolcock. (2004). Measuring Social Capital. An Integrated Questionnaire. Washington D.C.: The World Bank Working Paper No. 18.

Guarnizo, Luis Eduardo and Luz Marina Diaz. (1999). Transnational migration: a view from Colombia. Ethnic and Racial Studies 22, 2, 397-421.

Harrell-Bond, Barbara. (1986). Imposing Aid: Emergency Assistance to Refugees. Oxford: Oxford University Press.

Harrell-Bond, B. (August, 2000). Are Refugee Camps Good for Children? New Issues in Refugee Research, Working Paper No. 29. Retrieved October 30, 2003 from hitp://www.jha ac/articles/u029.htm

Hayden. Bridget A. (2003). Salvadorans in Costa Rica. Tucson: The University of Arizona Press.

Holtzman, Jon D. (2000). Nuer Journeys Nuer Lives. Sudanese Refugees in Minnesola. Indianapolis: Indiana University - Purdue University.

Kuhlman. Tom. (1991). The Economic Integration of Refugees in Developing Countries: A Research Model. Journal of Refugee Studies, 4, 1, 1-20. Retrieved October 30. 2003 from hutp://jrs.oxfordiournals.org/cgi/content/abstract/4/1/1 
Ley del Sistema Financiero Nacional para la Vivienda. (Noviembre, 2002). San Jose, Costa Rica: Editorial Investigaciones Juridicas S.A.

Ley General de Migracion y Extranjeria y su Reglamento. (Junio, 2002). San Jose. Costa Rica: Editorial Investigaciones Juridicas S.A.

Llamadas vinculan a Millot con asesinato de Ivannia Mora. (Martes 25 de mayo, 2004) Nacion (Costa Rica). Retrieved July 14, 2005 from www.nacion.com

Light. Ivan H. (1972). Ethnic Enterprise in America: Business and Welfare Among Chinese, Japanese and Blacks. Berkley and Los Angeles: University of California Press.

Light. Ivan H. (1979). "Disadvantaged Minorities in self-Employment." International Journal of Comparative Sociology 20.

Mahler, Sara J. (1995). American Dreaming: Immigrant Life on the Margins. New Jersey: Princeton University Press.

Mohasher. Mohsen, Sadri Mahmoud (Eds.). (2004). Migration, Glohalization. and Ethnic Relations. New Jersey: Pearson Prentice Hall.

Ong, Aihwa. (2003). Buddha is Hiding, Refugees, Citinzenship, the New America. Berkley: University of California Press.

Park, Robert E. (1928). Human Migration and the Marginal Man. American Journal of Sociology, 33, $881-893$.

Portes Alejandro and Julia Sensenbrenner. (May 1993). Embeddedness and Immigration: Notes on the Social Determinants of Economic Action. American Journal of Sociology, 98, 6, 1320-1350.

Portes, Alejandro and Alex Stepick. (1993). City on the Edge: The Transformation of Miami. Berkeley: University of California Press.

Portes. Alejandro and Robert L. Bach. (1985). Latin Journey: (uban and Mexican Immigrants in the United States. Berkeley: University of California Press.

Portes, Alejandro and Ruben G. Rumbaut. (1990). Immigrant America: A Portrait. Berkeley: University of California Press.

Portes, Alejandro and Ruben G. Rumbaut. (2001). Legacies: The Story of the Immigrant Second Generation. Berkley, Los Angeles, London: University of California Press. 
Proyecto Estado de la Nacion. (Octubre 2004). Decimo Informe Estado de la Nacion en Desarrollo Humano Sostenible. San Jose, Costa Rica: Programa Estado de la Nacion.

Putnam. Robert D. (2000). Bowling Alone. The Collapse and Revival of American Community: New York: Simon \& Schuster.

Putnam. Robert D. and Lewis M. Feldstein. (2003). Better Together. Restoring the American Community. New York: Simon \& Schuster.

Refugio abrio las puertas a sospechosos. (Jueves 27 de mayo, 2004) Nacion (Costa Rica). Retrieved July 14. 2005 from www.nacion.com

Rodriguez-Raga, Juan Carlos and Mitchell A. Seligson. (2004). The Political (ulture of Democracy in Colombia, 2004. Retrieved on February 23. 2006. http:/sitemason.vanderbiltedu/lapop

Rubio, Mauricio. (September, 1997). Perverse Social Capital - Some Evidenee From Colombia. Journal of Economic Issues 31, 3, 805-816.

Ruiz Arce, Johnny A. (2002). Analisis de la Poblacion Colombiana Refugiada en Costa Rica. Informe Tecnico. San Jose, Costa Rica: Ministerio de Trabajo y Seguridad Social.

Schmitter Heisler, Barbara. (2000). The Sociology of Immigration: From assimilation to Segmented Integration, from the American Experience to the Global Arena. In M. M. Mobasher. and M. Sadri. (Eds.), Migration, Glohalization, and Ethnic Relations. (22, pp. 307 -322). New Jersey: Pearson Prentice Hall.

Sospechosos Llevaban una vida poco llamativa. (Miercoles 26 de mayo, 2004). Nacion (Costa Rica). Retrieved July 14, 2005 from www.nacion.com

Sudarsky, John. (March, 2001). Colombia's Social Capital, the national Measurement with the BARCAS. Washington DC: World Bank.

Un año prisión preventiva para uruguayo y colombianos por crimen. (Lunes 24 de mayo. 2004) Nacion (Costa Rica). Retrieved July 14, 2005 from www.nacion.com

Un total de 36.910 colombianos han sido recibidos en condicion de refugiados en 24 paises. (June 16, 2004) . El Tiempo (Colombia). Retrieved June 20, 2004 from www.eltiempo.com

UNHCR Public Information Section (August, 1996). Convention and Protocol Relating 10 the Status of Refugees. Retrieved October 30. 2003. from http://www.unher.org/cgi-bin/texis/vtx/protect?id=3c0762eat 
UNHCR - UCR. (2003). Diagnowico Sobre el Grado de Motegracion Local de los Refugiados en Costa Rica, 2002. Costa Rica: Editorama.

UNHCR - UCR (2004). Diagnostico Sobre el Grado de Integracion Loral de la Poblacion Refugiada en Costa Rica, 2003. Costa Rica: Editorama.

UNHCR (2006). Country Operations Plan. Overview: Country: Costa Rica. Plamming lect: 2006. Retrieved January 4. 2006 from http:/mwimber.chegihin/texis/rtx/rsd/riddocriew.pdP?thl=RSDCOI\&id $=432540122$

Welaratna, Usha. (1993). Beyond the Killing Fields. Voices of Nine Cambodian Survivors in America. Stanford, California: Stanford University Press. 